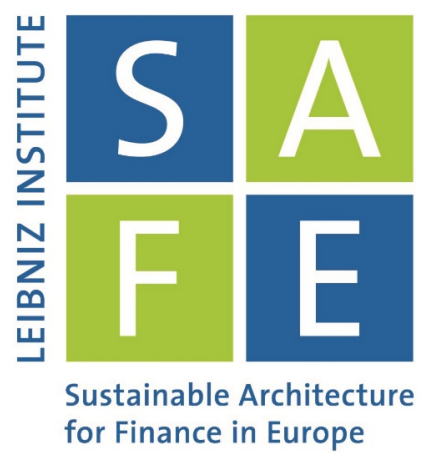

Christine Laudenbach | Benjamin Loos | Jenny Pirschel | Johannes Wohlfart

\title{
The Trading Response of Individual Investors to Local Bankruptcies
}

SAFE Working Paper No. 272

Leibniz Institute for Financial Research SAFE Sustainable Architecture for Finance in Europe 


\title{
The Trading Response of Individual Investors to Local
}

\author{
Bankruptcies*
}

\author{
Christine Laudenbach ${ }^{\dagger} \quad$ Benjamin $\operatorname{Loos}^{\ddagger}$
}

Jenny Pirschel ${ }^{\S} \quad$ Johannes Wohlfart ${ }^{5}$

\begin{abstract}
March 20, 2020
We use data from a German online brokerage and a survey to show that retail investors sharply reduce risk-taking in response to nearby firm bankruptcies, which are not predictive of returns. The effects on trading are spatially highly concentrated, immediate and not persistent. They seem to operate through more pessimistic expected returns and increased risk aversion and do not reflect wealth effects or changes in background risks. Investors learn about bankruptcies through immediate coverage in local newspapers. Our findings suggest that non-informative local experiences that make downside risks of stock investment more salient contribute to idiosyncratic short-term fluctuations in trading.
\end{abstract}

JEL Classification: D14, G11

Keywords: Individual investors, risk-taking, trading, experiences.

${ }^{*}$ We would like to thank the editor, Ron Kaniel, and an anonymous referees for thoughtful comments that improved the paper considerably. We are grateful for helpful comments from Tobias Berg, Utpal Bhattacharya, Jonathan Brogaard, Andreas Hackethal, Tobin Hanspal, Zwetelina Iliewa, Heiko Jacobs, Sebastian Müller, Alexandra Niessen-Ruenzi, Chris Roth, Nic Schaub, Sonja Settele, Stephan Siegel, Paul Smeets, Sascha Steffen, Annika Weber, Martin Weber as well as seminar and conference participants at the Foster School of Business (University of Washington), the University of Mannheim, the University of Maastricht, and the Università Cattolica del Sacro Cuore, the SAFE Household Finance Workshop, the ERIC (Stuttgart), the German Finance Conference (2017), the Research in Behavioral Finance Conference (Amsterdam), and the Swiss Finance Conference (2017). The activities of the Center for Economic Behavior and Inequality (CEBI) are funded by the Danish National Research Foundation. The survey instructions can be found at the following link: https://www.dropbox.com/s/cxzvt0kocl34g3e/ Bankruptcies_2019_Survey_Instructions.pdf?dl=0.

${ }^{\dagger}$ Christine Laudenbach (Corresponding Author), House of Finance, Goethe University Frankfurt, e-mail: laudenbach@finance.uni-frankfurt.de, phone: +49 6979833675

${ }^{\ddagger}$ Benjamin Loos, University of Technology Sidney, e-mail: Benjamin.Loos@uts.edu.au, phone: +61 (0) 402551116

§ Jenny Pirschel, Goethe University Frankfurt, e-mail: jennypirschel@googlemail.com, phone: +49 69 95150

${ }^{5}$ Johannes Wohlfart, Department of Economics and CEBI, University of Copenhagen, CESifo, e-mail: johannes.wohlfart@econ.ku.dk, phone: +45 35332061 


\section{Introduction}

Individual investors have been shown to extrapolate recently experienced stock returns, becoming more optimistic following high return realizations and more pessimistic following low returns (Amromin and Sharpe, 2014; Greenwood and Shleifer, 2014). Extrapolation of recently experienced returns is often negatively correlated with model-based expected returns, and there is only a very low degree of predictability of future aggregate stock returns based on recent returns. Moreover, higher average stock returns experienced over an investor's life-time are persistently reflected in more optimistic beliefs about the stock market and higher risk-taking and stock investment (Malmendier and Nagel, 2011), suggesting that experienced aggregate stock returns translate into long-term changes in behavior. Kuchler and Zafar (2019) document that individuals not only extrapolate from experienced aggregate economic conditions but also from their recent local personal experiences when forming expectations about aggregate unemployment and nationwide house price growth. However, so far it is not well understood i) how local personal experiences affect investors' behavior, and ii) how experiences of uninformative adverse events more generally affect investment behavior in the short-term, in particular how quickly such events lead to adjustments in risk-taking and how persistently they affect trading.

In this paper we address these research questions by investigating how bankruptcies of firms in an investor's local environment affect trading behavior and financial risktaking in the short-term. Bankruptcy filings should be non-informative of future stock returns since restructuring processes have already taken place and they should primarily reflect adverse events that happened much earlier (Brealey et al., 2016). Consequently, rational individual investors should not adjust their investment behavior in response to these events. At the same time, bankruptcies of local firms are noticeable through closing signs, coverage in the local news or word-of-mouth, and might draw investors' attention to the downside risks of stock investment, making the possibility of large losses more salient. These features make bankruptcies a unique setting to study how individual investors respond to local experiences that should be uninformative for future returns. 
We use a proprietary panel dataset from a large German brokerage firm that contains monthly portfolio holdings and exact transaction records for 47,782 individual investors from January 2007 to November 2012. We link this dataset with data from a German credit bureau on all bankruptcy filings of firms in Germany, 99 percent of which concern non-publicly listed firms. Drawing on information on the exact filing dates and firm headquarters' zip codes, as well as the zip codes of the investors' home residence, we are able to identify the effect of an investor's local experience separately from the effect of aggregate events experienced by the entire population at the same time. The panel structure of our data allows us to include investor fixed effects, which ensures that our findings are not driven by time-invariant differences in investment behavior that are correlated with the number of local bankruptcies. Moreover, our detailed account data enable us to include an extensive set of control variables such as recent returns on the investor's own portfolio and merged proxies for local economic conditions.

We find that a higher number of bankruptcies within a $25-\mathrm{km}$ radius of an investor's zip code in a given month is associated with significant adjustments in trading activity and portfolio risk. Specifically, a one percentage point increase in the share of local firms going bankrupt is associated with a 0.48 percentage point increase in overall monthly portfolio turnover. Moreover, the increase in turnover is reflected in a 0.82 percentage point decrease of the monthly buy-sell imbalance and an active downward adjustment of the risky portfolio share by 0.23 percentage points. The economic magnitude of these effects is similar to that of other variables which previous literature has shown to affect trading and risk-taking, such as the recent return on an investor's own portfolio. Given that bankruptcies in the home zip code are a noisy proxy for those bankruptcies that actually come to the attention of investors, these estimates can be interpreted as lower bounds on the actual effects of observing bankruptcies.

Next, we show that the effects are spatially and temporally highly concentrated. Specifically, bankruptcies occurring outside the $25 \mathrm{~km}$-radius around an investor's home zip code have no effect on trading. Similarly, the effects of bankruptcies on trading materialize within the same month and quickly die out after that, indicating that bankruptcies 
trigger a sharp change in trading activity, which is not persistent. This highlights that non-informative local experiences lead to an immediate adjustment in risk-taking through a one-time increase in trading.

Given that the trading response is driven by investors who face economic conditions highly comparable to those of their slightly more distant neighbors but who live slightly closer to local bankruptcies, our findings are unlikely to reflect direct wealth effects or changes in background risks due to correlated local shocks. We conduct additional checks against this possibility and show that the effects of bankruptcies are equally pronounced when we exclude investors working in cyclical industries or those working in the nontradable sector, who should be more strongly exposed to (local) economic fluctuations. Similarly, our results remain qualitatively unchanged when we exclude investors who show signs of financial distress (e.g. high cash withdrawals) or if we exclude months in which firm bankruptcies would be the most likely to indicate an actual worsening of local economic conditions (e.g. very large firm bankruptcies or an abnormally high number of cases). Moreover, the effect of bankruptcies on risk-taking is driven by smaller firms, which are very unlikely to be associated with direct wealth effects for the investors in our sample.

All of our findings on the effect of bankruptcies on trading behavior are stable across subsamples and robust to transformations of the independent variable. Moreover, we find no effects of bankruptcies in a set of placebo analyses. Finally, we replicate our findings using data on recalled bankruptcies and self-reported trading behavior from our own survey on an online panel of retail investors that is representative of the German population of stock market participants, which we conducted in August 2019.

Subsequently, we shed light on the mechanisms through which bankruptcies trigger changes in risk-taking, starting with the role of attention (Barber and Odean, 2007; Gilbert et al., 2012; Sicherman et al., 2015). First, one third of investors who responded to our survey have noticed local bankruptcies over the previous four weeks, mostly through coverage in the local newspaper, followed by word-of-mouth and visible closing signs. Moreover, both coverage of bankruptcies in local newspapers as well as people's demand 
for information about bankruptcies as measured through Google searches react immediately to changes in local bankruptcies. These points indicate that bankruptcies regularly come to the attention of retail investors. Second, the effects of bankruptcies on trading are reduced when investors' attention is likely lower. For instance, the effects are less pronounced during holiday periods and when there is distracting or conflicting nationwide information, such as high volatility of the aggregate stock market or very optimistic professional forecasts about aggregate stock returns. Moreover, when local bankruptcies are more salient because they occur in localities where people are less used to observing bankruptcies, they exert a stronger effect on trading, potentially due to higher attention among investors.

Does attention to bankruptcies affect trading behavior through changes in preferences or beliefs? Given that bankruptcies stand at the end of restructuring processes, they should reflect economic events that happened much earlier and not be informative for future returns. We provide further evidence for this by showing that bankruptcies do not add predictive power for local or aggregate stock returns or economic conditions in a model that includes a set of common economic indicators. Similarly, the effects of bankruptcies on trading in our brokerage sample do not vary across zip codes by the extent of correlation of zip code-level bankruptcies with aggregate stock returns or stock market volatility during the sample period. This suggests that the bankruptcies effect is not driven by rational updating of expectations about labor income or stock returns. Moreover, in our investor survey, recall of bankruptcies is not associated with changes in perceived background risk or subjective expectations about income or overall GDP growth. However, investors who have experienced more bankruptcies than usual over the previous fours weeks report that their expectations about stock returns have worsened over that time. They exhibit lower mean expected returns, which primarily reflect a higher perceived risk of large drops in stock prices, in line with recent evidence on the role of perceived disaster risk in shaping investment decisions (Choi and Robertson, 2020; Fagereng et al., 2017a; Giglio et al., 2020). There is no effect on subjective expectations about the returns of foreign stocks or bonds. Finally, investors who have experienced 
more bankruptcies than usual report that they have become less willing to take risks over the last four weeks according to a survey measure that separates risk aversion from current stock market expectations. In line with the survey results, we find that the effects of local bankruptcies in the brokerage data are concentrated in trading in German equity, while holdings of foreign equity are not affected, and that investors reduce the German market beta of their portfolios in response to bankruptcies. Taken together, these results indicate that the trading response to bankruptcies is driven by lower expected aggregate stock returns, with some role for changes in risk aversion.

Our paper adds to a literature on the role of experiences in shaping the expectations and behavior of retail investors. This literature has shown that higher aggregate stock returns, experienced over recent years or over an investor's lifetime, are associated with more optimistic expectations about future returns and higher stock investment (Amromin and Sharpe, 2014; Greenwood and Shleifer, 2014; Malmendier and Nagel, 2011). Moreover, experiences of large negative macroeconomic shocks permanently reduce an individual's tendency to invest in stocks, as shown by Knüpfer et al. (2017) in the context of the Finnish Great Depression or by Andersen et al. (2019) in the context of the Great Recession in Denmark. Recession experiences are also associated with different investment styles in the long-term (Cronqvist et al., 2015). ${ }^{1}$ Moreover, the literature has documented that local personal experiences shape beliefs about aggregate outcomes in other contexts, such as locally experienced home price changes for expected home price growth nationwide (Kuchler and Zafar, 2019), own job loss for expectations about national unemployment (Kuchler and Zafar, 2019), and price changes of frequently purchased goods for expectations about aggregate inflation (D'Acunto et al., 2019).

We contribute to this research effort by providing evidence that experiences of adverse local events that are non-informative of future returns trigger sharp adjustments in trading and risk-taking among retail investors. Thus, extrapolation of local experiences

\footnotetext{
${ }^{1}$ Macroeconomic experiences have also been shown to matter for inflation expectations (GoldfaynFrank and Wohlfart, 2019; Malmendier and Nagel, 2016), consumption decisions (Malmendier and Shen, 2019) and political attitudes (Alesina and Fuchs-Schündeln, 2007; Giuliano and Spilimbergo, 2014; Roth and Wohlfart, 2018). Evidence on the role of personal and peer experiences in shaping stock investment behavior is further provided by Cronqvist and Siegel (2014), Giannetti and Wang (2016), Kaustia and Knüpfer (2008) and Kaustia and Knüpfer (2012).
} 
does not only seem to be important for belief formation but also for shaping behavior, in a sample of relatively experienced and active retail investors. While previous literature has documented that experiences of mostly salient economy-wide conditions affect risktaking in the long-term, our findings suggest that a region-specific short-term component contributes to heterogeneity in trading behavior across investors. In addition, different to previous literature, the high frequency of our data on stock sales and purchases allows us to conduct a detailed analysis of the trading response to non-informative events, which mediates adjustments in risk-taking. This enables us to show that adjustments in risk-taking in response to non-informative experiences materialize immediately (i.e. in the same month) through a one-time increase in trading, and that trading is not permanently affected. Finally, we add to existing literature by providing new insights on the mechanisms though which experiences of non-informative events affect investment behavior, highlighting the roles of newspaper coverage and attention, and providing survey evidence on shifts in expected returns, specifically perceived disaster risk, and risk aversion. $^{2}$

Our findings also relate to the psychological literature on experience-based decisionmaking. This literature distinguishes between risky decisions from description, where clear descriptions of the payoff distribution are available to individuals, and risky decisions from experience, for which there often does not exist a clear description of the payoff distribution and in which individuals learn from repeated sampling over time. Most importantly, decisions from experience seem to be based on relatively small samples of information (neglect of sampling error), with an overweighting of recent information (recency bias) (Erev et al., 2010; Hertwig and Erev, 2009; Hertwig and Pleskac, 2010; Hertwig et al., 2004; Kaufmann et al., 2013). While this literature has mostly focused on evidence from laboratory experiments, our findings highlight that recency also seems to be key in decisions from experience in the field. ${ }^{3}$ Our finding of a role for salient local

\footnotetext{
${ }^{2}$ Previous literature has provided evidence that a substantial part of the heterogeneity in stock investment behavior across investors seems to be due to the local environment (Barnea et al., 2010; Guiso et al., 2004). However, none of these papers has focused on the immediate trading response to adverse economic events.

${ }^{3}$ Among others, studying this question in a field setting has the following important advantages: real world environments often change rapidly, which may not be adequately captured by laboratory settings;
} 
bankruptcies in driving financial decisions is in line with laboratory evidence indicating that decisions from memorable experiences are particularly common in complex choice environments (Lejarraga, 2010). Second, the psychology literature has established that changes in the public's perceptions of different risks tend to be triggered by adverse events, and are followed by increased attention to the downside potential of future outcomes (see Weber (2017) for an excellent review). We provide cleanly identified field evidence that changes in the perceived likelihood of large drops in stock prices triggered by the adverse event of local firm bankruptcies translate into trading decisions of retail investors.

The rest of this paper is structured as follows: In section 2 we describe the data and provide summary statistics. Section 3 presents our main results on the trading response to bankruptcies and provides an extensive set of robustness checks. Section 4 provides evidence on the mechanisms through which bankruptcies affect risk-taking, and section 5 concludes.

\section{Data}

Investor data We obtain data on month-end holdings and daily executed transactions of securities (including security identifiers, volume and price) of a randomly drawn sample of 63,024 individual investors who are clients of a large German online bank, covering the period from January 2007 to November 2012. The bank provides full bank services offering savings and credit products in addition to its brokerage entity, and is hence used by many clients as their principal bank. We merge information on the securities' market and property information (e.g., market prices, asset classes) from Thomson Reuters Datastream. We also obtain information on a range of client demographics, which were measured in November 2012, including the investor's zip code of residence. We exclude inactive accounts, defined as accounts with not more than one trade per year on average (5,701 investors), and investors with incomplete information on the relevant variables

financial stakes in real world settings are much higher than in the lab; different to a laboratory setting we do not have to draw investors' attention to particular aspects of a decision problem, which may have independent effects on their decisions. 
(9,541 investors), most of which concerns zip codes which could not be matched $(8,931$ investors). This leaves us with a sample of 47,782 investors. Panel A of Table 1 provides summary statistics of our sample. Our sample is comparable to samples used in previous literature (Barber and Odean, 1999, 2001) with regard to the share of male investors (83 percent vs. 79 percent in Barber and Odean (2001)) as well as average age (50 in both samples). Investors on average hold $€ 22,120$ in cash and $€ 61,424$ in their portfolio (vs. $\$ 47,000$ in equity positions in Barber and Odean (2001)), and execute on average 2.2 trades per month.

Trading and risk-taking variables In our analysis we study common measures of trading activity and changes in risk-taking. Throughout, we focus on non-automated trades only. To analyze how bankruptcies affect trading activity, we follow Barber and Odean (2001) and use daily transaction records to calculate purchase, sale and overall monthly portfolio turnover as follows:

$$
\begin{aligned}
\text { Turnover } & =0.5 \times \text { Sales turnover }+0.5 \times \text { Purchase turnover } \\
\text { Sales turnover } & =\frac{\text { Shares sold in } \mathrm{t} \times \text { Price per share }}{\text { Portfolio value at the beginning of } \mathrm{t}} \\
\text { Purchase turnover } & =\frac{\text { Shares purchased in } \mathrm{t} \times \text { Price per share }}{\text { Portfolio value at the beginning of } \mathrm{t}+1}
\end{aligned}
$$

Our main outcome variables of interest are measures of changes in risk-taking. The first measure we focus on is the monthly buy-sell imbalance, as for instance used in Goetzmann et al. (2014). The buy-sell imbalance approximates the investor's tendency to be a net buyer of risky assets, and is defined as the difference in monthly euro volume between purchases and sales, scaled by the total euro volume traded during that month:

$$
\text { Buy-sell imbalance }=\frac{\text { Value of purchases in } t-\text { Value of sales in } t}{\text { Total value of transactions in } t}
$$

Our second measure of risk-taking is the "active risky share", which is defined as the monthly change in an investor's risky portfolio share that is due to trades. We follow 
Calvet et al. (2009) and decompose the total monthly change in the risky share $\omega_{i, t}$, (i.e., portfolio value $P_{i, t}$ divided by total wealth including cash holdings $C_{i, t}$ at the bank) into a passive change, $\omega_{i, t}^{p}$, driven by market returns of the portfolio assets, $r_{t}$, and an active change, $\omega_{i, t}^{a}$, resulting from trading decisions of an investor:

$$
\begin{aligned}
\omega_{i, t}^{a} & =\omega_{i, t+1}-\omega_{i, t}^{p} \\
\omega_{i, t+1} & =\frac{P_{i, t+1}}{P_{i, t+1}+C_{i, t+1}} \\
\omega_{i, t}^{p} & =\frac{\omega_{i, t} \times\left(1+r_{t}\right)}{\omega_{i, t} \times\left(1+r_{t}\right)+\left(1-\omega_{i, t}\right)\left(1+r_{f, t}\right)}
\end{aligned}
$$

where $r_{f, t}$ is the risk-free interest rate paid on cash holdings at the bank.

All our dependent variables are expressed in percent or percentage points and therefore range between 0 and 100. Table 1 Panel B provides summary statistics of our main dependent variables. Investors in our sample display an average monthly portfolio turnover of 6.42 percent with a standard deviation of 17.86 percent. Our sample is hence comparable to Barber and Odean (2001)), who report a monthly turnover of 6 percent. Sales turnover in our sample is 6.09 percent, while purchase turnover is 6.75 percent. Our most important measure for risk-taking, the active risky share, has a mean change close to zero at -0.08 percent, implying that our sample investors on average show a very weak tendency to actively reduce their risky share over the sample period. The mean buy-sell imbalance is 20.18 percent, reflecting that our investors are net buyers on average.

Bankruptcy data Bankruptcies are noticeable to individual investors through visible closing signs, local news coverage and word-of-mouth. Observing bankruptcies could plausibly draw investors' attention to the downside risks of investing in firms and thereby make the possibility of incurring large losses through stock investment more salient. At the same time, bankruptcies occur when restructuring processes have already taken place: Brealey et al. (2016) argue that "bankruptcy is merely a legal mechanism for allowing creditors to take over when the decline in the value of assets triggers a default. Bankruptcy is not the cause of the decline in value. It is the result." Therefore, bankruptcies should 
not be informative for future stock returns.

We obtain bankruptcy data from the German credit agency Buergel. The data which we use for our analyses comprise all 182,379 bankruptcy filings of public and non-public firms in Germany from January 2007 to November 2012, which is the sample period of our investor data. The data include the insolvency date, the headquarter's zip code, and the identity of the legal entity, which we use to differentiate between bankruptcies of public versus private firms. For a subsample of bankrupt firms (58 percent of the firms), we also receive information on the number of employees. Table 1 Panel C presents summary statistics on the bankruptcy filings and firms. Non-public firms represent over 98 percent of the firms in our dataset. Most bankruptcies in our sample concern small and medium-sized firms with a mean number of eleven and a median number of three employees.

Panel A of Figure A1 in the online appendix displays how the raw number of firm bankruptcies is distributed across zip codes, and shows a higher number of bankruptcies in the north than in the south of Germany. As shown in Panel B of Figure A1, the raw number of bankruptcies peaked in 2009, after Germany had experienced its strongest recession since World War II (upper left graph). While there are no strong patterns of seasonality, the tendency to file for bankruptcy is slightly higher at the beginning of the year (upper right graph) and higher (lower) on the first (last) day of the month (lower left graph). In addition, bankruptcies are almost evenly distributed across days of the week (lower right graph).

To allow firm bankruptcies to affect investors' choices with a short lag, and to make the bankruptcy data consistent with the brokerage dataset, we aggregate all bankruptcy filings within a $25-\mathrm{km}$ radius around an investor's home zip code to a monthly measure. ${ }^{4}$

\footnotetext{
${ }^{4}$ We choose a $25-\mathrm{km}$ radius as this is close to the median daily commuting time of the German working population according to data from the German Statistical Office. The radius used to define the local environment of an investor in related research is often larger. For example, Coval and Moskowitz (1999, 2001), Ivković and Weisbenner (2005) and Ivković et al. (2008) study investment behavior using a radius of $100 \mathrm{~km}$ and $400 \mathrm{~km}$ to define the local environment, respectively. Similarly, Giannetti and Wang (2016) measure individuals' exposure to corporate scandals at the state level. While the local measures used in these studies are based on public firms, which are more visible across regions, our measures are predominantly based on small firms that are locally owned. In section 3.3 we also study how investors respond to bankruptcies within a larger area.
} 
The zip-code level average (median) number of monthly local bankruptcies is 28 (14) as shown in Table 1 Panel C. Finally, as explained in more detail in online appendix $\mathrm{C}$, we scale the number of bankruptcies by the previous year-end number of firms in the associated county ("Landkreis"). The bankruptcy measure is trimmed at the 99th percentile to minimize the influence of outliers. We multiply the resulting bankruptcy measure by 100 to make the coefficient estimates in our regressions easier to interpret. We merge this bankruptcies measure to our investor dataset using the zip code identifiers. This results in a bankruptcy measure that ranges between 0.003 and 1.14 with an average of 0.20 at the investor level, indicating that investors in our dataset are exposed to an average of 0.2 percent of local firms going bankrupt each month. Summary statistics of the bankruptcies measure at the investor level are shown in Table 1 Panel D.

How does the bankruptcies measure vary over time and zip codes, and how persistent are local bankruptcies? When regressing scaled bankruptcies only on time fixed effects (Table A1 column 1) or only on zip code fixed effects (column 2) in a zip code-level dataset, this gives an R-squared of 1.5 percent or 88.7 percent, respectively, indicating that most of the variation in bankruptcies is due to permanent differences across zip codes. ${ }^{5}$ The strong explanatory power of zip code fixed effects means that there is a lot of local persistence in bankruptcies, with an estimated effect of lagged bankruptcies of 0.9 (column 4). However, this effect is reduced to 0.2 once zip code fixed effects are included (column 5), as it is also done in our main estimations. There are also statistically significant effects of further lags, but these effects are economically small (columns 6-7). To rule out any concerns that we capture the effect of lagged bankruptcies, we check the robustness of our findings to including lagged bankruptcies in section 3.3.

Additional data We use the brokerage data to construct control variables such as the recent return of the investor's portfolio, and also merge geographic control variables to our dataset. We provide a more detailed description of the variables we use in online appendix C and Table A3.

\footnotetext{
${ }^{5}$ Including both sets of fixed effects together gives an R-squared of 90.9 percent (column 3).
} 
Investor survey To better understand the mechanisms behind our findings, we conducted our own survey with an online panel provided by the research company YouGov, which is widely used in economics and finance. Our working sample includes 1,422 individuals who either invest in stocks or in stock mutual funds. The sample is representative of the population of German stock market participants in terms of age, gender, region (East vs West) and income, as can be seen from the summary statistics in Table A2, which also provide a comparison with stock investors in the Bundesbank's Panel of Household Finances (PHF). Respondents to the survey are asked whether they have noticed any smaller business closures or larger firm bankruptcies in their county of residence over the previous four weeks. In addition, respondents answer questions on their planned and realized trading behavior, their expectations about asset returns and other outcomes, and their risk aversion. Details on the procedures of the survey, the wording of the survey questions and the construction of the sample are provided in online appendix D.

\section{Do bankruptcies predict changes in risk-taking?}

\subsection{Empirical specification}

We examine investors' trading response to nearby bankruptcies using two sets of specifications. First, for overall turnover, purchase turnover, and sales turnover, which refer to levels of behavior and which may be persistently high or low for any individual investor, we estimate the following fixed-effects specification using OLS:

$$
\mathrm{y}_{i, j, t}=\alpha_{0}+\alpha_{1} \text { Bankruptcies }_{i, t}+\boldsymbol{\Pi}^{T} \mathbf{X}_{i, j, t}+\text { time }_{t}+\text { investor }_{i}+\varepsilon_{i, j, t}
$$

where $\mathrm{y}_{i, j, t}$ measures behavior for investor i living in zip code $\mathrm{j}$ at time $\mathrm{t}$. We include investor fixed effects to control for unobserved time-invariant differences in trading behavior across investors that could be correlated with persistent differences in exposure to bankruptcies. We also control for time fixed effects to account for common macroeconomic conditions. Hence, we identify the bankruptcy effect from within-investor variation 
in trading activity over time and cross-sectional variation in the exposure to bankruptcies. The vector $\mathbf{X}_{i, j, t}$ includes a set of control variables, such as the investor's beginning of month portfolio value and the last month's return on the investor's portfolio, which should capture portfolio adjustments that are driven by personal trading history and success (Goetzmann et al., 2014; Grinblatt and Keloharju, 2001). Bankruptcy stands at the end of restructuring processes, so the insolvency date should not reflect a worsening of actual economic conditions (Brealey et al., 2016), which could simultaneously affect trading and local bankruptcies. To address any remaining concerns, we also control for a set of contemporaneous and lagged proxies for local economic conditions. ${ }^{6}$ Second, for the active change in the risky share and the buy-sell imbalance, which indicate changes in individual behavior and which should not be persistently high or low for any individual investor, we estimate the following first-difference specification:

$$
\mathrm{y}_{i, j, t}=\beta_{0}+\beta_{1} \Delta \text { Bankruptcies }_{i, t}+\mathbf{\Omega}^{T} \Delta \mathbf{X}_{i, j, t}+\text { time }_{t}+\varepsilon_{i, j, t}
$$

where active changes in the risky share or the buy-sell imbalance are regressed on the change in local bankruptcies. The focus on changes in behavior and bankruptcies implies that constant differences in risk-taking and bankruptcies across investors, which might be correlated with each other, are already accounted for. We therefore do not additionally control for investor fixed effects in these specifications. Again, we include time fixed effects to control for common shocks. In line with the main variables referring to changes, the control variables are coded as monthly changes in these specifications. Throughout, standard errors are two-way clustered by investor and time.

\subsection{Baseline results}

As shown in Table 2, retail investors who are exposed to local bankruptcies significantly change their trading activity and risk-taking. A 1 percentage point increase in the share of

\footnotetext{
${ }^{6}$ Specifically, we control for the current and last months' local unemployment rate and for the previous year's log of local GDP per capita, both measured at the county level. Moreover, we control for the current and last month's value-weighted average return on the stocks of all publicly listed firms within the 25-km zip code radius. We have made sure that the returns on stocks of firms that go bankrupt are not used for the construction of these indices.
} 
local firms that go bankrupt is associated with an increase in overall monthly turnover by 0.48 percentage points (column 1 ). This effect can be decomposed into an increase in sales turnover by 0.56 percentage points (column 2), and a smaller increase in purchase turnover by 0.41 percentage points (column 3). Thus, while experiencing local bankruptcies is associated with both increased buying and selling of risky assets, the effect on turnover is more pronounced for sales turnover. ${ }^{7}$ Does the increased trading activity translate into changes in risk-taking? Columns 4 and 5 show that a 1 percentage point increase in the bankruptcy measure reduces the buy-sell imbalance by 0.82 percentage points and is associated with an active downward adjustment of the risky portfolio share by 0.23 percentage points. All these effects are statistically significant at the 1 percent or at the 5 percent level.

What is the economic magnitude of these effects? There is a large degree of idiosyncratic variation in trading activity in our data, in line with comparable datasets, which has been the subject of a large literature. ${ }^{8}$ We therefore compare our estimated effect sizes to those of the recent return on an investor's own portfolio, which previous literature has shown to be one of the most important determinants of trading activity (Goetzmann et al., 2014; Grinblatt and Keloharju, 2001; Shefrin and Statman, 1985; Statman et al., 2006). The effect of a one standard deviation change in the bankruptcies measure is smaller but has the same order of magnitude as a one standard deviation change in the recent return on an investor's own portfolio. ${ }^{9}$ Our independent variable is the scaled number of bankruptcies that occurred in an investor's home zip code, which is only a noisy proxy for the number of bankruptcies that an investor actually has noticed. This is different to the return on the investor's own portfolio, which is measured with minimal error. Our estimates can therefore be interpreted as a lower bound on the effect of

\footnotetext{
${ }^{7}$ However, we are not powered to detect significant differences between effects on purchase and sales turnover.

${ }^{8}$ See e.g. Barberis and Thaler (2003); Campbell (2006); Curcuru et al. (2010); De Bondt (1998); Lakonishok and Maberly (1990).

${ }^{9} \mathrm{~A}$ one standard deviation increase of the return on the investor's own portfolio (7.64 percentage points) is associated with an increase in turnover by 0.50 percentage points and decreases in the buy-sell imbalance and the active change in the risky share by 0.50 and 0.12 percentage points, respectively. A one standard deviation increase in the bankruptcies measure ( 0.19 percentage points) leads to changes in turnover, the buy-sell imbalance and the risky share by $0.09,-0.15$ and -0.04 , respectively.
} 
noticing local bankruptcies on investment behavior. ${ }^{10}$

\subsection{Temporal and spatial proximity of bankruptcies}

Previous literature has shown that experiences of negative aggregate economic events persistently affect risk-taking of retail investors, even though these experiences are not predictive of future returns (Amromin and Sharpe, 2014; Greenwood and Shleifer, 2014; Malmendier and Nagel, 2011). Our evidence highlights how non-informative local experiences of adverse economic events lead to adjustments in risk-taking and increased trading in the short-term. How local are the effects of bankruptcies on trading? In this subsection we address this question by varying the spatial and temporal distance of local bankruptcies.

Spatial proximity The role of spatial proximity of experienced bankruptcies is of direct interest for better understanding the role of experiences in driving investment behavior. At the same time, varying the spatial proximity of bankruptcies helps to address the concern that our findings reflect local business cycles that could be driving both trading activity and bankruptcies. While local business cycles extend beyond zip code boundaries (Addoum et al., 2019), firm bankruptcies within zip codes should be particularly salient to the local population owing to visible closing signs, local news coverage, and word of mouth. First, we repeat our estimations extending the radius on which our bankruptcy measure is based from $25 \mathrm{~km}$ to $50 \mathrm{~km}, 100 \mathrm{~km}$, or $200 \mathrm{~km}$, thereby including additional bankruptcies that are more and more geographically distant. Second, we decompose the number of bankruptcies within a 200 km-radius into four accumulation intervals $(0-25$ $\mathrm{km}, 25-50 \mathrm{~km}, 50-100 \mathrm{~km}, 100-200 \mathrm{~km})$ and estimate the impact of each of the four bankruptcy measures on trading. Third, we calculate a bankruptcy measure based on all bankruptcies occurring in a given month in Germany excluding bankruptcies in the

\footnotetext{
${ }^{10}$ The estimated coefficients on other control variables are in line with previous literature. For instance, investors tend to increase their risky portfolio share in response to increases in wealth, and investors trade more actively during months of relatively high county-level unemployment.
} 
investor's home zip code. ${ }^{11}$ The results are shown in Figure 1. While bankruptcies within a $25 \mathrm{~km}$-radius have an economically meaningful effect on turnover, active adjustments in the risky share and the buy-sell imbalance, the effects become gradually smaller and quickly lose statistical significance when including more distant bankruptcies. Thus, our findings are driven by the trading response of individual investors who face economic conditions highly comparable to those of their slightly more distant neighbors but who live closer to bankruptcies.

Temporal proximity How many months ahead do bankruptcies affect trading? Figure 2 shows results from specifications where we replace the bankruptcies measure with its first, third, sixth, ninth or twelfth lag. Only bankruptcies occurring in the current month have a significant effect on trading and risk-taking. Moreover, in Table 3 we jointly include bankruptcies measures for the current month and for the previous two months, and show that also in this case only the contemporaneous measure has a significant effect on trading activity. ${ }^{12}$ These findings highlight that the effect of local bankruptcies on trading occurs immediately, and that the contemporaneous bankruptcies measure does not capture the lagged effect of earlier bankruptcies. Furthermore, even though there is no significant reversal of the effect over time, the estimated effects of more distant bankruptcies partially have the opposite sign and become noisy, indicating that the effect of bankruptcies on trading is not persistent. This highlights that adjustments in risktaking in response to non-informative adverse local experiences materialize immediately, and that trading activity is not permanently affected.

\subsection{Survey evidence on bankruptcies and risk-taking}

In our own survey, which we conducted to shed light on the mechanism behind our findings, we also elicited measures of trading activity, which we use to examine the robustness of our main findings. ${ }^{13}$ We regress dummies for having traded, having reduced

\footnotetext{
${ }^{11}$ Note that all measures are scaled by the same number of registered firms, which makes them comparable.

${ }^{12}$ We find no effect when we add further lags of the bankruptcies measure in unreported regressions.

${ }^{13}$ We present the results on mechanisms in section 4.2 .
} 
or increased equity holdings, or having rebalanced equity holdings during the previous four weeks on a dummy variable taking value one if the respondent indicates that he or she has noticed "more bankruptcies than usual" over the previous four weeks, and a set of control variables. ${ }^{14}$ Comparing individuals who have observed more bankruptcies than usual with those who have not observed more than usual, and who change their exposure to stocks in different ways should take out permanent differences in exposure to bankruptcies across zip codes and individuals, which may be correlated with levels of risk-taking.

Consistent with our main evidence, investors who have noticed more local business closures or firm bankruptcies than usual over the last four weeks are 17.4 percentage points more likely to report that they have traded with equity over the last four weeks (Table 4 Panel A column 1). This is fully driven by a higher tendency of having been a net seller of stocks (20.1 percentage points, column 3), while there is no effect on having been a net buyer (column 2) or simply having rebalanced the portfolio (column 4). Given a trading propensity of 37 percent and a net selling propensity of 7 percent among those who have not noticed more bankruptcies than usual, these effects are economically large. There is a similar relationship between recall of a higher than usual number of bankruptcies and planned trading activity over the next four weeks (Table 4 Panel B). Taken together, our main results replicate remarkably well in a survey dataset from a different time period and on a different sample, which supports the robustness of our findings.

\subsection{Changes in net worth and background risk}

Can our results be explained by changes in net worth or background risk? Bankruptcies should reflect adverse economic events that happened much earlier (Brealey et al., 2016) and the effect of bankruptcies is geographically and temporally very concentrated. Moreover, in our main brokerage sample we overwhelmingly use small firm bankruptcies, with public firms accounting for only 1.5 percent of all bankruptcies, and a median number

\footnotetext{
${ }^{14}$ Specifically, we control for gender, age, education, employment status, income, net wealth, participation in different asset classes and state of residence. The details on the construction of the control variables are provided in online appendix D.4.
} 
of employees of bankrupt firms of three. Thus, our findings are unlikely to be driven by omitted variables such as changes in actual net worth or background risks of investors. In this subsection we conduct an additional set of checks against this possibility. ${ }^{15}$

Brokerage data First, we examine the effect of bankruptcies within subsamples of investors in our brokerage data whose labor income is less exposed to fluctuations of the (local) economy. In a first set of tests, we exclude investors working in "cyclical" industries, that are exposed to the business cycle. For instance, individuals working in health and education or in the public sector should not be strongly affected by economic fluctuations, while individuals working in manufacturing or wholesale and retail should be more exposed (Takhtamanova and Sierminska, 2016). In a second set of tests, we exclude individuals working in an industry producing non-tradable goods and services, who should be particularly strongly exposed to fluctuations of the local economy (Mian and Sufi, 2014). ${ }^{16}$ However, as shown in Figure 3, we find equally strong results when we exclude investors working in cyclical industries or investors working in the non-tradable sector.

Second, investors who experience financial distress are likely to withdraw cash. We re-estimate our baseline specification(s) excluding for each investor observations above the 90th or above the 75th percentile of this investor's distribution of monthly cash withdrawals over the sample period. However, our coefficient estimates barely change in size and mostly remain strongly statistically significant in these subsamples (see Figure 3).

Third, we exclude months in which bankruptcies would be most likely to reflect an actual worsening of local economic conditions. Specifically, we exclude zip code-month

\footnotetext{
${ }^{15}$ There are two ways in which our estimates could capture increases in background risk or a worsening of investors' own economic situation. First, omitted unobserved variables, such as a worsening of local economic conditions, could be driving both bankruptcies and - through a worsening of investors' own economic situation and outlook - financial risk-taking. Second, investors could directly interpret bankruptcies as an adverse signal about future labor income and background risk. The checks conducted in this section speak to both possibilities. We shed more light on the second possibility in the mechanism sections 4.2.1 and 4.2.2.

${ }^{16}$ Industries are classified as cyclical or non-cyclical or as tradable or non-tradable following previous literature (Guvenen et al., 2017; Mian and Sufi, 2014; Takhtamanova and Sierminska, 2016). Our findings are robust to varying these classifications. Details are provided in online appendix C.
} 
observations above the 90 th or above the 75 th percentile in that zip code's distribution of monthly bankruptcies or the distribution of the number of affected employees, respectively. Again, the estimated coefficients remain statistically significant and have almost the same size as our baseline estimates (see Figure 3).

Fourth, a similar picture emerges if we split the bankruptcies measure into two independent variables capturing bankruptcies of smaller and larger firms separately. Specifically, we construct measures of bankruptcies of firms with less than four employees and of firms with at least four employees, of firms with less than ten and of firms with at least ten employees, of firms with below 50 and of firms with at least 50 employees, and of publicly listed as well as private firms. As can be seen in Figure 4, the effect of local bankruptcies on the active adjustment in the risky share is fully driven by smaller firms according to all of these measures, which are less likely confounded by a large fraction of the local population losing their jobs. ${ }^{17}$ We discuss the mechanism behind our findings, including a potential explanation for the effect being driven by smaller firms, in section 4 below.

Survey data Finally, only 3 percent of investors in our own survey indicate that they were personally in any way affected by local bankruptcies over the last four weeks. Reassuringly, we find very similar trading results in the survey if we exclude those investors from our estimations (Table A5 Panel B), providing additional evidence that our findings are unlikely driven by unobserved wealth effects.

Taken together, the analyses presented in this subsection provide strong evidence that our findings are unlikely driven by direct wealth effects or increased background risk due to shocks to the local economy.

\footnotetext{
${ }^{17}$ The results are slightly less clear-cut for the other outcome variables, turnover and the buy-sell imbalance, but those variables should be less likely confounded by changes in risk-taking due to increased background risk. The estimates for larger firms become noisy when we use very high cutoffs, given that there is only a small number of large firms going bankrupt in our dataset.
} 


\subsection{Additional subsample analysis and robustness checks}

We conduct a set of additional analyses and robustness checks in our brokerage sample, which are discussed in detail in online Appendix E. Specifically, we show that our results are not driven by any specific demographic group of investors or by investors who are more active or hold larger portfolios. We also demonstrate robustness to dropping inactive accounts using more or less conservative definitions, to excluding publicly listed firms from the bankruptcies measure, to applying various different transformations of the main independent variable, and to adding fixed effects for the interaction of quarter and state of residence. Finally, we use a placebo analysis to provide another check against the possibility that we are picking up omitted variables that are correlated with the bankruptcies measure over time or across geographies.

\section{How do bankruptcies affect risk-taking?}

In the previous section we have established that experiencing local bankruptcies increases portfolio turnover and reduces risk-taking of retail investors, and that these results are not driven by omitted variables such as an actual worsening of economic conditions. In this section we examine the mechanism behind our main findings. First, we examine what draws investors' attention to bankruptcies and how the effect of bankruptcies on trading varies with investors' attention to bankruptcies. Second, we examine different explanations for why bankruptcies change risk-taking, including changes in expectations and changes in risk aversion.

\subsection{Attention to bankruptcies}

\subsubsection{What draws investors' attention to bankruptcies?}

How do retail investors learn about local bankruptcies? In our survey 37 percent of investors have noticed bankruptcies in their region of residence over the previous four weeks, which implies that bankruptcies regularly come to the attention of individuals. 
Among those respondents who have noticed bankruptcies, 58 percent have read about bankruptcies in the local newspaper (Figure A4). This is followed by word of mouth (39 percent) and visible closing signs (38 percent). 18 percent have learned about firm closures through social media, and 15 percent have heard about bankruptcies in the radio. Only 2 percent indicate that they have heard about bankruptcies from other sources.

How does the supply of information about bankruptcies react to changes in the level of local bankruptcies? We obtain data on monthly mentions of the word "bankruptcy" ("Insolvenz" in German) from the 12 regional and local newspapers (mostly from major German cities) whose content is available in online archives for most of our sample period. ${ }^{18}$ Figure A5 Panels $\mathrm{C}$ to $\mathrm{H}$ show separately for six major German cities that bankruptcies and news coverage of bankruptcies move closely together. Moreover, pooling data from all 12 newspapers we estimate that a one standard deviation increase in local bankruptcies is associated with a 0.2 standard deviation increase in news mentions, conditional on newspaper region fixed effects (Table A6 column 1). ${ }^{19}$ This effect decreases slightly to 0.16 of a standard deviation when up to six lags of bankruptcies are included (columns 2-7), but remains strongly significant, while lags of local bankruptcies have no significant effect on news coverage.

Finally, if individuals care about local bankruptcies, they should seek out more information about bankruptcies when they observe a higher level of local insolvencies. We use monthly data from Google searches for the term "bankruptcy" at the state level as a measure of people's demand for information about bankruptcies. Figure A6 Panels C to H show separately for each of the six largest German states that state-level movements in Google searches and movements in actual bankruptcies are closely connected. ${ }^{20}$ As shown

\footnotetext{
${ }^{18}$ Specifically, we use data from Aachener Nachrichten/Aachener Zeitung, Berliner Zeitung/Berliner Kurier, General Anzeiger (Bonn), Hamburger Abendblatt, Kölner Express/Stadtanzeiger/Rundschau, Nordwest Zeitung (northwestern part of Lower Saxony), Nürnberger Nachrichten, Ostsee-Zeitung (northern part of Mecklenburg-Vorpommern), Stuttgarter Nachrichten/Stuttgarter Zeitung, Südwest Presse (Ulm), Weser-Kurier (Bremen), and Wiesbadener Kurier, which we accessed through the newspaper databases Factiva and LexisNexis.

${ }^{19}$ We obtain very similar results if we include time fixed effects, but the estimates are more noisy given that we have only 12 newspapers available. We use newspaper region-specific means and standard deviations over the sample period for the normalizations. Figure A5 Panels A and B display binned scatter plots highlighting the strong positive correlation in the pooled sample from all 12 newspapers.

${ }^{20}$ In unreported regressions we found a positive correlation for 15 out of the 16 German states, which is highly statistically significant for 12 states.
} 
in the binned scatter plot in Figure A6 Panel A, there is a strong positive correlation between Google searches and the number of bankruptcies at the state level, which also holds conditional on state fixed effects (Panel B). A one standard deviation increase in local bankruptcies is associated with a 0.4 standard deviation increase in Google searches (Table A7 column 1). The effect size drops to 0.23 of a standard of a standard deviation when we include lags of bankruptcies (columns 2-7). Again, lagged bankruptcies mostly have an insignificant effect on Google searches, which is smaller than the effect of current bankruptcies.

Taken together, these results indicate that bankruptcies immediately come to the attention of individuals through news coverage and Google searches, consistent with the sharp and immediate but quickly fading effect of local bankruptcies on trading documented in section 3.3 and in Figure 2 (spatial and temporal proximity of local bankruptcies). Our finding that local newspapers seem to play an key part in the transmission mechanism is in line with previous literature documenting an important role for local newspapers in the trading decisions of retail investors (Engelberg and Parsons, 2011).

\subsubsection{How does the effect of bankruptcies vary with investor attention?}

Previous studies highlight the importance of attention in shaping investor behavior (Barber and Odean, 2007; Gilbert et al., 2012; Ruenzi et al., 2019; Sicherman et al., 2015). Investors seem to have limited information processing capacity, which decreases attention to given pieces of news when investors have more information to process, are faced with conflicting information, or become distracted by other events. For example, Hirshleifer et al. (2009) show that the immediate price and volume reaction to earnings surprises is weaker on days with a greater number of earnings announcements. DellaVigna and Pollet (2009) document that the immediate responses to earnings announcements are smaller on Fridays, consistent with underreaction to information due to limited attention. Thus, the effect of local bankruptcies on trading activity should increase with investors' attention to bankruptcies. In this subsection we conduct four sets of tests of this idea. 
Market volatility We expect local bankruptcies to have a smaller effect on trading during times of noteworthy national-level information, which we capture by periods of elevated implied market volatility as measured with the VDAX. We re-estimate our main specifications adding interaction terms with a dummy indicating whether the VDAX is above its 75 th percentile or with a dummy indicating that it is above the 90th percentile within the sample period. As can be seen in Table 5 Panel A, the effects of bankruptcies on trading decrease in implied market volatility. The coefficients on the interaction term are noisily measured for the 75th percentile-dummy (columns 1, 3 and 5), but are very large and highly significant for the 90th percentile (columns 2, 4 and 6), indicating that periods of very high national-level market volatility moderate the effect of local bankruptcies on trading.

Holidays Similarly, retail investors should be less attentive to local bankruptcies during holiday seasons (Jacobs and Weber, 2011), which we measure by a dummy indicating the month of the long summer school holidays in the state of residence. When we include this dummy and an interaction term with this dummy, we find that the effects of bankruptcies emerge during non-holiday periods and are insignificant during holiday periods (see the tests reported in Table 5 Panel B), although the interaction term is only significant in the case of the buy-sell imbalance. This provides additional evidence that the effects are less pronounced when investors are distracted.

Conflicting information Moreover, we expect the effect of bankruptcies to be smaller when investors are faced with potentially conflicting information, which we proxy with professional forecasters being very optimistic about the 6-month ahead return of the German stock market index (DAX). ${ }^{21}$ In line with this idea, we find that the effects of bankruptcies are insignificant during periods in which professional forecasts about stock returns exceed the 75 th or the 90 th percentile within the sample period, even though the

\footnotetext{
${ }^{21}$ We take professional forecasts from the ZEW Financial Market Survey, as explained in detail in appendix section C.4 and Table A3. Roth and Wohlfart (2019) show that when participants in a survey experiment are confronted with optimistic professional forecasts about the aggregate economy they strongly update their expectations and become more likely to report net purchases of stocks in a follow-up survey.
} 
coefficients on the interaction terms are noisily measured (Table 5 Panel C).

Local salience of bankruptcies Finally, investors' attention should also increase in the bankruptcies' local salience (Bordalo et al., 2012, 2013). Specifically, a given bankruptcy should be less salient if the local population is more used to observing bankruptcies. To test this idea, we calculate for each zip code in our dataset the sample period-average of the monthly bankruptcies measure as well as the average monthly number of employees losing their jobs due to local bankruptcies divided by the size of the local population. When splitting the sample into zip codes above and zip codes below the cross-sectional averages of these measures, we find that the effects of bankruptcies on risk-taking are driven by zip codes that are not used to observing a high number of bankruptcies or not used to observing many employees losing their jobs due to bankruptcies (see Figure 5). ${ }^{22}$ These results provide suggestive evidence that higher local salience leads to a stronger effect of local bankruptcies on risk-taking through increased investor attention.

\subsection{Expectations, risk aversion and sentiment}

Local news coverage seems to play an important role in drawing investors' attention to bankruptcies, and bankruptcies have a stronger effect on risk-taking when investors are more attentive to them. But through which channels does attention to bankruptcies affect the behavior of retail investors? In this subsection we analyze in detail whether i) investors react to bankruptcies because they are informative of the future; whether investors adjust their subjective expectations about ii) their labor income or iii) stock returns in response to bankruptcies; and whether bankruptcies lead to changes in iv) risk aversion or v) sentiment.

\footnotetext{
${ }^{22}$ While this is true for the buy-sell imbalance and the active change in the risky share, the pattern goes into the opposite direction for overall turnover. However, once we split the turnover variable into sales and purchases, we find that there is no difference in sales turnover between the two groups. Interestingly, bankruptcies are associated with an increase in purchase turnover in areas where people are more used to them, even though they are not associated with changes in risk-taking in these areas.
} 


\subsubsection{Are local bankruptcies informative?}

If bankruptcies are predictive of the future health of the (local) economy, investors may rationally update their expectations about their own income or stock returns and adjust their behavior in response to bankruptcies. Given that bankruptcies only happen after extensive restructuring processes have taken place, they should primarily reflect adverse events that happened much earlier. To better understand the informational content of bankruptcies, we investigate whether future changes in (local) economic conditions can be forecast by (local) firm bankruptcies. Following Korniotis and Kumar (2013) we estimate predictability regressions of the following form:

$$
\mathrm{Y}_{j, t}=\beta \text { Bankruptcies }_{j, t-k}+\gamma_{1} \mathrm{Y}_{j, t-k}+\gamma_{2} \mathrm{X}_{j, t-k}+\text { time }_{t}+\text { geography }_{j}+\varepsilon_{j, t}
$$

where the dependent variable $\mathrm{Y}_{j, t}$ refers to different economic outcomes of interest, such as unemployment. Depending on the geographical level of the dependent variable of interest, j represents zip code, county or entire Germany. Depending on the temporal aggregation level of the outcome $\mathrm{Y}_{j, t}$, $\mathrm{t}$ refers to month or year. We separately estimate regressions for different prediction horizons, ranging from $\mathrm{k}=1$ to $\mathrm{k}=6$ time periods. We control for a set of lagged variables, $\mathrm{X}_{j, t-k}$, such as the return on stocks of local listed firms or local GDP, and a lagged dependent variable, $\mathrm{Y}_{j, t-k}$, to account for persistence or autocorrelation, but all our results are robust to the exclusion of the lagged dependent variable. The independent variable Bankruptcies $_{j, t-k}$ is adjusted to the geographic aggregation level j. ${ }^{23}$ We include geographical and time fixed effects in line with the aggregation levels of the dependent variable, $\mathrm{j}$ and $\mathrm{t}$, except for prediction regressions at the national level.

As shown in Table 6, bankruptcies have no systematic predictive power for returns of stocks of public companies located in the $25-\mathrm{km}$ radius around the zip code (column 1), zip-code level spending capacity (column 2), unemployment rate and log GDP per

\footnotetext{
${ }^{23}$ The bankruptcies measure is constructed as previously for outcome variables at the zip code level. For outcomes at the county level ("Landkreis") or the national level we divide the number of bankruptcies by the number of firms registered in that county or in all of Germany in the previous year. The specific controls included in each set of regressions are provided in the footnote of Table 6 .
} 
capita at the county level (columns 3 and 4), or national-level stock returns, stock market volatility or unemployment (columns 5 to 7 ). Only three coefficient estimates are (marginally) significant, two of which show an increase in stock returns following higher bankruptcies, opposite to what would be consistent with a rational interpretation of our findings. ${ }^{24}$

Next, we examine separately for each zip code whether during our sample period bankruptcies in that zip code are predictive of changes in national economic conditions, similarly as done by Kuchler and Zafar (2019) for house price experiences and expectations. For each zip code and month we regress i) the CDAX return over the next 12 months, ii) the average value of the volatility index VDAX over the next 12 months, and iii) the national unemployment rate in 12 months (controlling for the current rate), on the local bankruptcies measure. Higher local bankruptcies predict lower CDAX returns for only 8.7 percent and higher national unemployment for only 7.3 percent of our investor observations, and for the majority of our observations (56.2 percent) higher local bankruptcies are not predictive of higher volatility of the aggregate stock market.

Finally, we examine how the effect of bankruptcies on trading and risk-taking differs across investors living in zip codes with different levels of predictive power of local bankruptcies. As shown in Table 7 columns 2 and 3, our main results remain almost unchanged when we exclude the (minorities of) zip codes for which higher local bankruptcies predict lower CDAX returns or higher national unemployment. Moreover, bankruptcies have very similar effects on trading and risk-taking in zip codes where they predict higher or lower volatility of the aggregate stock market (columns 4 and 5).

Taken together, these findings strongly suggest that trading and changes in risk-taking in response to bankruptcies are not driven by rational updating of expectations about the stock market, income or background risks, and support the notion that bankruptcies are no signal of an actual worsening of future economic conditions.

\footnotetext{
${ }^{24}$ Naturally, when testing multiple hypotheses a few estimates will turn out significant even if the true effect is zero.
} 


\subsubsection{Subjective income expectations and perceived background risk}

Even though bankruptcies are not predictive of actual changes in (local) economic conditions, observing bankruptcies may still trigger changes in subjective expectations of income growth and perceived background risk, which in turn may lead investors to reduce their financial risk-taking (Engelberg and Parsons, 1996; Fagereng et al., 2017b; Heaton and Lucas, 2000). The evidence of a strong trading response among groups facing only a low background risk presented in section 3.5 already indicates that this is an unlikely explanation for our findings. We provide more direct evidence on this channel using our investor survey. Among others, respondents to the survey answered questions on their subjective expectations regarding their household labor income. Specifically, respondents had to assign probabilities to six ranges of household labor income growth over the next year that are mutually exclusive and collectively exhaustive. We use their responses to this question to construct mean and standard deviation of their expected labor income growth. ${ }^{25}$ Respondents also answered qualitative questions on whether their subjective income prospects and their expectations about GDP growth had improved or worsened over the previous four weeks.

We regress measures of subjectively expected labor income growth on a dummy variable taking value one if the respondent indicates that he or she has noticed "more bankruptcies than usual" over the previous four weeks, conditional on the same set of controls as in section 3.4. Again, we compare individuals who have or have not observed more bankruptcies than usual, which is similar to including an individual fixed effect. Table 8 Panel A shows that having observed more bankruptcies than usual has no significant effect on mean or standard deviation of expected labor income growth over the next year (columns 1 and 2). Similarly, there is no effect on the subjective probability assigned to a drastic reduction in labor income by more than 20 percent (column 3) or on the tendency to report that income prospects (column 4) or expected real GDP growth

\footnotetext{
${ }^{25}$ Respondents had to assign probabilities to realizations of their household's labor income growth of less than -20 percent, -20 to -10 percent, -10 to 0 percent, 0 to 10 percent, 10 to 20 percent or more than 20 percent. We use midpoints of these bins and assign -30 percent and 30 percent to the two open bins, but our findings are robust to varying the exact values assigned to these bins. We set to missing 226 responses where the indicated probabilities do not sum to 100.
} 
(column 5) have worsened over the last four weeks. Thus, the effect of bankruptcies on risk-taking does not seem to be driven by changes in expected labor income growth or perceived background risk.

\subsubsection{Subjective return expectations}

Another channel through which bankruptcies could affect trading and risk-taking are changes in subjective expectations about stock returns. Kuchler and Zafar (2019) show that recent local house price changes affect households' expectations about nationwide house price growth. Similarly, investors could interpret local bankruptcies as a signal about the aggregate stock market and adjust their expectations about stock returns accordingly.

Survey evidence In the investor survey we find that having noticed a higher than usual number of local bankruptcies over the last four weeks is associated with a significant reduction in expected stock returns, as measured by the mean of a respondent-level subjective probability distribution, by 2.3 percentage points (Table 8 Panel B column 1). ${ }^{26}$ While there is no significant increase in the subjective standard deviation of stock returns (column 2), respondents assign a 4.3 percentage points higher probability to large negative events of stock returns of less than -20 percent (column 3). These effects are economically large, given mean expected returns of 2.3 percent and a mean probability assigned to large losses of 5.4 percent among those who have not noticed more bankruptcies than usual. In unreported regressions we find no significant effect on the probability assigned to any other individual return interval. Having experienced more bankruptcies than usual also makes investors 9.1 percentage points more likely to report that their subjective expectations about stock returns have worsened over the last four weeks (column 4), compared to a baseline share of 14 percent. This evidence suggests that local bankruptcies make investors more pessimistic about stock returns by increasing the perceived probability of

\footnotetext{
${ }^{26}$ The bins are the same as for the subjective probability distribution over labor income growth. For stocks, we use conditional mean historical realized returns instead of the midpoints of the bins to calculate respondent-level mean and standard deviation over one year-ahead returns.
} 
large losses, potentially because bankruptcies make such a possibility more salient. These results are in line with recent findings showing that perceived disaster risk seems to play an important role in individuals' stock investment decisions (Choi and Robertson, 2020; Fagereng et al., 2017a; Giglio et al., 2020). ${ }^{27}$

Do investors extrapolate from local bankruptcies not only to future returns of German stocks but also to future returns of foreign stocks? Having experienced more bankruptcies than usual has no significant effect on the respondents' tendency to report that their expectations about the returns of foreign stocks have worsened over the last four weeks (column 5). Moreover, there is no significant effect on the respondents' expectations about the returns on government bonds (column 6). This suggests that individual investors interpret local bankruptcies as a signal about future returns of German stocks, but do not adjust their expectations about the returns of all assets.

Brokerage data If our findings operate through changes in subjective expectations about the returns of German but not of foreign stocks, this should be reflected in a stronger effect of local bankruptcies on trading in German stocks than trading in foreign stocks in our brokerage data. We calculate overall turnover and the buy-sell imbalance separately for European equity, German equity, non-German European equity, and nonEuropean equity. Table 9 shows that local bankruptcies significantly increase turnover (Panel A) and significantly decrease the buy-sell imbalance (Panel B) of European equity (column 1), both driven by trading of German equity (column 2). There are no significant effects on trading in European non-German equity (column 3) or trading in Non-European equity (column 4). These results replicate with larger effect sizes if we only focus on those investors who held the particular asset class in the previous month (columns 58). Together with our survey evidence, these findings strongly suggest that at least part of the effect operates through subjective return expectations, which are concentrated in

\footnotetext{
${ }^{27}$ (Perceived) disaster risk is at the core of various theories of portfolio choice (Barro, 2006; Gabaix, 2012; Rietz, 1988). The perceived probability of large losses is also central to accounts of the role of trust in shaping stock investment (Guiso et al., 2008).
} 
expected returns of German stocks. ${ }^{28}$

Moreover, Meeuwis et al. (2019) document that the election of Donald Trump triggered an increase in risk-taking and in the market beta of Republican investors relative to Democrats, presumably through its effect on expected returns. Similarly, if our main findings operate through investors becoming more pessimistic about the aggregate stock market, they should reduce the market beta of their portfolios in response to observing local bankruptcies. We calculate for each month the market beta of each investor's portfolio for the German stock market indices DAX and CDAX and for the international stock market indices MSCI Europe and MSCI World after partialling out the performance of the CDAX (as described in more detail in online appendix C.6). As shown in Table 10, investors reduce the exposure of their portfolios to both the DAX and the CDAX when they observe more local bankruptcies, but they do not reduce their exposure to the non-German European and global stock markets. Moreover, in line with the evidence presented in section 4.2.2, investors do not reduce their portfolio's beta to aggregate GDP growth. These patterns provide further evidence that our main findings operate through specific extrapolation from local events to the expected aggregate return of the German stock market.

Finally, if extrapolation from local (uninformative) events to the nation-wide outlook is driving the effect of local bankruptcies on risk-taking, then this also offers an explanation for our earlier finding that the effects are driven by bankruptcies of smaller firms (see Section 3.5 and Figure 4). Specifically, extrapolation should be more pronounced if less information about the specific (often idiosyncratic) cause of a given bankruptcy is available. While it may be well-known by the local population that the bankruptcy of a local medium-sized firm is due to idiosyncratic reasons such as foreign competition in the firm's market segment or poor management decisions, much less information will be available about the cause of bankruptcies of smaller firms, leaving room for extrapolation

\footnotetext{
${ }^{28}$ Note that statistical significance is lower than in the main estimations if we focus on equity from only a particular region, as for instance in the case of the buy-sell imbalance of German equity in Table 9 Panel B Column 6. We believe that this is likely because we have less variation available when we restrict the outcome measures to only one asset class. In this example, the coefficient estimate for German equity is still larger than for equity from other regions and the effect on the overall buy-sell imbalance of equity is strongly significant, as shown in our main estimations.
} 
to the aggregate outlook.

\subsubsection{Risk aversion}

Alternatively, bankruptcies could affect risk-taking of retail investors through changes in risk aversion, which can be a source of fluctuations in the risky portfolio share (Brunnermeier and Nagel, 2008; Guiso et al., 2018). Time-varying risk aversion would predict a reduction of the willingness to take all types of financial risks, and cannot by itself explain why our findings in the brokerage data are concentrated in holdings of German equity. In our survey we elicit a measure of risk aversion that should be orthogonal to investors' expected returns of German or non-German equity. Specifically, our respondents have to invest a hypothetical amount of $€ 1.000$ for one year, and they can choose how much to invest in a riskless asset which pays a return of 2 percent in all states of the world, and how much to invest in a risky asset which pays a return of 15 percent or a return of -7 percent with equal probability. By holding the return distribution fixed, this measure is orthogonal to the respondent-level expectations about actual returns of German or foreign stocks. Respondents are also asked how they would have divided the $€ 1.000$ four weeks before the survey. ${ }^{29}$

We find that having experienced more bankruptcies than usual over the last four weeks is associated with a significant reduction of the share invested in the risky asset relative to four weeks ago by 5.5 percentage points (Table 8 Panel A column 6). This effect is economically large, given an average share invested in the risky asset of 48 percent currently and 44 percent four weeks ago. These results suggest that besides changes in subjective return expectations, part of the effect of bankruptcies on risk-taking seems to work through time-varying risk aversion.

\footnotetext{
${ }^{29}$ We set 261 responses to missing for which the amounts invested in the risky and in the riskless asset do not sum to $€ 1.000$.
} 


\subsubsection{Affect and sentiment}

Finally, bankruptcies could change risk-taking through affect or changes in mood, sentiment and overall pessimism (see e.g. Andre et al. (2019); Hirshleifer (2001); Kaustia and Rantapuska (2016); Lucey and Dowling (2005)). In this case we should observe that having noticed more bankruptcies than usual is associated with an increase in pessimism across all domains. However, while experienced bankruptcies seem to affect expectations about German stocks and risk aversion, there is no effect on people's expectations about their labor income, economic growth or foreign stock returns. In addition, an effect operating through affect or sentiment should arguably be more pronounced for bankruptcies of larger firms, where more employees are losing their jobs, inconsistent with our earlier finding that the effect is more pronounced for smaller firms (see Section 3.5 and Figure 4). Thus, our findings do not seem to be due to shifts in general pessimism, sentiment or affect.

\subsubsection{Robustness}

All of our findings from the survey data are robust to a variety of adjustments. Table A5 repeats the main estimations on the survey data on a subsample of respondents who report that local bankruptcies did not affect them personally over the last four weeks (Panel B), using more fine-grained geographical fixed effects corresponding to the first two digits of a respondent's zip code (Panel C), and clustering standard errors at the coarser level of the first two digits of the zip code of residence (Panel D). None of these adjustments meaningfully affects our findings.

\subsubsection{Summary}

In this subsection we have examined whether local bankruptcies affect risk-taking through changes in preferences or beliefs. Bankruptcies are not predictive of actual changes in nationwide or local economic conditions or stock returns, and having experienced bankruptcies does not make investors subjectively more pessimistic about their own labor income 
or future GDP growth. At the same time, investors become more pessimistic about German stock returns following bankruptcies, largely driven by a higher probability assigned to large losses, while there is no effect on expected returns on foreign stocks or bonds. In line with this, the trading response to local bankruptcies is concentrated in European and specifically German equity. We also find some evidence of shifts in general risk aversion in response to bankruptcies.

\section{Conclusion}

Using data from a large German brokerage, we show that retail investors react to local firm bankruptcies by increasing their monthly turnover and by actively reducing the risky share of their portfolios. The effects on trading are spatially and temporally highly concentrated, and do not seem to be driven by unobserved changes in wealth or background risk. We show that investors' attention is drawn to bankruptcies through coverage in the local news, and bankruptcies exert a stronger effect on trading and risk-taking when investors are more attentive to them. We provide survey evidence that local bankruptcies affect trading through shifts in subjective expectations about aggregate German stock returns and time-varying risk aversion.

Our findings demonstrate that non-informative local experiences that make the downside risks of stock investment more salient cause idiosyncratic fluctuations in trading, contributing to heterogeneity in investment behavior across households. While previous literature has shown that experiences of economy-wide conditions are reflected in longterm and persistent differences in risk-taking (Knüpfer et al., 2017; Malmendier and Nagel, 2011), we document that adjustments in risk-taking in response to (local) non-informative adverse events occur through sharp and immediate one-time increases in trading activity. Our paper adds to evidence that individuals extrapolate from local experiences to expectations about aggregate unemployment, house prices and inflation (D'Acunto et al., 2019; Kuchler and Zafar, 2019) by showing that local experiences also shape expectations about the aggregate stock market and, most importantly, ultimately affect the behavior 
of individuals, even in a sample of relatively experienced and active investors. Finally, our paper provides new evidence on the role of attention in shaping investment decisions, in particular on how attention governs the weight that non-informative events receive in the beliefs and trading decisions of individuals.

\section{References}

Addoum, Jawad, Alok Kumar, Nhan Le, and Alexandra Niessen-Ruenzi, "Local Bankruptcy and Geographic Contagion in the Bank Loan Market," Review of Finance, 2019.

Alesina, Alberto and Nicola Fuchs-Schündeln, "Good-bye Lenin (or not?): The Effect of Communism on People's Preferences," The American Economic Review, 2007, $97(4), 1507-1528$.

Amromin, Gene and Steven A Sharpe, "From the Horse's Mouth: Economic Conditions and Investor Expectations of Risk and Return," Management Science, 2014, 60 (4), 845-866.

Andersen, Steffen, Tobin Hanspal, and Kasper Meisner Nielsen, "Once Bitten, Twice Shy: The Power of Personal Experiences in Risk Taking," Journal of Financial Economics, 2019, 132 (3), 97-117.

Andre, Peter, Carlo Pizzinelli, Christopher Roth, and Johannes Wohlfart, "Subjective Models of the Macroeconomy: Evidence from Experts and a Representative Sample," Working Paper, 2019.

Armantier, Olivier, Giorgio Topa, Wilbert Van der Klaauw, and Basit Zafar, "An Overview of the Survey of Consumer Expectations," Economic Policy Review, 2017, (23-2), 51-72.

Barber, Brad M and Terrance Odean, "Do Investors Trade Too Much?," American Economic Review, 1999, 89 (5), 262.

_ and _ , "Boys will Be Boys: Gender, Overconfidence, and Common Stock Investment," The Quarterly Journal of Economics, 2001, 116 (1), 261-292.

_ and _ , "All that Glitters: The Effect of Attention and News on the Buying Behavior of Individual and Institutional Investors," The Review of Financial Studies, 2007, 21 (2), 785-818.

Barberis, Nicholas and Richard Thaler, "A Survey of Behavioral Finance," Handbook of the Economics of Finance, 2003, 1, 1053-1128.

Barnea, Amir, Henrik Cronqvist, and Stephan Siegel, "Nature or Nurture: What Determines Investor Behavior?," Journal of Financial Economics, 2010, 98 (3), 583604 . 
Barro, Robert J, "Rare Disasters and Asset Markets in the Twentieth Century," The Quarterly Journal of Economics, 2006, 121 (3), 823-866.

Bordalo, Pedro, Nicola Gennaioli, and Andrei Shleifer, "Salience Theory of Choice Under Risk," The Quarterly journal of economics, 2012, 127 (3), 1243-1285.

_ , _, and _ , "Salience and consumer choice," Journal of Political Economy, 2013, 121 (5), 803-843.

Brealey, Richard A., Stewart C. Myers, Franklin Allen, and Pitabas Mohanty, Principles of Corporate Finance. 12th International Edition, McGraw-Hill Education, Maidenhead, 2016.

Brunnermeier, Markus K and Stefan Nagel, "Do Wealth Fluctuations Generate Time-Varying Risk Aversion? Micro-Evidence on Individuals," American Economic Review, 2008, 98 (3), 713-36.

Calvet, Laurent E, John Y Campbell, and Paolo Sodini, "Fight or Flight? Portfolio Rebalancing by Individual Investors," The Quarterly Journal of Economics, 2009, 124 (1), 301-348.

Campbell, John Y, "Household Finance," The Journal of Finance, 2006, 61 (4), 15531604.

Choi, James J and Adriana Z Robertson, "What Matters to Individual Investors? Evidence from the Horse's Mouth," Journal of Finance, 2020.

Coval, Joshua D and Tobias J Moskowitz, "Home Bias at Home: Local Equity Preference in Domestic Portfolios," The Journal of Finance, 1999, 54 (6), 2045-2073.

_ and _ , "The Geography of Investment: Informed Trading and Asset Prices," Journal of Political Economy, 2001, 109 (4), 811-841.

Cronqvist, Henrik and Stephan Siegel, "The Genetics of Investment Biases," Journal of Financial Economics, 2014, 113 (2), 215-234.

_, _, and Frank Yu, "Value versus Growth Investing: Why Do Different Investors Have Different Styles?," Journal of Financial Economics, 2015, 117 (2), 333-349.

Curcuru, Stephanie, John Heaton, Deborah Lucas, and Damien Moore, "Heterogeneity and Portfolio Choice: Theory and Evidence," in "Handbook of Financial Econometrics: Tools and Techniques," Elsevier, 2010, pp. 337-382.

D’Acunto, Francesco, Ulrike Malmendier, Juan Ospina, and Michael Weber, "Exposure to Daily Price Changes and Inflation Expectations," Working Paper, 2019.

De Bondt, Werner FM, "A Portrait of the Individual Investor," European Economic Review, 1998, 42 (3-5), 831-844.

DellaVigna, Stefano and Joshua M Pollet, "Investor Inattention and Friday Earnings Announcements," The Journal of Finance, 2009, 64 (2), 709-749. 
Elton, Edwin J., Martin J. Gruber, and Christopher R. Blake, "An Examination of Mutual Fund Timing Ability Using Monthly Holdings Data," Review of Finance, 03 2011, 16 (3), 619-645.

_ , _ , and _ , "Holdings Data, Security Returns, and the Selection of Superior Mutual Funds," The Journal of Financial and Quantitative Analysis, 2011, 46 (2), 341-367.

Engelberg, Joseph E and Christopher A Parsons, "Income Risk, Borrowing Constraints, and Portfolio Choice," The American Economic Review, 1996, 86 (1), 158-172.

_ and _ , "The Causal Impact of Media in Financial Markets," The Journal of Finance, 2011, 66 (1), 67-97.

Erev, Ido, Eyal Ert, Alvin E Roth, Ernan Haruvy, Stefan M Herzog, Robin Hau, Ralph Hertwig, Terrence Stewart, Robert West, and Christian Lebiere, "A Choice Prediction Competition: Choices from Experience and from Description," Journal of Behavioral Decision Making, 2010, 23 (1), 15-47.

Fagereng, Andreas, Charles Gottlieb, and Luigi Guiso, "Asset Market Participation and Portfolio Choice over the Life-cycle," The Journal of Finance, 2017, 72 (2), $705-750$.

_ , Luigi Guiso, and Luigi Pistaferri, "Portfolio Choices, Firm Shocks, and Uninsurable Wage Risk," The Review of Economic Studies, 2017, 85 (1), 437-474.

Gabaix, Xavier, "Variable Rare Disasters: An Exactly Solved Framework for Ten Puzzles in Macro-Finance," The Quarterly Journal of Economics, 2012, 127 (2), 645-700.

Giannetti, Mariassunta and Tracy Yue Wang, "Corporate Scandals and Household Stock Market Participation," The Journal of Finance, 2016, 71 (6), 2591-2636.

Giglio, Stefano, Matteo Maggiori, Johannes Stroebel, and Stephen P Utkus, "Five Facts About Beliefs and Portfolios," Working Paper, 2020.

Gilbert, Thomas, Shimon Kogan, Lars Lochstoer, and Ataman Ozyildirim, "Investor Inattention and the Market Impact of Summary Statistics," Management Science, 2012, 58 (2), 336-350.

Giuliano, Paola and Antonio Spilimbergo, "Growing up in a Recession," The Review of Economic Studies, 2014, 81 (2), 787-817.

Goetzmann, William N, Dasol Kim, Alok Kumar, and Qin Wang, "Weatherinduced Mood, Institutional Investors, and Stock Returns," The Review of Financial Studies, 2014, 28 (1), 73-111.

Goldfayn-Frank, Olga and Johannes Wohlfart, "Expectation Formation in a New Environment: Evidence from the German Reunification," Journal of Monetary Economics, 2019.

Greenwood, Robin and Andrei Shleifer, "Expectations of Returns and Expected Returns," The Review of Financial Studies, 2014, 27 (3), 714-746. 
Grinblatt, Mark and Matti Keloharju, "What Makes Investors Trade?," The Journal of Finance, 2001, 56 (2), 589-616.

Guiso, Luigi, Paola Sapienza, and Luigi Zingales, "The Role of Social Capital in Financial Development," The American Economic Review, 2004, 94 (3), 526-556.

_ , _, and _, "Trusting the Stock Market," The Journal of Finance, 2008, 63 (6), $2557-2600$.

_ , _, and _, "Time Varying Risk Aversion," Journal of Financial Economics, 2018, $128(3), 403-421$.

Guvenen, Fatih, Sam Schulhofer-Wohl, Jae Song, and Motohiro Yogo, "Worker Betas: Five Facts About Systematic Earnings Risk," American Economic Review Papers and Proceedings, 2017, 107 (5), 398-403.

Heaton, John and Deborah Lucas, "Portfolio Choice in the Presence of Background Risk," Economic Journal, 2000, 110 (460), 1-26.

Hertwig, Ralph and Ido Erev, "The Description-Experience Gap in Risky Choice," Trends in Cognitive Sciences, 2009, 13 (12), 517-523.

- and Timothy J Pleskac, "Decisions from Experience: Why Small Samples?," Cognition, 2010, 115 (2), 225-237.

_ , Greg Barron, Elke U Weber, and Ido Erev, "Decisions from Experience and the Effect of Rare Events in Risky Choice," Psychological Science, 2004, 15 (8), 534-539.

Hirshleifer, David, "Investor Psychology and Asset Pricing," The Journal of Finance, 2001, 56 (4), 1533-1597.

_ , Sonya Seongyeon Lim, and Siew Hong Teoh, "Driven to Distraction: Extraneous Events and Underreaction to Earnings News," The Journal of Finance, 2009, 64 (5), $2289-2325$.

Ivković, Zoran and Scott Weisbenner, "Local Does as Local Is: Information Content of the Geography of Individual Investors' Common Stock Investments," The Journal of Finance, 2005, 60 (1), 267-306.

_ , Clemens Sialm, and Scott Weisbenner, "Portfolio Concentration and the Performance of Individual Investors," Journal of Financial and Quantitative Analysis, 2008, $43(3), 613-655$.

Jacobs, Heiko and Martin Weber, "The Trading Volume Impact of Local Bias: Evidence from a Natural Experiment," Review of Finance, 2011, 16 (4), 867-901.

Kaufmann, Christine, Martin Weber, and Emily Haisley, "The Role of Experience Sampling and Graphical Displays on One's Investment Risk Appetite," Management Science, 2013, 59 (2), 20-33.

Kaustia, Markku and Elias Rantapuska, "Does Mood Affect Trading Behavior?," Journal of Financial Markets, 2016, 29, 1-26. 
_ and Samuli Knüpfer, "Do Investors Overweight Personal Experience? Evidence from IPO Subscriptions," The Journal of Finance, 2008, 63 (6), 2679-2702.

_ and _ , "Peer Performance and Stock Market Entry," Journal of Financial Economics, 2012, 104 (2), 321-338.

Knüpfer, Samuli, Elias Rantapuska, and Matti Sarvimäki, "Formative Experiences and Portfolio Choice: Evidence from the Finnish Great Depression," The Journal of Finance, 2017, 72 (1), 133-166.

Korniotis, George $\mathbf{M}$ and Alok Kumar, "State-level Business Cycles and Local Return Predictability," The Journal of Finance, 2013, 68 (3), 1037-1096.

Kuchler, Theresa and Basit Zafar, "Personal Experiences and Expectations about Aggregate Outcomes," Journal of Finance, 2019, 74 (5), 2491-2542.

Lakonishok, Josef and Edwin Maberly, "The Weekend Effect: Trading Patterns of Individual and Institutional Investors," The Journal of Finance, 1990, 45 (1), 231-243.

Lejarraga, Tomás, "When Experience is Better than Description: Time Delays and Complexity," Journal of Behavioral Decision Making, 2010, 23 (1), 100-116.

Lucey, Brian M and Michael Dowling, "The Role of Feelings in Investor DecisionMaking," Journal of Economic Surveys, 2005, 19 (2), 211-237.

Malmendier, Ulrike and Leslie S Shen, "Scarred Consumption," Working Paper, 2019.

- and Stefan Nagel, "Depression Babies: Do Macroeconomic Experiences Affect RiskTaking?," The Quarterly Journal of Economics, 2011, 126 (1), 373-416.

_ and _ , "Learning from Inflation Experiences," The Quarterly Journal of Economics, 2016, $131(1), 53-87$.

Meeuwis, Maarten, Jonathan A Parker, Antoinette Schoar, and Duncan I Simester, "Belief Disagreement and Portfolio Choice," Working Paper, 2019.

Mian, Atif and Amir Sufi, "What Explains the 2007-2009 Drop in Employment?," Econometrica, 2014, 82 (6), 2197-2223.

Rietz, Thomas A, "The Equity Risk Premium a Solution," Journal of Monetary Economics, 1988, 22 (1), 117-131.

Roth, Christopher and Johannes Wohlfart, "Experienced Inequality and Preferences for Redistribution," Journal of Public Economics, 2018, 167, 251-262.

_ and _, "How Do Expectations About the Macroeconomy Affect Personal Expectations and Behavior?," Review of Economics and Statistics, 2019.

Ruenzi, Stefan, Alok Kumar, and Michael Ungeheuer, "Daily Winners and Losers," Working Paper, 2019. 
Shefrin, Hersh and Meir Statman, "The Disposition to Sell Winners Too Early and Ride Losers Too Long: Theory and Evidence," The Journal of finance, 1985, 40 (3), $777-790$.

Sicherman, Nachum, George Loewenstein, Duane J Seppi, and Stephen P Utkus, "Financial Attention," The Review of Financial Studies, 2015, 29 (4), 863-897.

Statman, Meir, Steven Thorley, and Keith Vorkink, "Investor Overconfidence and Trading Volume," The Review of Financial Studies, 2006, 19 (4), 1531-1565.

Takhtamanova, Yelena F and Eva Sierminska, "Impact of the Great Recession on Industry Unemployment: A 1976-2011 Comparison," Working Paper, 2016.

Weber, Elke U, "Understanding Public Risk Perception and Responses to Changes in Perceived Risk," in "Policy Shock: Recalibrating Risk and Regulation after Oil Spills, Nuclear Accidents and Financial Crises," Cambridge University Press, 2017, pp. 82106.

\section{Main figures}


Panel A: Turnover

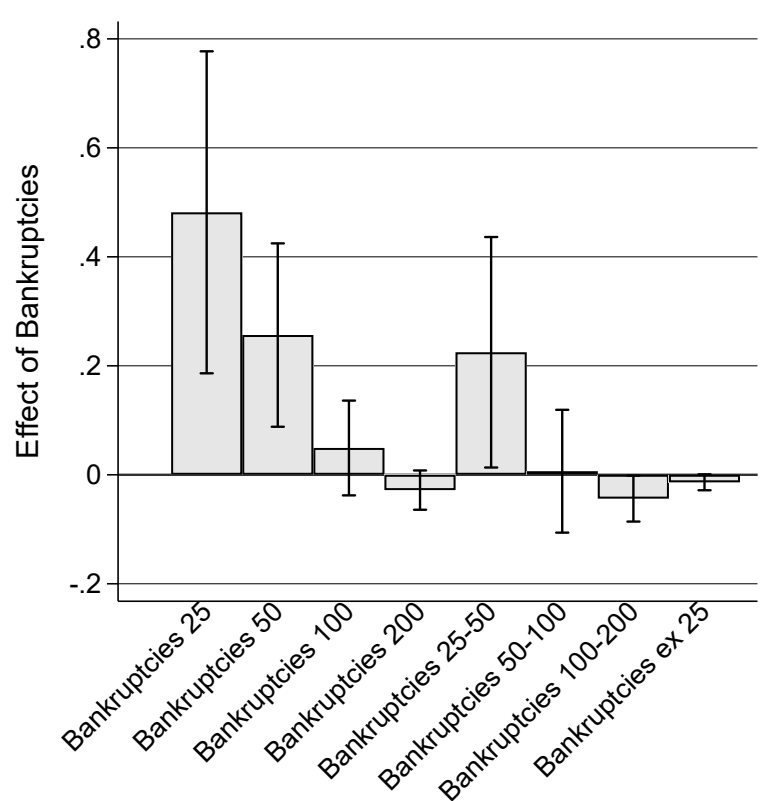

Panel B: Buy-Sell Imbalance

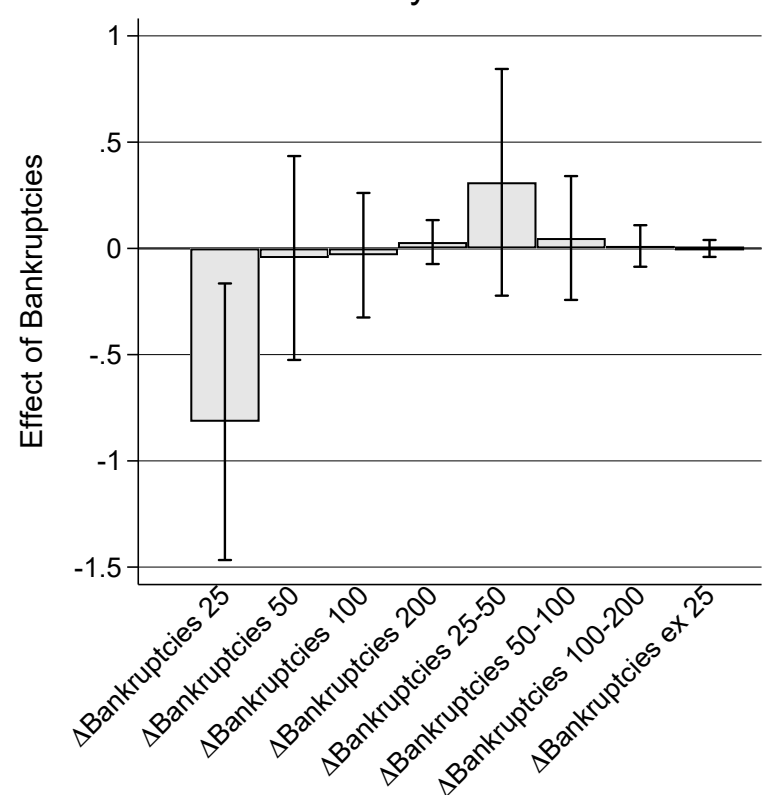

Panel C: Active Risky

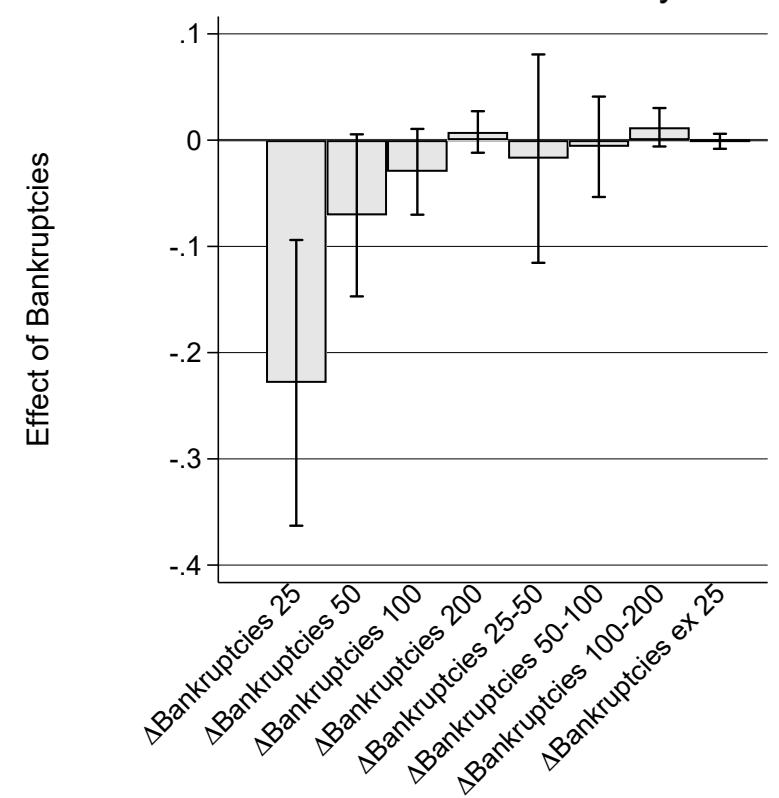

Notes: This figure examines the role of spatial proximity of local bankruptcies for their effects on trading and risk-taking. The bars display OLS coefficient estimates of the effect of (changes in) bankruptcies obtained in individual estimations for each bankruptcies measure. We use the fixed effects model in equation 1 for turnover (Panel A) and of the first difference model in equation 2 for the buy-sell imbalance and active changes in the risky share (Panels B and C). The dependent variables capture portfolio turnover and changes in risk-taking as defined in section 2. The bankruptcies variable used differs across regressions: Bankruptcies $\mathrm{X}$ is the number of monthly bankruptcies within an X-km radius around an investor's home zip code, scaled by the previous year end's number of firms in the county of residence. Bankruptcies Y-X is the number of monthly bankruptcies at least X kilometers and at most Y kilometers away from an investor's home zip code, scaled by the previous year end's number of firms in the county of residence. Bankruptcies ex 25 captures all bankruptcies except the ones occurring within a 25 -km radius around the home zip code. The independent variable and the dependent variables are expressed as percentages. All specifications include fixed effects for each month of the sample period and control for the recent monthly return on the investor's portfolio and the log of the total wealth of the investor, both measured at the end of the previous month, for the log of GDP per capita in the county of residence over the previous calendar year, and current and last month's values of both the county-level unemployment rate and the value-weighted average monthly return on the stocks of local publicly listed firms. Controls are coded as monthly changes in the first difference specifications in Panels B and C. All variables are defined in more detail in appendix Table A3. The sample period is January 2007 to November 2012. The sample is restricted to active investors (more than one yearly trade on average during their time in the sample), with complete information on all relevant variables, and with valid information on zip code of residence. Error bands show 90-percent confidence bands constructed from standard errors that are two-way clustered by investor and time period. 
Figure 2: Brokerage data: Temporal proximity

Panel A: Turnover

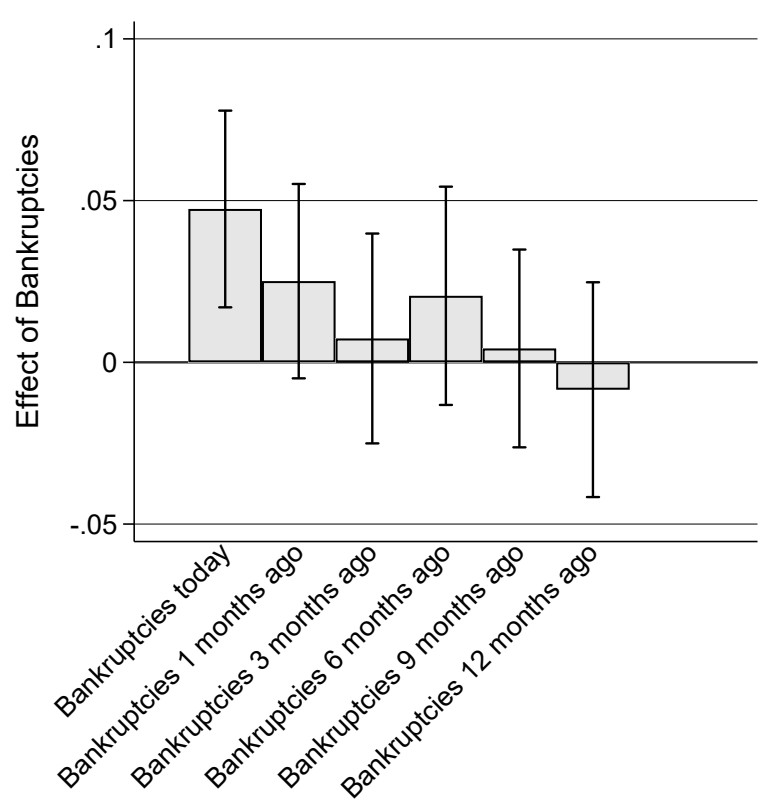

Panel B: Buy-Sell Imbalance

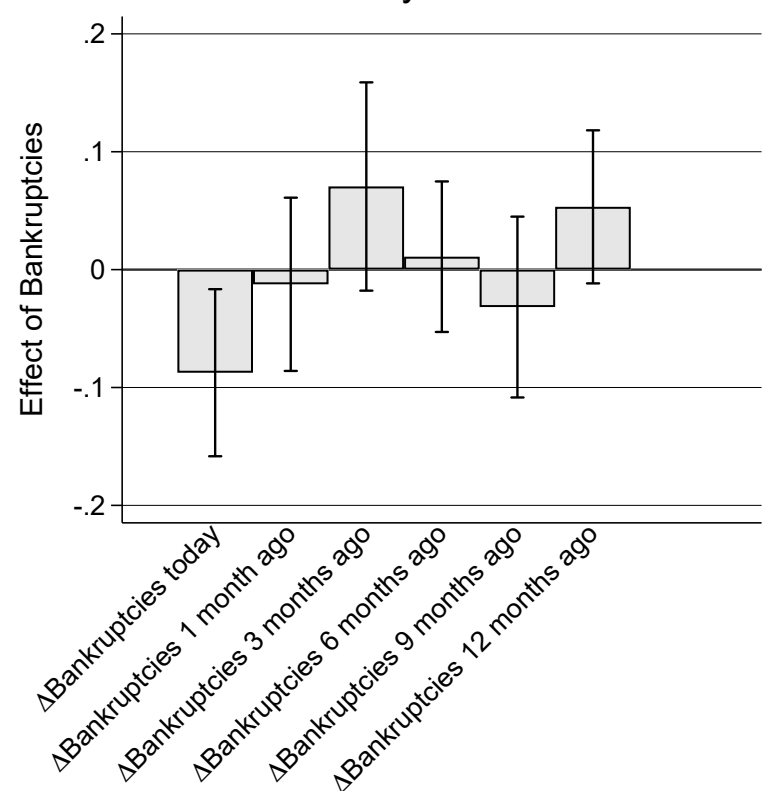

Panel C: Active Risky Share

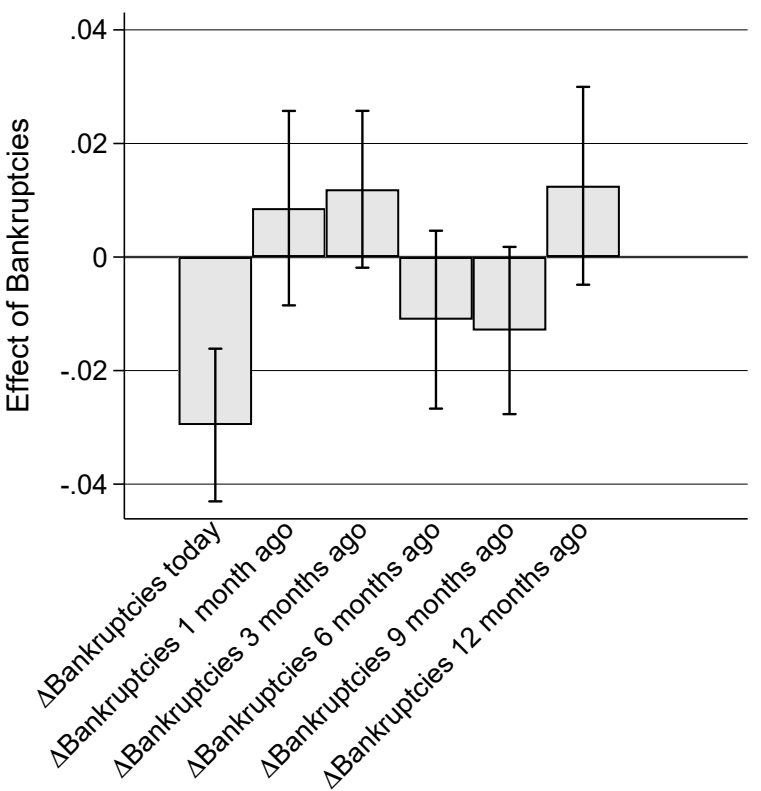

Notes: This figure examines the role of temporal proximity of local bankruptcies for their effects on trading and risk-taking. The bars display OLS coefficient estimates of the effect of (changes in) bankruptcies obtained in individual estimations for each bankruptcies measure. We use the fixed effects model in equation 1 for turnover (Panel A) and of the first difference model in equation 2 for the buy-sell imbalance and active changes in the risky share (Panels B and C). The dependent variables capture portfolio turnover and changes in risk-taking as defined in section 2 . The bankruptcies variable used differs across regressions: Bankruptcies today is the standard bankruptcies measure used in the baseline regressions. Bankruptcies X months ago is the number of bankruptcies within a 25-km radius around an investor's home zip code, scaled by the previous year end's number of firms in the county of residence, that occurred X months ago. The independent variable and the dependent variables are expressed as percentages. All specifications include fixed effects for each month of the sample period and control for the recent monthly return on the investor's portfolio and the log of the total wealth of the investor, both measured at the end of the previous month, for the log of GDP per capita in the county of residence over the previous calendar year, and current and last month's values of both the county-level unemployment rate and the value-weighted average monthly return on the stocks of local publicly listed firms. Controls are coded as monthly changes in the first difference specifications in Panels B and C. All variables are defined in more detail in appendix Table A3. The sample period is January 2007 to November 2012. The sample is restricted to active investors (more than one yearly trade on average during their time in the sample), with complete information on all relevant variables, and with valid information on zip code of residence. Error bands show 90-percent confidence bands constructed from standard errors that are two-way clustered by investor and time period. 
Figure 3: Brokerage data: Wealth effects and background risk

Panel A: Turnover

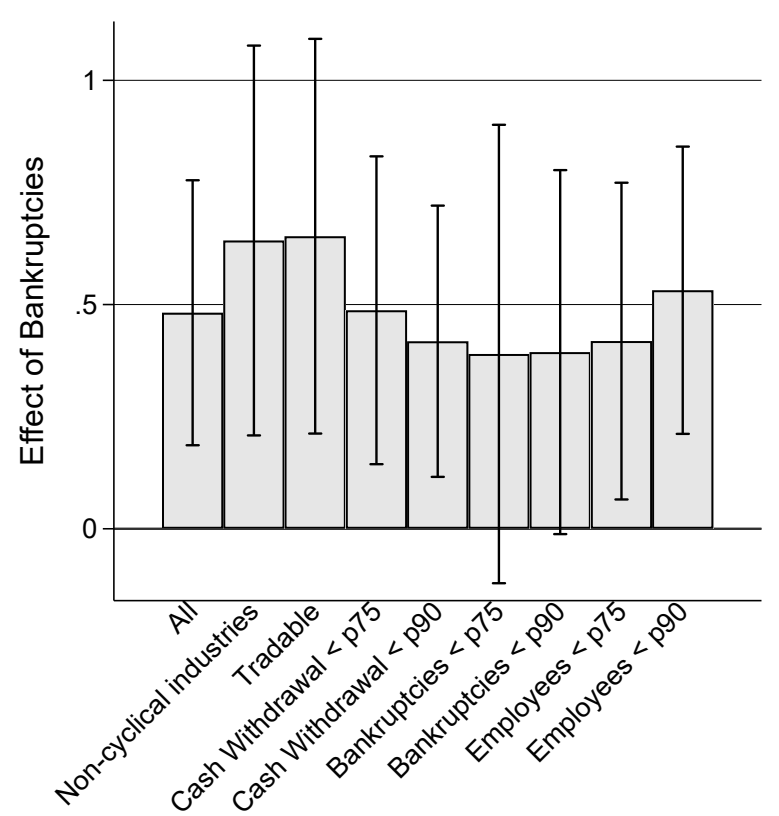

Panel B: Buy-Sell Imbalance

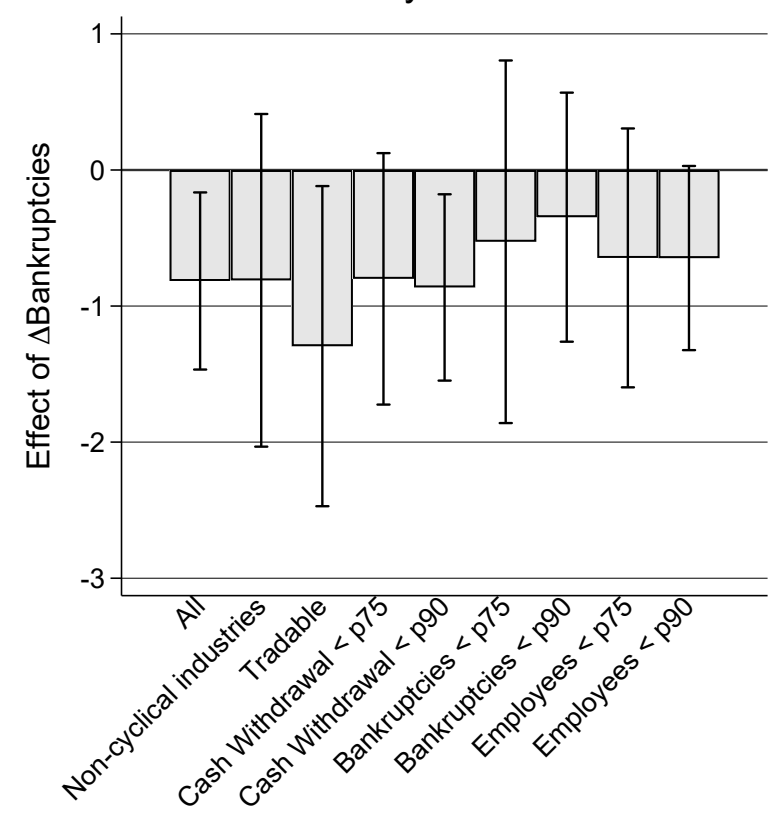

Panel C: Active Risky Share

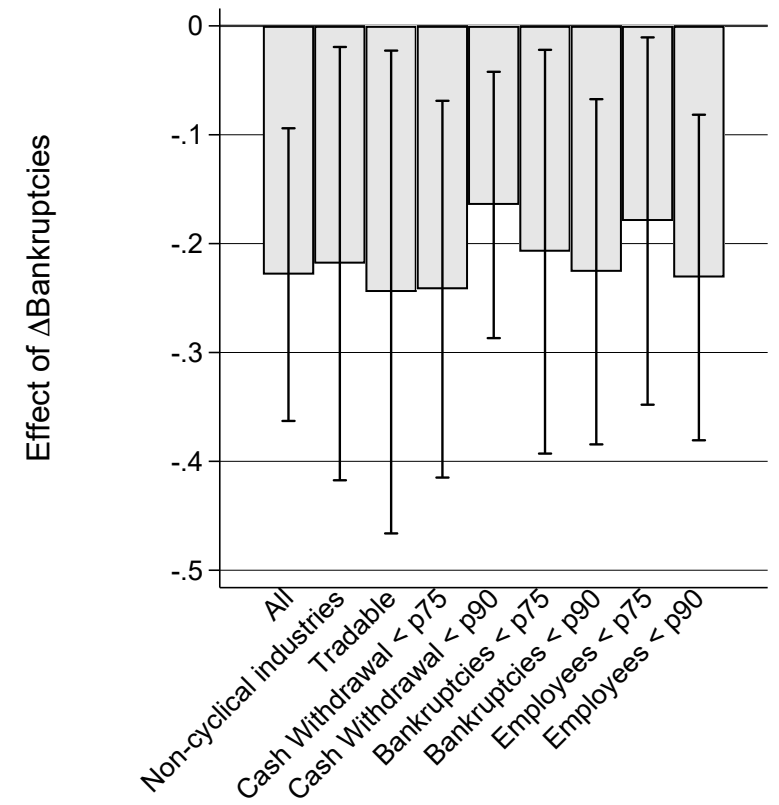

Notes: This figure displays several checks against the possibility that our findings reflect unobserved wealth effects or changes in background risk. Specifically, we re-estimate our main specifications excluding investors working in cyclical industries or those working in the non-tradable sector (both defined in appendix C.5), dropping the top 25 percent or the top 10 percent of each investor's distribution of monthly cash withdrawals, dropping the top 25 percent or the top 10 percent of each zip code's distribution of the bankruptcies measure over time, or dropping the top 25 percent or the top 10 percent of each zip code's distribution of monthly number of employees losing their jobs due to bankruptcies over time. The bars display OLS coefficient estimates of the effect of (changes in) bankruptcies obtained in individual estimations for each subgroup of the fixed effects model in equation 1 for turnover (Panel A) and of the first difference model in equation 2 for active changes in the risky share and the buy-sell imbalance (Panels B and C). The dependent variables capture portfolio turnover and changes in risk-taking as defined in section 2. The main independent variable, Bankruptcies $25_{t}$, is the number of monthly bankruptcies within a 25-km radius around an investor's home zip code, scaled by the previous year end's number of firms in the county of residence. The independent variable and the dependent variables are expressed as percentages. All specifications include fixed effects for each month of the sample period and control for the recent monthly return on the investor's portfolio and the log of the total wealth of the investor, both measured at the end of the previous month, for the log of GDP per capita in the county of residence over the previous calendar year, and current and last month's values of both the county-level unemployment rate and the value-weighted average monthly return on the stocks of local publicly listed firms. Controls are coded as monthly changes in the first difference specifications in Panels B and C. All variables are defined in more detail in appendix Table A3. The sample period is January 2007 to November 2012. The sample is restricted to active investors (more than one yearly trade on average during their time in the sample), with complete information on all relevant variables, and with valid information on zip code of residence. Error bands show 90-percent confidence bands constructed from standard errors that are two-way clustered by investor and time period. 
Figure 4: Brokerage data: Bankruptcies of smaller and larger firms

Panel A: Turnover

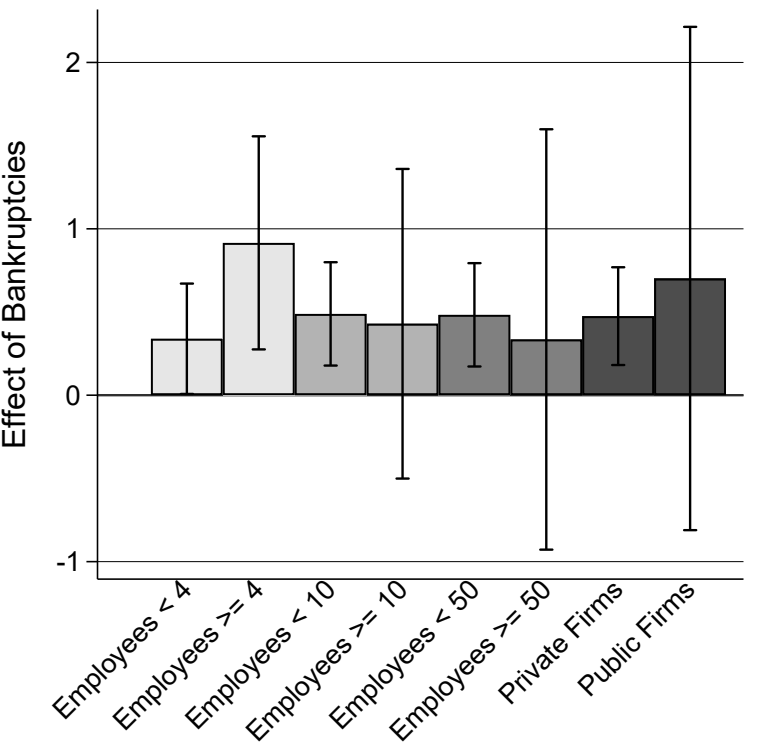

Firm Size
Panel B: Buy-Sell Imbalance

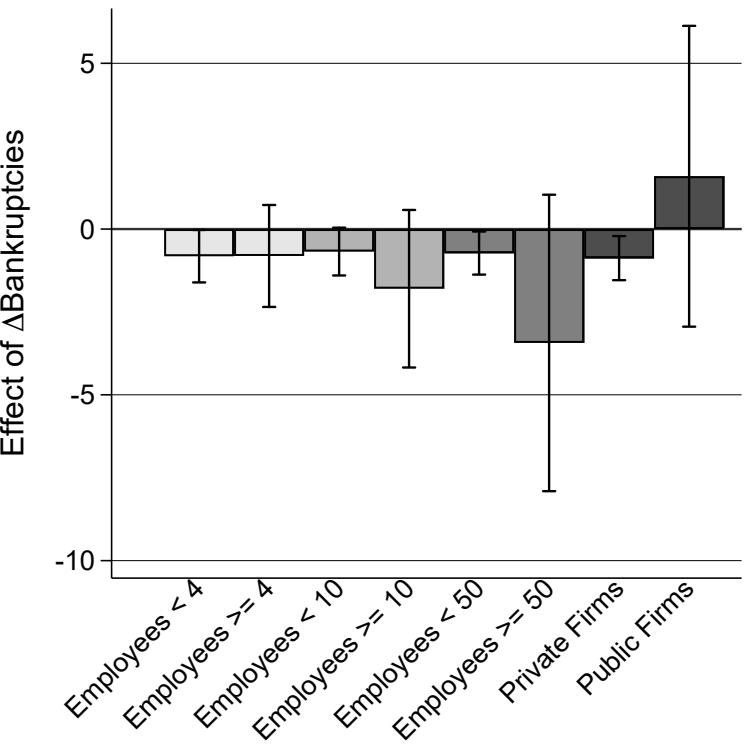

Firm Size
Panel C: Active Risky Share

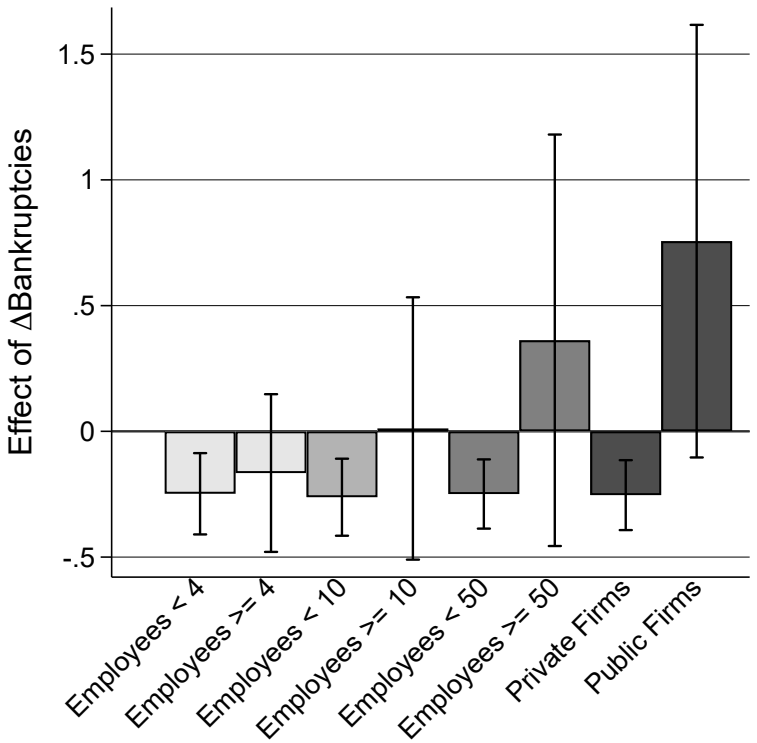

Firm Size

Notes: This figure displays coefficient estimates from regressions that each includes two bankruptcies measures. Specifically, each regression splits the bankruptcy measures into two groups of firms of different size, mostly using different thresholds for the number of employees as cutoff (less than four vs at least four, less than ten vs at least ten, less than 50 vs at least 50, private firms vs publicly listed firms). Within each panel, coefficient estimates obtained from the same regression are displayed in the same color. The bars display OLS coefficient estimates of the effect of (changes in) bankruptcies obtained in individual estimations for each subgroup of the fixed effects model in equation 1 for turnover (Panel A) and of the first difference model in equation 2 for active changes in the risky share and the buy-sell imbalance (Panels B and C). The dependent variables capture portfolio turnover and changes in risk-taking as defined in section 2. The independent variables are the number of monthly bankruptcies within a 25-km radius around an investor's home zip code of firms with the indicated number of employees, scaled by the previous year end's overall number of firms in the county of residence. The independent variable and the dependent variables are expressed as percentages. All specifications include fixed effects for each month of the sample period and control for the recent monthly return on the investor's portfolio and the log of the total wealth of the investor, both measured at the end of the previous month, for the log of GDP per capita in the county of residence over the previous calendar year, and current and last month's values of both the county-level unemployment rate and the value-weighted average monthly return on the stocks of local publicly listed firms. Controls are coded as monthly changes in the first difference specifications in Panels B and C. All variables are defined in more detail in appendix Table A3. The sample period is January 2007 to November 2012. The sample is restricted to active investors (more than one yearly trade on average during their time in the sample), with complete information on all relevant variables, and with valid information on zip code of residence. Error bands show 90-percent confidence bands constructed from standard errors that are two-way clustered by investor and time period. 
Figure 5: Brokerage data: Local salience of bankruptcies

Panel A: Local mean monthly layoffs

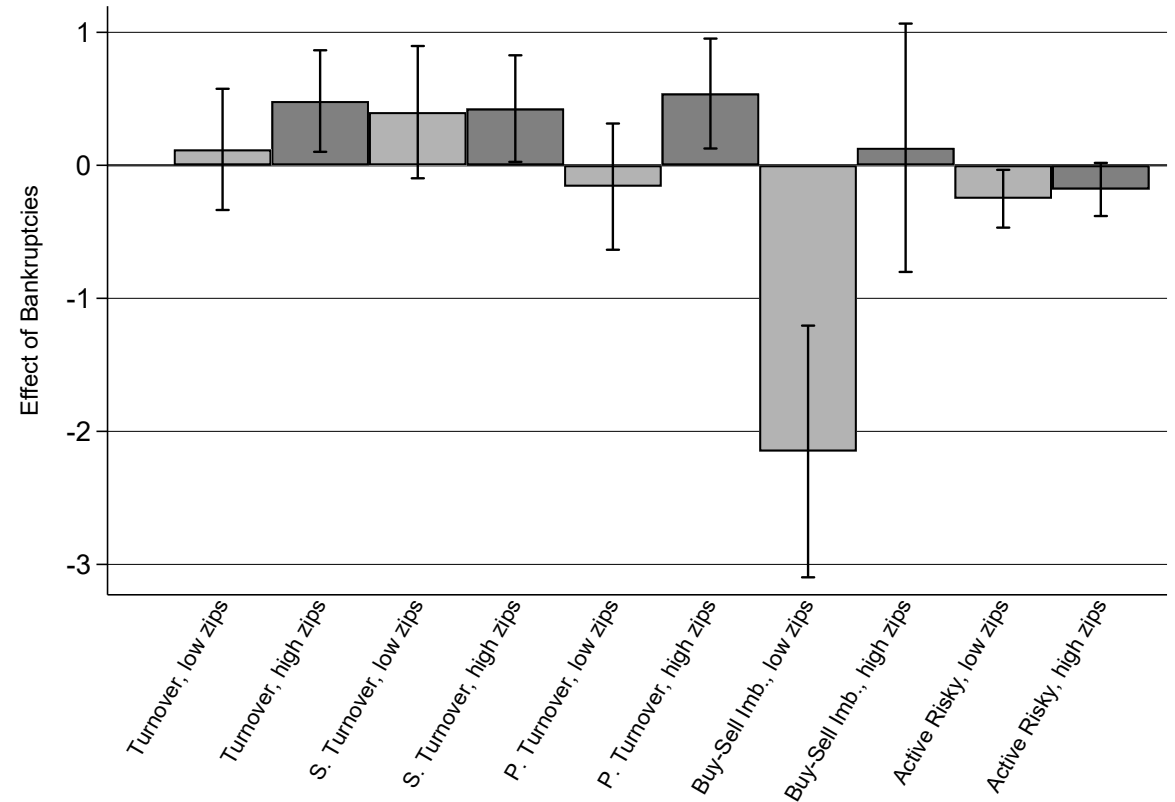

Panel B: Local mean monthly bankruptcies

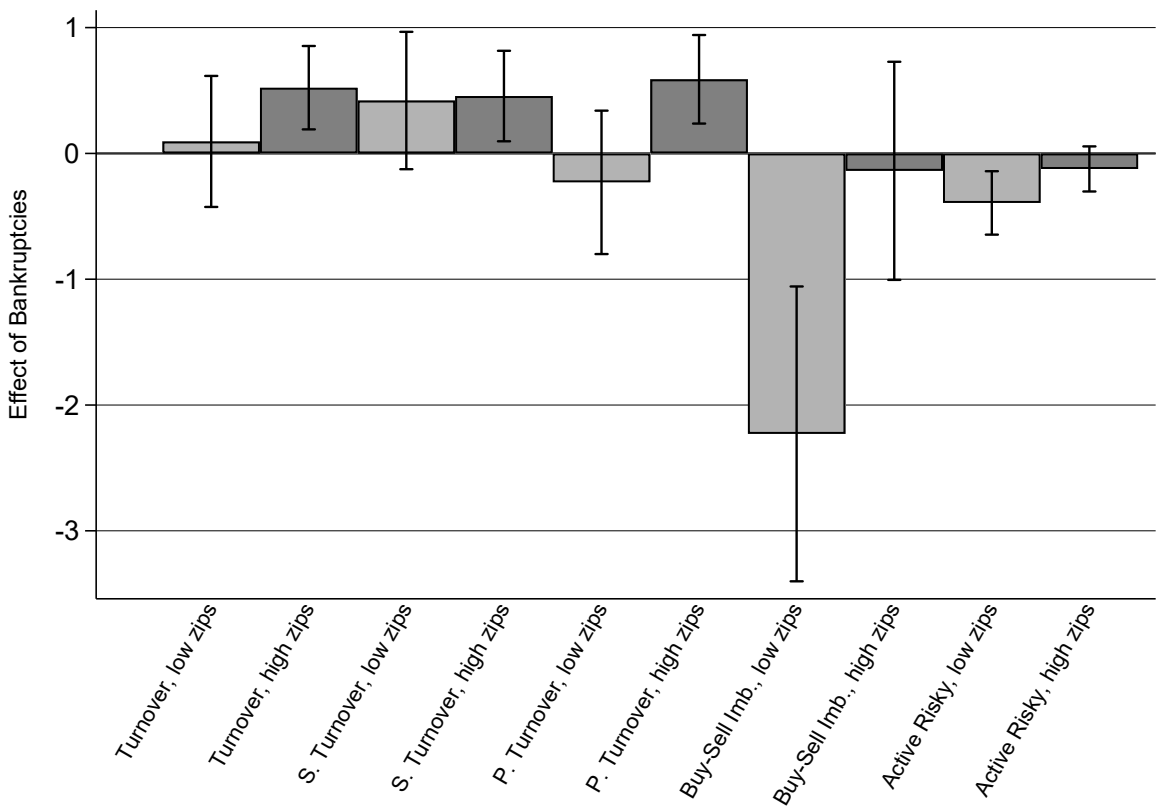

Notes: This figure examines the effect of local bankruptcies on trading and risk-taking separately for investors for whom bankruptcies should be more salient and for those for whom bankruptcies should be less salient. Specifically, Panel A splits the sample into zip codes with an above-mean and zip codes with a below-mean average monthly number of employees losing their job due to bankruptcies (scaled by population size) over the sample period, while Panel B splits the sample into zip codes with an above-mean and zip codes with a below-mean average number of local bankruptcies (scaled by the number of local firms) over the sample period. Within each panel, coefficient estimates obtained from regressions on the same sample are displayed in the same color. The bars display OLS coefficient estimates of the effect of (changes in) bankruptcies obtained in individual estimations for each subgroup of the fixed effects model in equation 1 for turnover and of the first difference model in equation 2 for active changes in the risky share and the buy-sell imbalance. The dependent variables capture portfolio turnover and changes in risk-taking as defined in section 2. The independent variables are the number of monthly bankruptcies within a 25-km radius around an investor's home zip code of firms with the indicated number of employees, scaled by the previous year end's overall number of firms in the county of residence. The independent variable and the dependent variables are expressed as percentages. All specifications include fixed effects for each month of the sample period and control for the recent monthly return on the investor's portfolio and the log of the total wealth of the investor, both measured at the end of the previous month, for the log of GDP per capita in the county of residence over the previous calendar year, and current and last month's values of both the county-level unemployment rate and the value-weighted average monthly return on the stocks of local publicly listed firms. Controls are coded as monthly changes in the first difference specifications for the buy-sell imbalance and the active change in the risky share. All variables are defined in more detail in appendix Table A3. The sample period is January 2007 to November 2012. The sample is restricted to active investors (more than one yearly trade on average during their time in the sample), with complete information on all relevant variables, and with valid information on zip code of residence. Error bands show 90-percent confidence bands constructed from standard errors that are two-way clustered by investor and time period. 


\section{Main tables}

Table 1: Brokerage data: Summary statistics

\begin{tabular}{lcccccc}
\hline & $(1)$ & $(2)$ & $(3)$ & $(4)$ & $(5)$ & $(6)$ \\
& Mean & Median & SD & Min & Max & N \\
\hline Panel A: Investor Sample & & & & & & \\
Female & 0.17 & 0.00 & 0.38 & 0.00 & 1.00 & 47782 \\
Age & 49.60 & 48.00 & 12.60 & 1.00 & 102.00 & 47782 \\
Relationship with Bank (yrs) & 2.01 & 0.33 & 2.89 & 0.08 & 16.17 & 38739 \\
Married & 0.58 & 1.00 & 0.49 & 0.00 & 1.00 & 47782 \\
Risk Tolerance & 3.40 & 4.00 & 1.64 & 0.00 & 5.00 & 47782 \\
Yearly Income & 60177.75 & 50000.00 & 31488.36 & 10000.00 & 375000.00 & 25485 \\
Average Portfolio Value & 61424.20 & 33231.00 & 208133.22 & 0.00 & $3.61 \mathrm{e}+07$ & 47782 \\
Average Cash Holdings & 22120.19 & 10538.59 & 35513.80 & -39377.04 & 312219.09 & 47782 \\
Average Financial Wealth & 76021.29 & 46696.26 & 93434.21 & 0.00 & 735162.31 & 47782 \\
Trades per Month & & 0.89 & 8.77 & 0.08 & 1230.28 & 2.19 \\
\hline
\end{tabular}

Notes: This table displays summary statistics on characteristics of the investors in the brokerage data. Gender, age, length of relationship with the bank, marital status, risk tolerance and yearly income are measured in November 2012. Risk tolerance is measured on a categorical scale reaching from 1 (unwilling to take risks) to 5 (very willing to take risks). Average portfolio value, cash holdings and trades per month are calculated over the period an investor is in the sample. Detailed variable definitions are provided in Table A3. In line with the main analysis, the investor sample is restricted to active investors (more than one yearly trade on average during the time in the sample), with complete information on all relevant variables, and with valid information on zip code of residence. The statistics are displayed for the sample period January 2007 to November 2012. 
Table 1 (continued): Brokerage data: Summary statistics

\begin{tabular}{lcccccc}
\hline & $(1)$ & $(2)$ & $(3)$ & $(4)$ & $(5)$ & $(6)$ \\
& Mean & Median & SD & Min & Max & N \\
\hline Panel B: Trading Variables & & & & & & \\
Portfolio Turnover & 6.42 & 0.00 & 17.86 & 0.00 & 100.00 & 2822177 \\
Sales Turnover & 6.09 & 0.00 & 18.77 & 0.00 & 100.00 & 2822177 \\
Purchase Turnover & 6.75 & 0.00 & 18.97 & 0.00 & 100.00 & 2822177 \\
Buy-Sell-Imbalance & 20.17 & 0.00 & 56.79 & -100.00 & 100.00 & 2742639 \\
Active Risky Share & -0.08 & 0.00 & 9.96 & -69.81 & 62.92 & 2742639 \\
Turnover Europe Equity & 4.39 & 0.00 & 14.21 & 0.00 & 100.00 & 2822311 \\
BSI Europe Equity & 14.40 & 0.00 & 49.21 & -100.00 & 100.00 & 2742639 \\
Turnover German Equity & 4.21 & 0.00 & 14.37 & 0.00 & 100.00 & 2822311 \\
BSI German Equity & 9.47 & 0.00 & 43.13 & -100.00 & 100.00 & 2742639 \\
Turnover Europe ex Germany & 0.94 & 0.00 & 6.36 & 0.00 & 100.00 & 2822311 \\
BSI Europe ex Germany & 9.54 & 0.00 & 37.58 & -100.00 & 100.00 & 2742639 \\
Turnover Non Europe & 2.76 & 0.00 & 10.88 & 0.00 & 100.00 & 2822311 \\
BSI Non Europe & 8.87 & 0.00 & 41.45 & -100.00 & 100.00 & 2742639 \\
Beta DAX & 0.74 & 0.74 & 0.41 & -23.56 & 17.53 & 2810278 \\
Beta CDAX & 0.76 & 0.76 & 0.42 & -23.19 & 17.64 & 2810278 \\
Beta MSCI Europe excl. CDAX & 0.57 & 0.56 & 0.64 & -36.85 & 40.22 & 2810278 \\
Beta MSCI World excl. CDAX & 0.47 & 0.45 & 0.46 & -29.25 & 29.58 & 2810278 \\
Beta GDP growth & 0.04 & 0.05 & 0.32 & -32.51 & 117.78 & 2813309 \\
\hline
\end{tabular}

Notes: This table displays summary statistics for the main dependent variables on trading and risktaking. Portfolio Turnover is the average of Sales Turnover and Purchase Turnover, which are defined as the nominal value of shares sold, divided by portfolio value at the beginning of the period, and as the nominal value of shares bought, divided by the portfolio value at the end of the period, which are both multiplied by 100. The Buy-Sell Imbalance captures the difference between the value of purchases and the value of sales, divided by the sum of the two, and is multiplied by 100 . The Active Risky Share captures the percentage point change in the risky portfolio share resulting from active trading decisions and not from price changes. Turnover and the Buy-Sell Imbalance are also shown separately for European equity, German equity, European excluding German equity, and non-European equity. The beta variables capture portfolio betas relative to different stock markets (DAX, CDAX, MSCI Europe conditional on the CDAX, MSCI World conditional on the CDAX) and relative to quarterly real German GDP per capita growth (seasonally adjusted). Detailed variable definitions are provided in section 2 and in Table A3. In line with the main analysis, the investor sample is restricted to active investors (more than one yearly trade on average during the time in the sample), with complete information on all relevant variables, and with valid information on zip code of residence. The statistics are displayed for the sample period January 2007 to November 2012. 
Table 1 (continued): Brokerage data: Summary statistics

\begin{tabular}{lcccccc}
\hline & $(1)$ & $(2)$ & $(3)$ & $(4)$ & $(5)$ & $(6)$ \\
& Mean & Median & SD & Min & Max & N \\
\hline Panel C: Bankruptcy Filings & & & & & & \\
Firm Level & .01 & 0 & .12 & 0 & 1 & 182379 \\
$\begin{array}{l}\text { Dummy Public Firm } \\
\text { Number of Employees (Bankrupt Firm) }\end{array}$ & 10.87 & 3 & 102.07 & 1 & 17440 & 105920 \\
Zip Code Level & & & & & & \\
Monthly Number of Bankruptcies & 28.33 & 14 & 36.45 & 1 & 238 & 433067 \\
Number of Firms & 22018.25 & 9872 & 39844.02 & 1649 & 219580 & 433067 \\
\hline
\end{tabular}

Notes: This table displays summary statistics for local bankruptcies in firm- and zip-code level datasets. It displays the share of bankruptcies of public firms, as well as the average number of employees of bankrupt firms. Monthly Number of Bankruptcies captures the number of monthly firm closures within a 25-km radius around an investor's home zip code, and Number of Firms captures the number of registered firms in the county the zip code belongs to in the previous calendar year. The variables are defined in detail in section 2 and appendix Table A3. The statistics are displayed for the sample period January 2007 to November 2012.

\begin{tabular}{lcccccc}
\hline & $(1)$ & $(2)$ & $(3)$ & $(4)$ & $(5)$ & $(6)$ \\
& Mean & Median & SD & Min & Max & N \\
\hline Panel D: Independent Variables & & & & & & \\
Bankruptcies 25 & 0.20 & 0.14 & 0.19 & 0.00 & 1.14 & 2822311 \\
Personal Return & -0.01 & 0.34 & 7.64 & -49.91 & 43.43 & 2822273 \\
Ln Wealth & 10.64 & 10.78 & 1.32 & 1.84 & 13.44 & 2822311 \\
Local Return & 0.14 & 0.00 & 8.30 & -31.20 & 38.46 & 2822311 \\
Ln Local GDP per Capita) & 10.43 & 10.34 & 0.41 & 9.45 & 11.75 & 2822311 \\
Local Unemployment & 6.69 & 5.95 & 3.21 & 1.00 & 23.59 & 2822311 \\
\hline
\end{tabular}

Notes: The table displays summary statistics for the main independent variables used in the main analysis from the final dataset that merges brokerage, bankruptcies and geographical data. Bankruptcies 25 is the monthly number of bankruptcies within the $25 \mathrm{~km}$-neighborhood of the investor's zip code of residence divided by the previous calendar year's number of firms in the county ("Landkreis") in percent. Personal Return is the return on the investor's portfolio, expressed in percent, over the previous month. Ln Wealth is the natural logarithm of the euro value of the investor's total wealth held with the brokerage, multiplied by 100, as measured at the end of the previous month. Local Return 25 is the monthly valueweighted average return on the stocks of all publicly listed firms within $25 \mathrm{~km}$ around the investor's zip code in percent. Ln Local GDP per Capita is the natural logarithm of the previous calendar year's county-level GDP per capita, multiplied by 100. Local Unemployment is the end-of-month county-level unemployment rate in percent. The variables are defined in detail in section 2 , online appendix $\mathrm{C}$ and appendix Table A3. In line with the main analysis, the investor sample is restricted to active investors (more than one yearly trade on average during the time in the sample), with complete information on all relevant variables, and with valid information on zip code of residence. The statistics are displayed for the sample period January 2007 to November 2012. 
Table 2: Brokerage data: Risk-taking around bankruptcies

\begin{tabular}{|c|c|c|c|c|c|}
\hline & $\frac{\text { Turnover }}{(1)}$ & $\begin{array}{c}\begin{array}{c}\text { Sales } \\
\text { Turnover }\end{array} \\
(2)\end{array}$ & $\begin{array}{c}\text { Purchase } \\
\text { Turnover } \\
(3)\end{array}$ & $\begin{array}{c}\begin{array}{c}\text { Buy-Sell } \\
\text { Imbalance }\end{array} \\
(4)\end{array}$ & $\begin{array}{c}\text { Active } \\
\text { Risky Share } \\
(5)\end{array}$ \\
\hline Bankruptcies $25_{t}$ & $\begin{array}{c}0.482^{* * *} \\
(0.180)\end{array}$ & $\begin{array}{c}0.557^{* * *} \\
(0.191)\end{array}$ & $\begin{array}{l}0.407^{* *} \\
(0.191)\end{array}$ & & \\
\hline Personal Return $_{t-1}$ & $\begin{array}{c}0.066^{* * *} \\
(0.008)\end{array}$ & $\begin{array}{c}0.086^{* * *} \\
(0.009)\end{array}$ & $\begin{array}{c}0.045^{* * *} \\
(0.008)\end{array}$ & & \\
\hline Ln Wealth W-1 $_{t}$ & $\begin{array}{c}1.597^{* * *} \\
(0.104)\end{array}$ & $\begin{array}{c}2.124^{* * *} \\
(0.111)\end{array}$ & $\begin{array}{c}1.070^{* * *} \\
(0.101)\end{array}$ & & \\
\hline$\Delta$ Bankruptcies $25_{t}$ & & & & $\begin{array}{c}-0.816^{* *} \\
(0.396)\end{array}$ & $\begin{array}{c}-0.228^{* * *} \\
(0.082)\end{array}$ \\
\hline$\Delta$ Personal Return ${ }_{t-1}$ & & & & $\begin{array}{c}-0.065^{* * *} \\
(0.022)\end{array}$ & $\begin{array}{c}-0.016^{* * *} \\
(0.003)\end{array}$ \\
\hline$\Delta$ Ln Wealth W-1 $_{t}$ & & & & $\begin{array}{c}4.883^{* * *} \\
(0.883)\end{array}$ & $\begin{array}{c}1.658^{* * *} \\
(0.433)\end{array}$ \\
\hline Controls & Yes & Yes & Yes & Yes & Yes \\
\hline Investor FE & Yes & Yes & Yes & No & No \\
\hline Time FE & Yes & Yes & Yes & Yes & Yes \\
\hline $\begin{array}{l}\text { Adj. R-squared } \\
\text { Observations }\end{array}$ & $\begin{array}{c}.388 \\
2822177\end{array}$ & $\begin{array}{c}.34 \\
2822177\end{array}$ & $\begin{array}{c}.36 \\
2822177\end{array}$ & $\begin{array}{c}.008 \\
2783109\end{array}$ & $\begin{array}{c}.025 \\
2783109\end{array}$ \\
\hline
\end{tabular}

Notes: This table examines the effect of local bankruptcies on trading and risk-taking. It displays OLS estimates of the fixed effects model in equation 1 (columns 1-3) and the first difference model in equation 2 (columns 4-5). The dependent variables capture portfolio turnover and changes in risk-taking as defined in section 2. The main independent variable, Bankruptcies $25_{t}$, is the number of monthly bankruptcies within a $25-\mathrm{km}$ radius around an investor's home zip code, scaled by the previous year end's number of firms in the county of residence. The independent variable and the dependent variables are expressed as percentages. All specifications include fixed effects for each month of the sample period and control for the recent monthly return on the investor's portfolio and the log of the total wealth of the investor, both measured at the end of the previous month, for the log of GDP per capita in the county of residence over the previous calendar year, and current and last month's values of both the county-level unemployment rate and the value-weighted average monthly return on the stocks of local publicly listed firms. Controls are coded as monthly changes in the first difference specifications in columns 4-5. All variables are defined in more detail in appendix Table A3. The sample period is January 2007 to November 2012. The sample is restricted to active investors (more than one yearly trade on average during their time in the sample), with complete information on all relevant variables, and with valid information on zip code of residence. Standard errors that are two-way clustered by investor and time period are in parentheses. ${ }^{*}$ denotes significance at 10 pct., ${ }^{* *}$ at 5 pct., and ${ }^{* * *}$ at 1 pct. level. 
Table 3: Brokerage data: Temporal proximity

\begin{tabular}{|c|c|c|c|c|c|c|c|c|c|}
\hline & \multicolumn{3}{|c|}{ Turnover } & \multicolumn{3}{|c|}{ Buy-Sell Imbalance } & \multicolumn{3}{|c|}{ Active Risky Share } \\
\hline & $(1)$ & $(2)$ & (3) & (4) & (5) & (6) & (7) & (8) & (9) \\
\hline Bankruptcies $25_{t}$ & $\begin{array}{c}0.482^{* * *} \\
(0.180)\end{array}$ & $\begin{array}{l}0.394^{* *} \\
(0.165)\end{array}$ & $\begin{array}{c}0.354^{* *} \\
(0.164)\end{array}$ & & & & & & \\
\hline Bankruptcies $25_{t-1}$ & & $\begin{array}{c}0.162 \\
(0.167)\end{array}$ & $\begin{array}{c}0.101 \\
(0.160)\end{array}$ & & & & & & \\
\hline Bankruptcies $25_{t-2}$ & & & $\begin{array}{c}0.289 \\
(0.191)\end{array}$ & & & & & & \\
\hline$\Delta$ Bankruptcies $25_{t}$ & & & & $\begin{array}{c}-0.816^{* *} \\
(0.396)\end{array}$ & $\begin{array}{c}-1.155^{* *} \\
(0.530)\end{array}$ & $\begin{array}{c}-0.996^{*} \\
(0.511)\end{array}$ & $\begin{array}{c}-0.228^{* * *} \\
(0.082)\end{array}$ & $\begin{array}{c}-0.242^{* * *} \\
(0.078)\end{array}$ & $\begin{array}{c}-0.270^{* * *} \\
(0.084)\end{array}$ \\
\hline$\Delta$ Bankruptcies $25_{t-1}$ & & & & & $\begin{array}{c}-0.654 \\
(0.582)\end{array}$ & $\begin{array}{c}-0.374 \\
(0.538)\end{array}$ & & $\begin{array}{c}-0.041 \\
(0.105)\end{array}$ & $\begin{array}{l}-0.099 \\
(0.115)\end{array}$ \\
\hline$\Delta$ Bankruptcies $25_{t-2}$ & & & & & & $\begin{array}{c}0.197 \\
(0.458)\end{array}$ & & & $\begin{array}{l}-0.079 \\
(0.110)\end{array}$ \\
\hline Controls & Yes & Yes & Yes & Yes & Yes & Yes & Yes & Yes & Yes \\
\hline Investor FE & Yes & Yes & Yes & No & No & No & No & No & No \\
\hline Time FE & Yes & Yes & Yes & Yes & Yes & Yes & Yes & Yes & Yes \\
\hline Adj. R-squared & .388 & .388 & .389 & .008 & .008 & .008 & .025 & .025 & .025 \\
\hline Observations & 2822177 & 2800845 & 2773255 & 2783109 & 2766476 & 2742526 & 2783109 & 2766476 & 2742526 \\
\hline
\end{tabular}

Notes: This table examines the effect of contemporaneous and lagged local bankruptcies on trading and risk-taking. It displays OLS estimates of the fixed effects model in equation 1 (columns 1-3) and the first difference model in equation 2 (columns 4-9). The dependent variables capture portfolio turnover and changes in risk-taking as defined in section 2. The main independent variable, Bankruptcies $25_{t}$, is the contemporaneous number of monthly bankruptcies within a 25 -km radius around an investor's home zip code, scaled by the previous year end's number of firms in the county of residence. Bankruptcies $25_{t-1}$ and Bankruptcies $25_{t-2}$ indicate the first and the second lag of the monthly bankruptcies measure, respectively. The independent variables and the dependent variables are expressed as percentages. All specifications include fixed effects for each month of the sample period and control for the recent monthly return on the investor's portfolio and the $\log$ of the total wealth of the investor, both measured at the end of the previous month, for the log of GDP per capita in the county of residence over the previous calendar year, and current and last month's values of both the county-level unemployment rate and the value-weighted average monthly return on the stocks of local publicly listed firms. Controls are coded as monthly changes in the first difference specifications in columns 4-9. All variables are defined in more detail in appendix Table A3. The sample period is January 2007 to November 2012. The sample is restricted to active investors (more than one yearly trade on average during their time in the sample), with complete information on all relevant variables, and with valid information on zip code of residence. Standard errors that are two-way clustered by investor and time period are in parentheses. ${ }^{*}$ denotes significance at 10 pct., ${ }^{* *}$ at 5 pct., and $* * *$ at 1 pct. level. 
Table 4: Investor survey: Trading response to bankruptcies

\begin{tabular}{|c|c|c|c|c|}
\hline & $\frac{\text { Trade }}{(1)}$ & $\frac{\text { Net buy }}{(2)}$ & $\frac{\text { Net sell }}{(3)}$ & $\frac{\text { Rebalance }}{(4)}$ \\
\hline \multicolumn{5}{|c|}{ Panel A: Last 4 weeks (realized) } \\
\hline $\begin{array}{l}\text { More bankruptcies than } \\
\text { usual last } 4 \text { weeks }\end{array}$ & $\begin{array}{c}0.174^{* * *} \\
(0.052)\end{array}$ & $\begin{array}{l}-0.024 \\
(0.044)\end{array}$ & $\begin{array}{c}0.201^{* * *} \\
(0.047)\end{array}$ & $\begin{array}{c}-0.004 \\
(0.028)\end{array}$ \\
\hline Individual controls & Yes & Yes & Yes & Yes \\
\hline Adj. R-squared & .096 & .057 & .039 & .019 \\
\hline Observations & 1422 & 1422 & 1422 & 1422 \\
\hline
\end{tabular}

\section{Panel B: Next 4 weeks (planned)}

$\begin{array}{lcccc}\text { More bankruptcies than } & 0.264^{* * *} & 0.058 & 0.164^{* * *} & 0.043 \\ \text { usual last } 4 \text { weeks } & (0.049) & (0.049) & (0.045) & (0.037) \\ & \text { Yes } & \text { Yes } & \text { Yes } & \text { Yes } \\ \text { Individual controls } & & & & \\ & .108 & .054 & .034 & .006 \\ \text { Adj. R-squared } & 1422 & 1422 & 1422 & 1422 \\ \begin{array}{l}\text { Observations } \\ \text { The }\end{array}\end{array}$

Notes: This table examines the effect of recall of local bankruptcies on trading activity of respondents to our own investor survey conducted in August 2019 using OLS. The dependent variables capture (changes in) expectations and risk aversion as explained in section 3.4 in the main text. The main independent variable, More bankruptcies than usual last 4 weeks, is a dummy variable taking value one if an investor reports to have noticed more bankruptcies than usual in his or her county of residence. The dependent variables are dummy variables indicating whether the investor traded with equity, was a net buyer, was a net seller, or only rebalanced the portfolio over the last four weeks (Panel A), or whether the investor plans any of these activities over the next four weeks (Panel B). All specifications control for gender, age, education, employment status, household income, household net wealth, participation in different asset classes, and state ("Bundesland") of residence. The variables are defined in detail in online appendix D and appendix Table A3. The sample is restricted to investors with complete information on all relevant variables and response time roughly above the first percentile. Robust standard errors are in parentheses. * denotes significance at 10 pct., ${ }^{* *}$ at 5 pct., and ${ }^{* * *}$ at 1 pct. level. 
Table 5: Brokerage data: Distraction and conflicting information

\begin{tabular}{|c|c|c|c|c|c|c|}
\hline & \multicolumn{2}{|c|}{ Portfolio Turnover } & \multicolumn{2}{|c|}{ Buy-Sell Imbalance } & \multicolumn{2}{|c|}{ Active Risky Share } \\
\hline & (1) & (2) & (3) & (4) & (5) & (6) \\
\hline \multicolumn{7}{|l|}{ Panel A: VDAX } \\
\hline Bankruptcies $25_{t}$ (a) & $\begin{array}{l}0.485^{* *} \\
(0.184)\end{array}$ & $\begin{array}{l}0.472^{* *} \\
(0.182)\end{array}$ & $\begin{array}{c}-0.893^{* *} \\
(0.402)\end{array}$ & $\begin{array}{l}-1.036^{* *} \\
(0.404)\end{array}$ & $\begin{array}{c}-0.237^{* * *} \\
(0.085)\end{array}$ & $\begin{array}{c}-0.263^{* * *} \\
(0.087)\end{array}$ \\
\hline Bankruptcies $25_{t}$ x VDAX75 (b) & $\begin{array}{l}-0.106 \\
(0.105)\end{array}$ & & $\begin{array}{l}-0.018 \\
(0.179)\end{array}$ & & $\begin{array}{c}0.019 \\
(0.069)\end{array}$ & \\
\hline Bankruptcies $25_{t}$ x VDAX90 (b) & & $\begin{array}{l}-0.191 \\
(0.152)\end{array}$ & & $\begin{array}{c}1.136^{* * *} \\
(0.357)\end{array}$ & & $\begin{array}{l}0.257^{* *} \\
(0.113)\end{array}$ \\
\hline $\operatorname{Pr}(a+b)=0$ & 0.056 & 0.211 & 0.029 & 0.835 & 0.029 & 0.962 \\
\hline
\end{tabular}

Panel B: Holidays

\begin{tabular}{|c|c|c|c|}
\hline Bankruptcies $25_{t}(\mathrm{a})$ & $\begin{array}{l}0.472^{* *} \\
(0.183)\end{array}$ & $\begin{array}{c}-1.193^{* * *} \\
(0.403)\end{array}$ & $\begin{array}{c}-0.227^{* *} \\
(0.086)\end{array}$ \\
\hline Bankruptcies $25_{t}$ x Summer Holidays (b) & $\begin{array}{l}-0.025 \\
(0.177)\end{array}$ & $\begin{array}{c}3.362^{*} \\
(1.694)\end{array}$ & $\begin{array}{c}-0.056 \\
(0.260)\end{array}$ \\
\hline Summer Holidays & $\begin{array}{c}-0.124^{* * *} \\
(0.037)\end{array}$ & $\begin{array}{c}-0.246 \\
(0.173)\end{array}$ & $\begin{array}{c}-0.031 \\
(0.040)\end{array}$ \\
\hline $\operatorname{Pr}(a+b)=0$ & 0.060 & 0.188 & 0.266 \\
\hline
\end{tabular}

\section{Panel C: Analyst Forecasts}

\begin{tabular}{|c|c|c|c|c|c|c|}
\hline Bankruptcies $25_{t}$ (a) & $\begin{array}{c}0.501^{* * *} \\
(0.185)\end{array}$ & $\begin{array}{c}0.475^{* *} \\
(0.182)\end{array}$ & $\begin{array}{c}-1.284^{* * *} \\
(0.475)\end{array}$ & $\begin{array}{c}-0.995^{* *} \\
(0.416)\end{array}$ & $\begin{array}{c}-0.239^{* * *} \\
(0.085)\end{array}$ & $\begin{array}{c}-0.237^{* * *} \\
(0.083)\end{array}$ \\
\hline Bankruptcies $25_{t}$ x Forecast75 (b) & $\begin{array}{l}-0.178 \\
(0.146)\end{array}$ & & $\begin{array}{c}1.749 \\
(1.068)\end{array}$ & & $\begin{array}{c}0.033 \\
(0.224)\end{array}$ & \\
\hline Bankruptcies $25_{t}$ x Forecast90 (b) & & $\begin{array}{l}-0.089 \\
(0.144)\end{array}$ & & $\begin{array}{c}1.186 \\
(1.661)\end{array}$ & & $\begin{array}{c}0.058 \\
(0.369)\end{array}$ \\
\hline $\operatorname{Pr}(a+b)=0$ & 0.147 & 0.088 & 0.602 & 0.904 & 0.335 & 0.624 \\
\hline Controls & Yes & Yes & Yes & Yes & Yes & Yes \\
\hline Time FE & Yes & Yes & Yes & Yes & Yes & Yes \\
\hline
\end{tabular}

Notes: This table examines how the effect of local bankruptcies on trading and risk-taking varies with proxies for distraction and conflicting information. It displays OLS estimates of the fixed effects model in equation 1 (columns 1-2) and the first difference model in equation 2 (columns 3-6). The dependent variables capture portfolio turnover and changes in risk-taking as defined in section 2 . The main independent variables are Bankruptcies $25_{t}$, the number of monthly bankruptcies within a 25 -km radius around an investor's home zip code, scaled by the previous year end's number of firms in the county of residence, and its interactions with different dummy variables. The independent variables and the dependent variables are expressed as percentages. VDAX75 and VDAX90 (Panel A) and Forecast75 and Forecast90 (Panel C) are dummies for whether the VDAX or mean analyst forecasts about the return of the German stock market index DAX over the next 6 months were above their 75 th or 90th percentile within the sample period, respectively. Summer Holidays (Panel B) is a dummy for the month of the long summer school holidays in an investor's state of residence. All specifications include fixed effects for each month of the sample period and control for the recent monthly return on the investor's portfolio and the log of the total wealth of the investor, both measured at the end of the previous month, for the log of GDP per capita in the county of residence over the previous calendar year, and current and last month's values of both the county-level unemployment rate and the value-weighted average monthly return on the stocks of local publicly listed firms. Controls are coded as monthly changes in the first difference specifications in columns 3-6. All variables are defined in more detail in appendix Table A3. The sample period is January 2007 to November 2012. The sample is restricted to active investors (more than one yearly trade on average during their time in the sample), with complete information on all relevant variables, and with valid information on zip code of residence. Standard errors that are two-way clustered by investor and time period are in parentheses. * denotes significance at 10 pct., ** at 5 pct., and $* * *$ at 1 pct. level. 
Table 6: Are bankruptcies predictive?

\begin{tabular}{|c|c|c|c|c|c|c|c|}
\hline & \multicolumn{2}{|c|}{ Zip code level } & \multicolumn{2}{|c|}{ County level } & \multicolumn{3}{|c|}{ National level } \\
\hline & $\begin{array}{c}(1) \\
\text { Local } \\
\text { Return 25 }\end{array}$ & $\begin{array}{c}(2) \\
\text { Local } \\
\text { Spending }\end{array}$ & $\begin{array}{c}(3) \\
\text { Local } \\
\text { Unemployment }\end{array}$ & $\begin{array}{c}(4) \\
\text { Ln Local GDP } \\
\text { per Capita }\end{array}$ & $\begin{array}{c}(5) \\
\text { Stock Market } \\
\text { Return (CDAX) }\end{array}$ & $\begin{array}{c}(6) \\
\text { Stock Market } \\
\text { Volatility (VDAX) }\end{array}$ & $\begin{array}{c}(7) \\
\text { Aggregate } \\
\text { Unemployment }\end{array}$ \\
\hline Bankruptcies $_{t-1}$ & $\begin{array}{l}-1.072 \\
(0.999)\end{array}$ & $\begin{array}{l}-0.037 \\
(0.072)\end{array}$ & $\begin{array}{c}0.062 \\
(0.050)\end{array}$ & $\begin{array}{l}-0.012 \\
(0.010)\end{array}$ & $\begin{array}{c}-196.868^{*} \\
(99.282)\end{array}$ & $\begin{array}{l}-131.392 \\
(135.882)\end{array}$ & $\begin{array}{c}3.225 \\
(11.914)\end{array}$ \\
\hline Bankruptcies $_{t-3}$ & $\begin{array}{c}-0.936 \\
(1.591)\end{array}$ & & $\begin{array}{c}0.145 \\
(0.096)\end{array}$ & $\begin{array}{l}-0.014 \\
(0.015)\end{array}$ & $\begin{array}{c}246.257 \\
(158.543)\end{array}$ & $\begin{array}{c}88.452 \\
(257.715)\end{array}$ & $\begin{array}{c}-4.083 \\
(16.331)\end{array}$ \\
\hline Bankruptcies $_{t-4}$ & $\begin{array}{l}-0.502 \\
(0.924)\end{array}$ & & $\begin{array}{c}0.206 \\
(0.131)\end{array}$ & $\begin{array}{c}0.003 \\
(0.011)\end{array}$ & $\begin{array}{c}-289.031 \\
(177.780)\end{array}$ & $\begin{array}{c}185.876 \\
(230.305)\end{array}$ & $\begin{array}{c}-0.206 \\
(16.450)\end{array}$ \\
\hline Bankruptcies $_{t-6}$ & $\begin{array}{c}0.017 \\
(0.866)\end{array}$ & & $\begin{array}{c}0.235 \\
(0.143)\end{array}$ & $\begin{array}{c}0.015 \\
(0.009)\end{array}$ & $\begin{array}{c}107.037 \\
(215.402)\end{array}$ & $\begin{array}{c}85.117 \\
(235.155)\end{array}$ & $\begin{array}{c}-23.749 \\
(17.942)\end{array}$ \\
\hline $\begin{array}{l}\text { Spatial unit } \\
\text { Time unit } \\
\text { Controls } \\
\text { Spatial FE } \\
\text { Time FE }\end{array}$ & $\begin{array}{l}\text { Zip code } \\
\text { Month } \\
\text { Yes } \\
\text { Yes } \\
\text { Yes }\end{array}$ & $\begin{array}{c}\text { Zip code } \\
\text { Year } \\
\text { Yes } \\
\text { Yes } \\
\text { Yes }\end{array}$ & $\begin{array}{c}\text { County } \\
\text { Month } \\
\text { Yes } \\
\text { Yes } \\
\text { Yes }\end{array}$ & $\begin{array}{c}\text { County } \\
\text { Year } \\
\text { Yes } \\
\text { Yes } \\
\text { Yes }\end{array}$ & $\begin{array}{l}\text { Nation } \\
\text { Month } \\
\text { Yes } \\
\text { No } \\
\text { No }\end{array}$ & $\begin{array}{l}\text { Nation } \\
\text { Month } \\
\text { Yes } \\
\text { No } \\
\text { No }\end{array}$ & $\begin{array}{c}\text { Nation } \\
\text { Month } \\
\text { Yes } \\
\text { No } \\
\text { No }\end{array}$ \\
\hline
\end{tabular}

Notes: This table examines whether bankruptcies are predictive for future returns or economic conditions estimating equation 3 using OLS. Each displayed coefficient estimate is obtained from an individual regression. Bankruptcies ${ }_{t-k}$ is the k-th (monthly or yearly) lag of the number of bankruptcies in the geographical unit and time unit, scaled by the previous year end's number of firms in that geographical unit. Local Return 25 is the value weighted average of monthly returns of public companies within the 25-km neighborhood of a zip code (column 1). Local Spending Capacity is measured at the zip code-year level and only available for 2008-2010 (column 2). County unemployment is measured at the county-month level (column 3) and the log of county GDP per capita is measured at the county-year level (column 4). The CDAX return (the return of a German stock market index), the volatility index VDAX of the German stock market, and aggregate unemployment (seasonally adjusted) are measured at the nation-month level (columns 5-7). Controls in columns 1 and 3 include the log of county-level GDP per capita over the previous calendar year, and current and last month's values of both the countylevel unemployment rate and the value-weighted average monthly return on the stocks of local publicly listed firms. Column 2 controls for current spending capacity, for current and last year's values of the county-level log of GDP per capita, of the county-level unemployment rate and of the value-weighted average yearly return on the stocks of local publicly listed firms. Column 4 controls for current and last year's values of the county-level log of GDP per capita, of the county-level unemployment rate and of the value-weighted average yearly return on the stocks of local publicly listed firms. Columns 5-7 control for the previous two quarters' log of real aggregate GDP per capita (seasonally adjusted), current and last month's values of the aggregate unemployment rate (seasonally adjusted), of the return of the CDAX and of the volatility index VDAX, the current level of the CDAX and a dummy indicating the recession 2008-9. Bankruptcies at the zip code level (at the 99th percentile) and local returns (at the 1st and the 99th percentile), and, in regressions where they are used as outcome, local spending, local unemployment and local GDP (at the 99th percentile) are trimmed to account for extreme outliers, but the results are not sensitive to these choices. All variables are defined in more detail in appendix $\mathrm{C}$ and in appendix Table A3. The specifications in columns 1-4 control for time and geographical fixed effects at the relevant aggregation levels. The sample period is January 2007 to November 2012. The sample in columns 1-4 consist of the geographical-time unit cells in which we observe at least one investor. The regressions in columns 1-4 are weighted by the average monthly number of investors observed in that geographical unit during the time the geographical unit appears in our investor sample. Standard errors that are two-way clustered by spatial unit and time unit (columns 1-4) or robust (columns 5-7) are in parentheses. ${ }^{*}$ denotes significance at 10 pct., ${ }^{* *}$ at 5 pct., and ${ }^{* * *}$ at 1 pct. level. 
Table 7: Brokerage data: Risk-taking around bankruptcies by zip code predictability

\begin{tabular}{|c|c|c|c|c|c|}
\hline & All & $\begin{array}{l}\text { Excl. predict } \\
\text { lower CDAX ret }\end{array}$ & $\begin{array}{c}\text { Excl. predict } \\
\text { higher unemployment }\end{array}$ & $\begin{array}{c}\text { Predict } \\
\text { higher volatility }\end{array}$ & $\begin{array}{c}\text { Preditc } \\
\text { lower volatility }\end{array}$ \\
\hline & (1) & (2) & (3) & (4) & (5) \\
\hline \multicolumn{6}{|l|}{ Panel A: Turnover } \\
\hline Bankruptcies $25_{t}$ & $\begin{array}{c}0.482^{* * *} \\
(0.180)\end{array}$ & $\begin{array}{c}0.523^{* * *} \\
(0.188)\end{array}$ & $\begin{array}{c}0.564^{* * *} \\
(0.191)\end{array}$ & $\begin{array}{c}0.307 \\
(0.268)\end{array}$ & $\begin{array}{l}0.586^{* *} \\
(0.247)\end{array}$ \\
\hline Controls and Fixed Effects & Yes & Yes & Yes & Yes & Yes \\
\hline Adj. R-squared & .398 & .399 & .397 & .394 & .402 \\
\hline Observations & 2822177 & 2575487 & 2617001 & 1236284 & 1585893 \\
\hline \multicolumn{6}{|c|}{ Panel B: Buy-Sell Imbalance } \\
\hline$\Delta$ Bankruptcies $25_{t}$ & $\begin{array}{c}-0.816^{* *} \\
(0.396)\end{array}$ & $\begin{array}{l}-0.683 \\
(0.426)\end{array}$ & $\begin{array}{l}-0.859^{*} \\
(0.448)\end{array}$ & $\begin{array}{l}-0.604 \\
(0.659)\end{array}$ & $\begin{array}{l}-0.936 \\
(0.570)\end{array}$ \\
\hline Controls and Fixed Effects & Yes & Yes & Yes & Yes & Yes \\
\hline Adj. R-squared & .008 & .008 & .008 & .008 & .008 \\
\hline Observations & 2783109 & 2544582 & 2585193 & 1215522 & 1567587 \\
\hline \multicolumn{6}{|c|}{ Panel C: Active Risky Share } \\
\hline$\Delta$ Bankruptcies $25_{t}$ & $\begin{array}{c}-0.228^{* * *} \\
(0.082)\end{array}$ & $\begin{array}{l}-0.174^{*} \\
(0.092)\end{array}$ & $\begin{array}{c}-0.208^{* *} \\
(0.090)\end{array}$ & $\begin{array}{l}-0.222^{*} \\
(0.115)\end{array}$ & $\begin{array}{l}-0.236^{*} \\
(0.127)\end{array}$ \\
\hline Controls and Fixed Effects & Yes & Yes & Yes & Yes & Yes \\
\hline Adj. R-squared & .025 & .025 & .025 & .025 & .025 \\
\hline Observations & 2783109 & 2544582 & 2585193 & 1215522 & 1567587 \\
\hline
\end{tabular}

Notes: This table examines whether the effect of local bankruptcies on trading and risk-taking differs by how predictive local bankruptcies are of changes in aggregate economic conditions. It displays OLS estimates of the fixed effects model in equation 1 (Panel A) and the first difference model in equation 2 (Panels B and C). Column 1 presents the baseline results, while columns 2 and 3 exclude investors from zip codes in which local bankruptcies predict lower aggregate stock returns (CDAX returns) or higher seasonally-adjusted national unemployment during the sample period, respectively. Columns 4 and 5 show results from subsamples of investors from zip codes in which local bankruptcies predict higher or lower stock market volatility (as measured by the VDAX), respectively. The dependent variables capture portfolio turnover and changes in risk-taking as defined in section 2. The main independent variable, Bankruptcies $25_{t}$, is the number of monthly bankruptcies within a 25 -km radius around an investor's home zip code, scaled by the previous year end's number of firms in the county of residence. The independent variable and the dependent variables are expressed as percentages. All specifications include fixed effects for each month of the sample period and control for the recent monthly return on the investor's portfolio and the log of the total wealth of the investor, both measured at the end of the previous month, for the log of GDP per capita in the county of residence over the previous calendar year, and current and last month's values of both the county-level unemployment rate and the value-weighted average monthly return on the stocks of local publicly listed firms. Controls are coded as monthly changes in the first difference specifications in Panels B and C. All variables are defined in more detail in appendix Table A3. The sample period is January 2007 to November 2012. The sample is restricted to active investors (more than one yearly trade on average during their time in the sample), with complete information on all relevant variables, and with valid information on zip code of residence. Standard errors that are two-way clustered by investor and time period are in parentheses. $*$ denotes significance at 10 pct., ${ }^{* *}$ at 5 pct., and ${ }^{* * *}$ at 1 pct. level. 
Table 8: Investor survey: Expectations and risk aversion

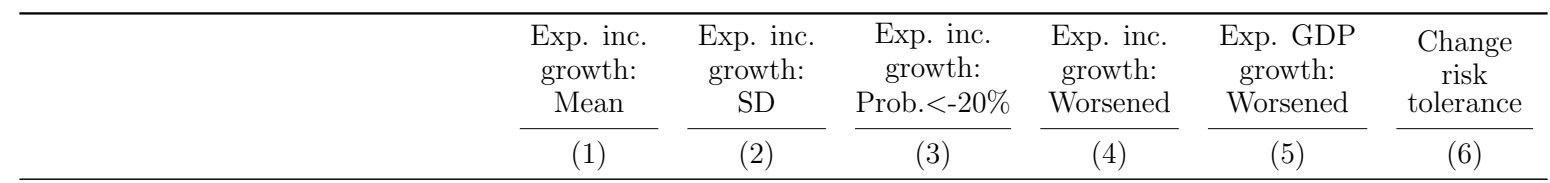

Panel A: Inc. exp. \& risk aver.

$\begin{array}{lcccccc}\text { More bankruptcies than } & -0.820 & 0.931 & 1.943 & 0.025 & 0.052 & -5.493^{* *} \\ \text { usual last 4 weeks } & (1.282) & (0.844) & (1.700) & (0.051) & (0.042) & (2.745) \\ & \text { Yes } & \text { Yes } & \text { Yes } & \text { Yes } & \text { Yes } & \text { Yes } \\ \text { Individual controls } & & & & & & .028 \\ & .046 & .077 & .002 & .025 & .016 \\ \text { Adj. R-squared } & 1196 & 1196 & 1196 & 1422 & 1422 & 1161 \\ \text { Observations } & \end{array}$

\begin{tabular}{|c|c|c|c|c|c|}
\hline $\begin{array}{l}\text { Exp. stock } \\
\text { returns: } \\
\text { Mean }\end{array}$ & $\begin{array}{l}\text { Exp. stock } \\
\text { returns: } \\
\text { SD }\end{array}$ & $\begin{array}{c}\text { Exp. stock } \\
\text { returns: } \\
\text { Prob. }<-20 \%\end{array}$ & $\begin{array}{l}\text { Exp. stock } \\
\text { returns: } \\
\text { Worsened }\end{array}$ & $\begin{array}{l}\text { Exp. foreign } \\
\text { returns: } \\
\text { Worsened }\end{array}$ & $\begin{array}{l}\text { Exp. bond } \\
\text { returns: } \\
\text { Worsened }\end{array}$ \\
\hline (1) & (2) & (3) & (4) & (5) & (6) \\
\hline
\end{tabular}

\section{Panel B: Return expectations}

\begin{tabular}{|c|c|c|c|c|c|c|}
\hline $\begin{array}{l}\text { More bankruptcies than } \\
\text { usual last } 4 \text { weeks }\end{array}$ & $\begin{array}{c}-2.251^{* *} \\
(1.116)\end{array}$ & $\begin{array}{c}0.268 \\
(0.830)\end{array}$ & $\begin{array}{l}4.272^{* *} \\
(2.133)\end{array}$ & $\begin{array}{l}0.091^{* *} \\
(0.046)\end{array}$ & $\begin{array}{c}0.044 \\
(0.047)\end{array}$ & $\begin{array}{c}0.068 \\
(0.044)\end{array}$ \\
\hline Individual controls & Yes & Yes & Yes & Yes & Yes & Yes \\
\hline Adj. R-squared & .012 & .024 & .019 & .019 & .021 & .013 \\
\hline Observations & 1180 & 1180 & 1180 & 1422 & 1421 & 1421 \\
\hline
\end{tabular}

Notes: This table examines the effect of recall of local bankruptcies on expectations and risk aversion of respondents to our own investor survey conducted in August 2019 using OLS. The dependent variables capture (changes in) expectations and risk aversion as explained in section 4.2 in the main text. The main independent variable, More bankruptcies than usual last 4 weeks, is a dummy variable taking value one if an investor reports to have noticed more bankruptcies than usual in his or her county of residence. The dependent variables in Panel A columns 1, 2, 3 and 6 and in Panel B columns 1,2 and 3 are expressed as percentages. The outcome variables in Panel A columns 4 and 5 and in Panel B columns 4-6 are dummy variables taking value one if the respondent indicates that his or her outlook regarding the specific variable has worsened over the last four weeks. All specifications control for gender, age, education, employment status, household income, household net wealth, participation in different asset classes, and state ("Bundesland") of residence. The variables are defined in detail in online appendix D and appendix Table A3. The sample is restricted to investors with complete information on all relevant variables and response time roughly above the first percentile. Robust standard errors are in parentheses. * denotes significance at 10 pct., ${ }^{* *}$ at 5 pct., and ${ }^{* * *}$ at 1 pct. level. 
Table 9: Brokerage data: What do investors trade following bankruptcies?

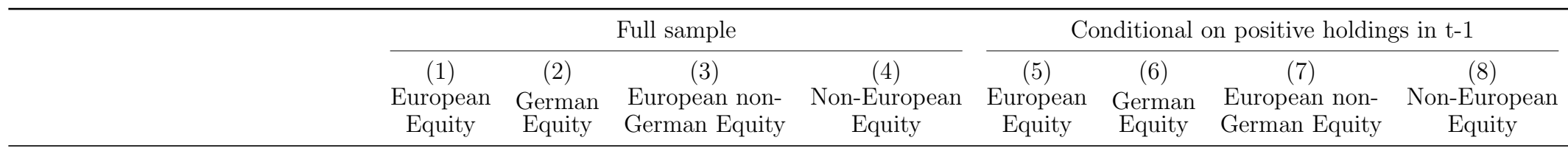

\section{Panel A: Turnover}

\begin{tabular}{|c|c|c|c|c|c|c|c|c|}
\hline Bankruptcies $25_{t}$ & $\begin{array}{c}0.289^{*} \\
(0.146)\end{array}$ & $\begin{array}{c}0.284^{*} \\
(0.158)\end{array}$ & $\begin{array}{c}-0.023 \\
(0.075)\end{array}$ & $\begin{array}{c}0.035 \\
(0.121)\end{array}$ & $\begin{array}{l}0.321^{* *} \\
(0.157)\end{array}$ & $\begin{array}{c}0.441^{* *} \\
(0.183)\end{array}$ & $\begin{array}{l}-0.022 \\
(0.105)\end{array}$ & $\begin{array}{l}-0.002 \\
(0.147)\end{array}$ \\
\hline Controls & Yes & Yes & Yes & Yes & Yes & Yes & Yes & Yes \\
\hline Investor FE & Yes & Yes & Yes & Yes & Yes & Yes & Yes & Yes \\
\hline Time FE & Yes & Yes & Yes & Yes & Yes & Yes & Yes & Yes \\
\hline Adj. R-squared & .265 & .253 & .108 & .179 & .273 & .297 & .189 & .221 \\
\hline Observations & 2822311 & 2822311 & 2822311 & 2822311 & 2691133 & 2272033 & 1848677 & 2201152 \\
\hline
\end{tabular}

\begin{tabular}{|c|c|c|c|c|c|c|c|c|}
\hline$\Delta$ Bankruptcies $25_{t}$ & $\begin{array}{c}-0.620^{* *} \\
(0.292)\end{array}$ & $\begin{array}{c}-0.514^{*} \\
(0.286)\end{array}$ & $\begin{array}{c}-0.044 \\
(0.238)\end{array}$ & $\begin{array}{l}-0.227 \\
(0.351)\end{array}$ & $\begin{array}{c}-0.653^{* *} \\
(0.303)\end{array}$ & $\begin{array}{l}-0.529 \\
(0.358)\end{array}$ & $\begin{array}{l}-0.050 \\
(0.361)\end{array}$ & $\begin{array}{l}-0.269 \\
(0.388)\end{array}$ \\
\hline Controls & Yes & Yes & Yes & Yes & Yes & Yes & Yes & Yes \\
\hline Time FE & Yes & Yes & Yes & Yes & Yes & Yes & Yes & Yes \\
\hline Adj. R-squared & .008 & .007 & .005 & .005 & .008 & .008 & .008 & .284 \\
\hline Observations & 2783109 & 2783109 & 2783109 & 2783109 & 2656841 & 2245371 & 1829521 & 2176434 \\
\hline
\end{tabular}

Notes: This table examines the effect of local bankruptcies on trading of equity from different countries. It displays OLS estimates of the fixed effects model in equation 1 for overall turnover (Panel A) and the first difference model in equation 2 for the buy-sell imbalance (Panel B) for equity from different countries. Columns 1-4 use the full main sample, while columns 5-8 use the subsample of investors who hold the relevant asset class in the previous month. The dependent variables capture portfolio turnover and changes in risk-taking as defined in section 2, using only equity from the specified region. The main independent variable, Bankruptcies $25_{t}$, is the number of monthly bankruptcies within a 25 -km radius around an investor's home zip code, scaled by the previous year end's number of firms in the county of residence. The independent variable and the dependent variables are expressed as percentages. All specifications include fixed effects for each month of the sample period and control for the recent monthly return on the investor's portfolio and the log of the total wealth of the investor, both measured at the end of the previous month, for the log of GDP per capita in the county of residence over the previous calendar year, and current and last month's values of both the county-level unemployment rate and the value-weighted average monthly return on the stocks of local publicly listed firms. Controls are coded as monthly changes in the first difference specifications in Panel B. All variables are defined in more detail in appendix Table A3. The sample period is January 2007 to November 2012. The sample is restricted to active investors (more than one yearly trade on average during their time in the sample), with complete information on all relevant variables, and with valid information on zip code of residence. Standard errors that are two-way clustered by investor and time period are in parentheses. $*$ denotes significance at 10 pct., ${ }^{* *}$ at 5 pct., and ${ }^{* * *}$ at 1 pct. level. 
Table 10: Brokerage data: Change in market beta

\begin{tabular}{|c|c|c|c|c|c|}
\hline & $\begin{array}{l}\text { beta } \\
\text { DAX }\end{array}$ & $\begin{array}{l}\text { beta } \\
\text { CDAX }\end{array}$ & $\begin{array}{c}\text { beta } \\
\text { MSCI Europe } \\
\text { excl. CDAX }\end{array}$ & $\begin{array}{l}\text { beta } \\
\text { MSCI World } \\
\text { excl. CDAX }\end{array}$ & $\begin{array}{c}\text { beta } \\
\text { GDP growth }\end{array}$ \\
\hline & (1) & (2) & (3) & (4) & (5) \\
\hline Bankruptcies $25_{t}$ & $\begin{array}{c}-0.011^{* *} \\
(0.005)\end{array}$ & $\begin{array}{c}-0.010^{* *} \\
(0.005)\end{array}$ & $\begin{array}{c}0.005 \\
(0.009)\end{array}$ & $\begin{array}{c}0.007 \\
(0.005)\end{array}$ & $\begin{array}{l}-0.002 \\
(0.003)\end{array}$ \\
\hline Controls & Yes & Yes & Yes & Yes & Yes \\
\hline Investor FE & Yes & Yes & Yes & Yes & Yes \\
\hline Time FE & Yes & Yes & Yes & Yes & Yes \\
\hline $\begin{array}{l}\text { Adj. R-squared } \\
\text { Observations }\end{array}$ & $\begin{array}{c}.56 \\
2810245\end{array}$ & $\begin{array}{c}.56 \\
2810245\end{array}$ & $\begin{array}{c}.35 \\
2810245\end{array}$ & $\begin{array}{c}.48 \\
2268577\end{array}$ & $\begin{array}{c}.319 \\
2269007\end{array}$ \\
\hline
\end{tabular}

Notes: This table examines the effect of local bankruptcies on the market beta of investor's portfolios. It displays OLS estimates of the fixed effects model in equation 1. The dependent variables capture the investor's portfolio's market beta calculated relative to the German stock market indices DAX (column 1) and CDAX (column 2), the European stock market index MSCI Europe (partialling out the performance of the CDAX, column 3) and the global stock market index MSCI World (partialling out the performance of the CDAX, column 4), as well as the investor's portfolio beta relative to the quarterly growth of real GDP per capita (seasonally adjusted, column 5 ). The main independent variable, Bankruptcies $25_{t}$, is the number of monthly bankruptcies within a $25-\mathrm{km}$ radius around an investor's home zip code, scaled by the previous year end's number of firms in the county of residence. The independent variable is expressed as percentage, and the dependent variables are expressed as the ratio between the covariance of the portfolio return with a given market return and the variance of that market return. All specifications include fixed effects for each month of the sample period as well as investor fixed effects, and control for the recent monthly return on the investor's portfolio and the log of the total wealth of the investor, both measured at the end of the previous month, for the log of GDP per capita in the county of residence over the previous calendar year, and current and last month's values of both the county-level unemployment rate and the value-weighted average monthly return on the stocks of local publicly listed firms. All variables are defined in more detail in appendix Table A3. The sample period is January 2007 to November 2012. The sample is restricted to active investors (more than one yearly trade on average during their time in the sample), with complete information on all relevant variables, and with valid information on zip code of residence. Standard errors that are two-way clustered by investor and time period are in parentheses. * denotes significance at 10 pct., ${ }^{* *}$ at 5 pct., and ${ }^{* * *}$ at 1 pct. level. 


\title{
Online Appendix: The Trading Response of Individual Investors to Local Bankruptcies
}

\author{
Christine Laudenbach ${ }^{1} \quad$ Benjamin $\operatorname{Loos}^{2}$ \\ Jenny Pirschel ${ }^{3} \quad$ Johannes Wohlfart ${ }^{4}$
}

\section{Summary of the online appendix}

Section A and section B provide additional figures and tables, respectively. In section $\mathrm{C}$ we provide additional information on the data used in the main analysis, including the scaling of the bankruptcies measure (section C.1), the construction of variables from the brokerage data (section C.2), geographical variables that we merge to our brokerage dataset (section C.3), the macroeconomic variables we use in some of our analyses (section C.4), the classification of working investors into those working in cyclical/non-cyclical industries and those working in the tradable/non-tradable sector (section C.5), and the construction of the portfolio betas used in the mechanism analysis (section C.6). In section $\mathrm{D}$ we discuss the details of our own survey, including procedural details (section D.1), a translation of the survey questions (section D.2), coding of variables (section D.3), included control variables (section D.4) and the definition of the sample (section D.5). Finally, section E provides subsample analyses and a set of robustness checks on the main brokerage data.

\section{A Additional figures}

\footnotetext{
${ }^{1}$ Christine Laudenbach (Corresponding Author), House of Finance, Goethe University Frankfurt, e-mail: laudenbach@finance.uni-frankfurt.de, phone: +49 6979833675

${ }^{2}$ Benjamin Loos, University of Technology Sidney, e-mail: Benjamin.Loos@uts.edu.au, phone: +61 (0) 402551116

${ }^{3}$ Jenny Pirschel, Goethe University Frankfurt, e-mail: jennypirschel@googlemail.com, phone: +49 69 95150

${ }^{4}$ Johannes Wohlfart, Department of Economics and CEBI, University of Copenhagen, CESifo, e-mail: johannes.wohlfart@econ.ku.dk, phone: +45 35332061
} 
Figure A1: Panel A: Geographical distribution of bankruptcies

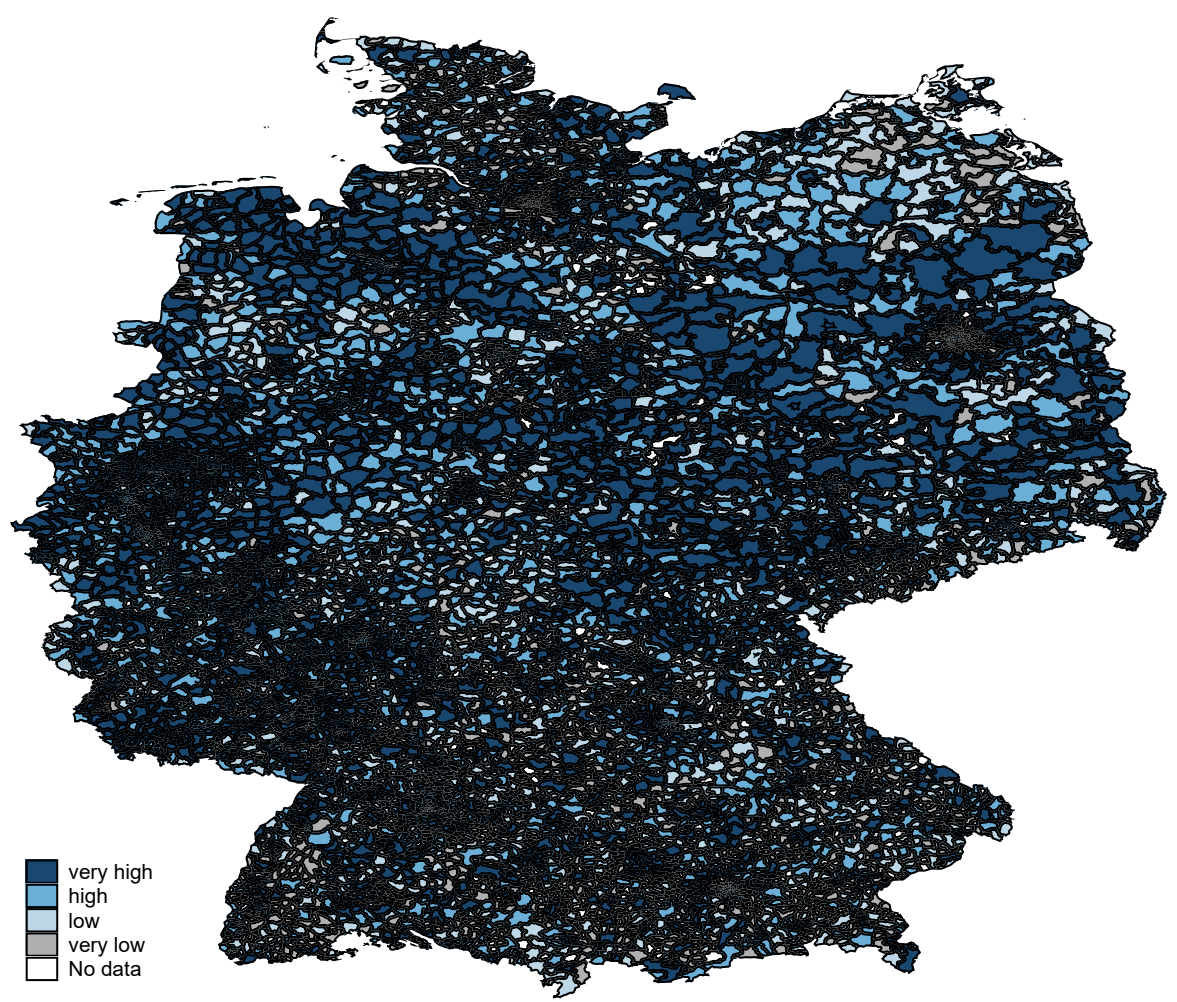

Notes: This figure displays the geographical distribution of all 182,379 bankruptcy filings between January 2007 and November 2012 across zip codes in Germany. The number of bankruptcy filings in a zip code is scaled by the previous year end's number of firms in the respective county ("Landkreis"). 
Figure A1: Panel B: Temporal distribution of bankruptcies
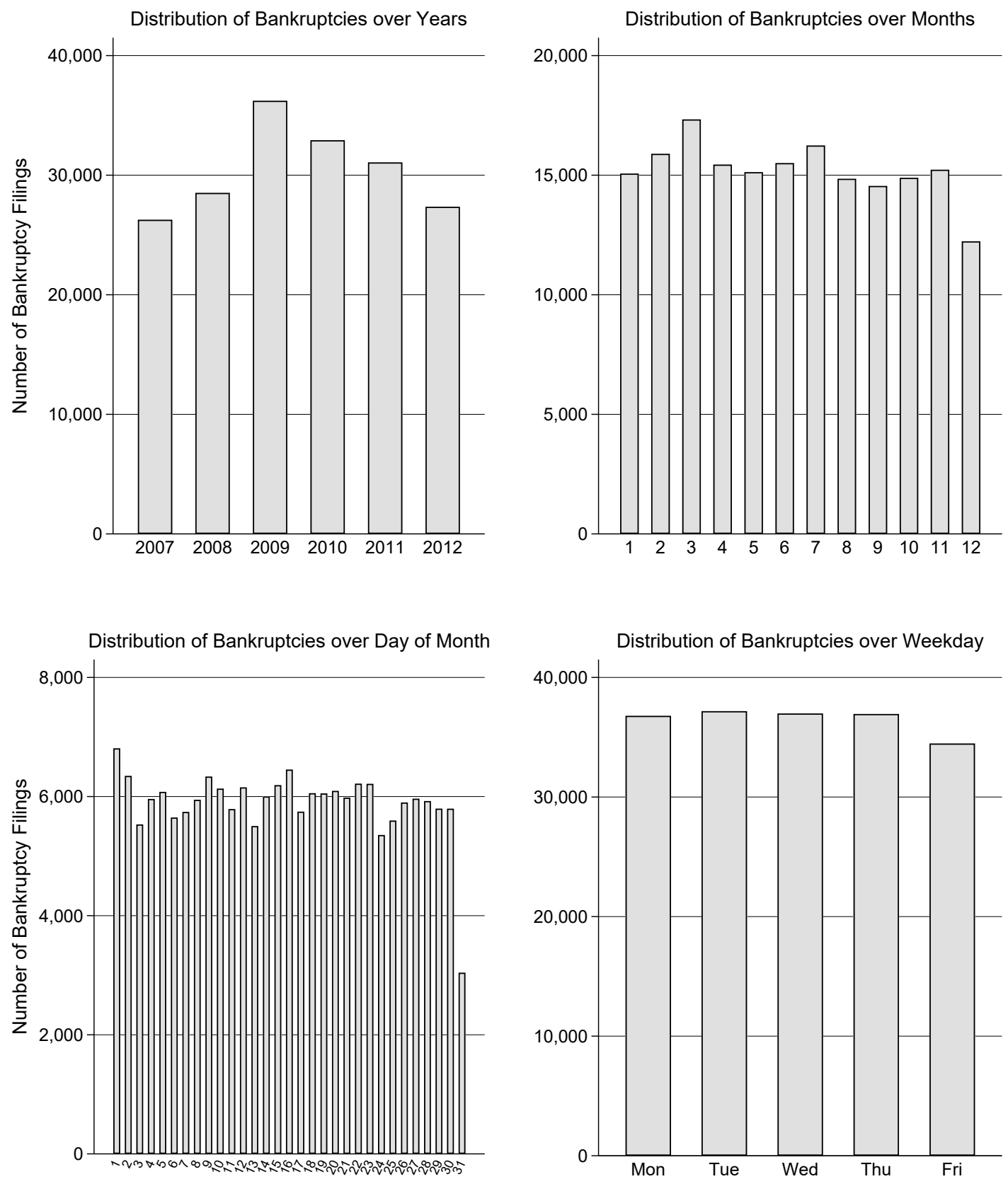

Notes: This figure displays the temporal distribution of bankruptcy filings in Germany between January 2007 and November 2012 across years (upper left panel), across calender months (upper right panel), across days of the month (lower left panel), and across days of the week (lower right panel). 
Figure A2: Placebo analysis Panel A: Bankruptcies assigned from same time period but randomly drawn zip code
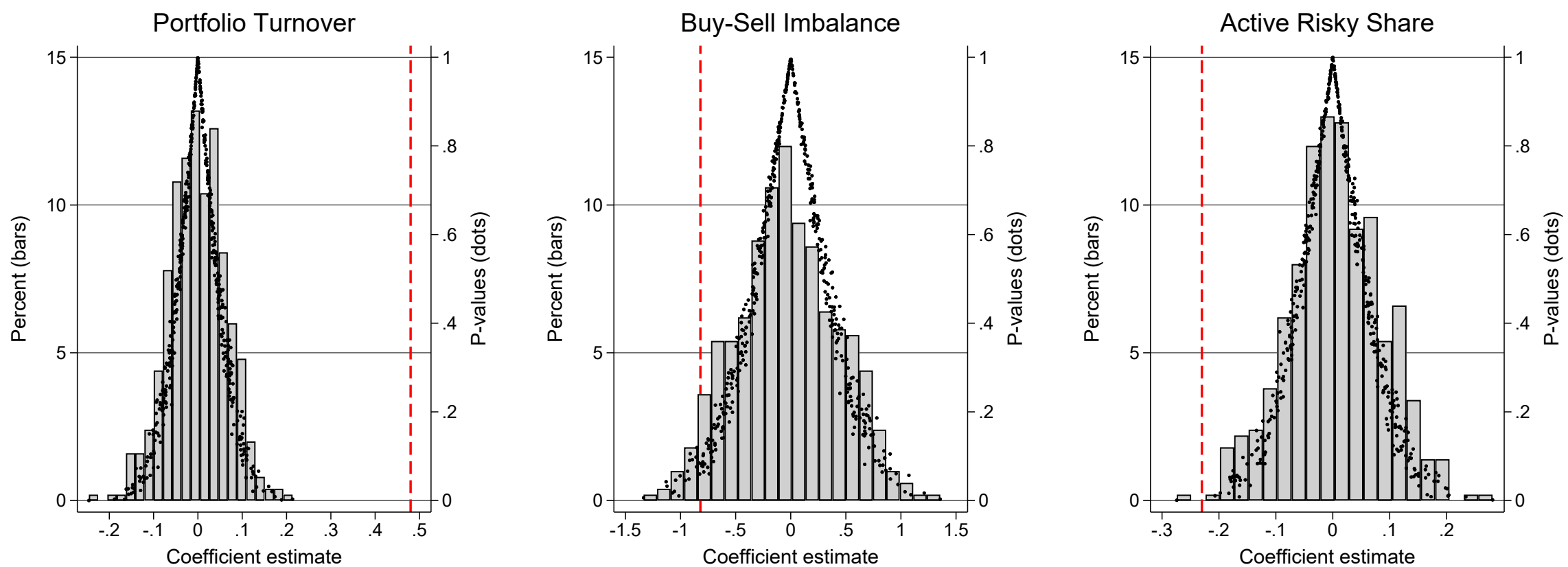

Notes: Panel A presents the results of placebo tests in which we re-estimate equation 1 for overall turnover on the left and equation 2 for the buy-sell imbalance (middle) and the active change in the risky share (right) 500 times using artificial bankruptcies measures. For each zip code-month observation the (change in the) bankruptcies measure is randomly drawn (with replacement) from the set of all zip code-level (changes in) bankruptcies occurring in the relevant month. The graphs show histograms of the 500 placebo coefficient estimates (displayed as bars) and p-values (displayed as dots) of the bankruptcies effect for our three main outcome variables, respectively. The x-axes denote the values of the coefficient estimates. The y-axes on the left denote the frequency of coefficient estimates of different size in percent. The y-axes on the right indicate the p-values of the coefficient estimates constructed from standard errors that are two-way clustered by investor and time period. The red dashed horizontal lines indicate the coefficient estimates obtained using the actual bankruptcies measure, which are displayed as baseline results in Table 2. The independent variables and the dependent variables are expressed as percentages. All specifications include fixed effects for each month of the sample period and control for the recent monthly return on the investor's portfolio and the log of the total wealth of the investor, both measured at the end of the previous month, for the log of GDP per capita in the county of residence over the previous calendar year, and current and last month's values of both the county-level unemployment rate and the value-weighted average monthly return on the stocks of local publicly listed firms. Controls are coded as monthly changes in the first difference specifications. All variables are defined in more detail in appendix Table A3. The sample period is January 2007 to November 2012. The sample is restricted to active investors (more than one yearly trade on average during their time in the sample), with complete information on all relevant variables, and with valid information on zip code of residence. 
Figure A2: Placebo analysis Panel B: Bankruptcies assigned from same zip code but randomly drawn time period
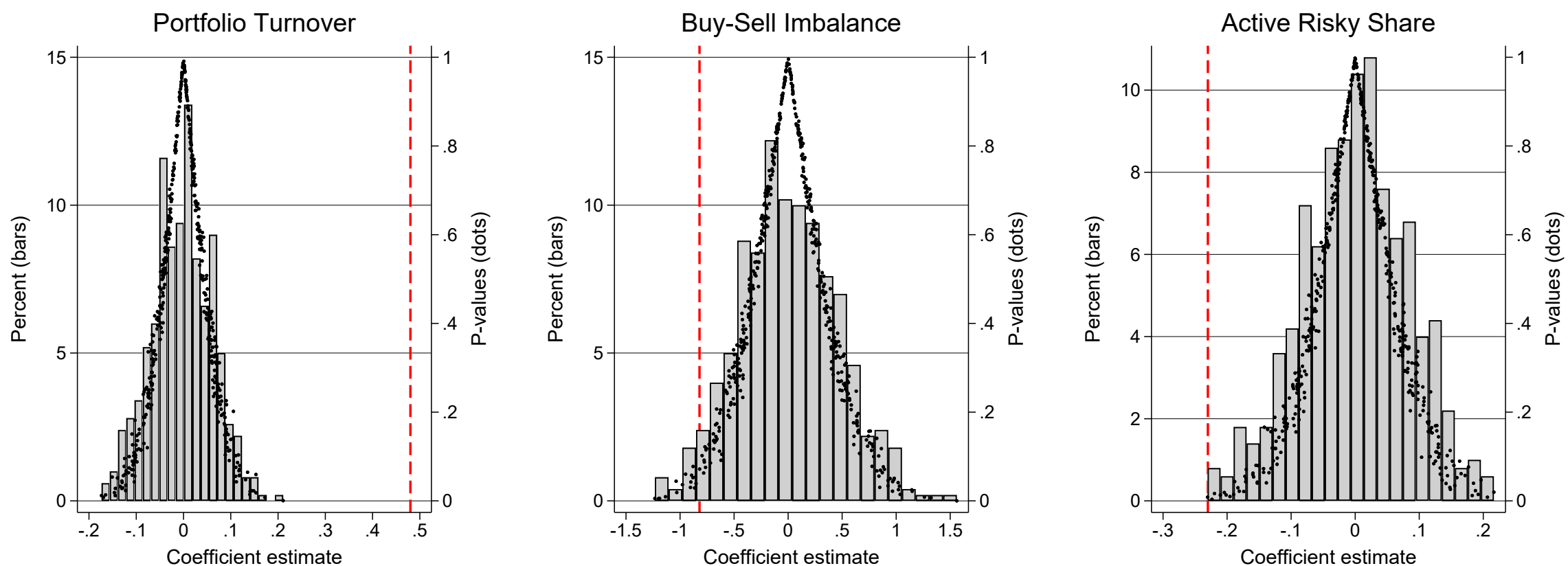

Notes: Panel B presents the results of placebo tests in which we re-estimate equation 1 for overall turnover on the left and equation 2 for the buy-sell imbalance (middle) and the active change in the risky share (right) 500 times using artificial bankruptcies measures. For each case, the (changes in) bankruptcies measure is randomly drawn (with replacement) from the set of all monthly (changes in) bankruptcies realizations that occurred within the relevant zip code over the sample period. The graphs show histograms of the 500 placebo coefficient estimates (displayed as bars) and p-values (displayed as dots) of the bankruptcies effect for our three main outcome variables, respectively. The x-axes denote the values of the coefficient estimates. The y-axes on the left denote the frequency of coefficient estimates of different size in percent. The y-axes on the right indicate the p-values of the coefficient estimates constructed from standard errors that are two-way clustered by investor and time period. The red dashed horizontal lines indicate the coefficient estimates obtained using the actual bankruptcies measure, which are displayed as baseline results in Table 2. The independent variables and the dependent variables are expressed as percentages. All specifications include fixed effects for each month of the sample period and control for the recent monthly return on the investor's portfolio and the log of the total wealth of the investor, both measured at the end of the previous month, for the log of GDP per capita in the county of residence over the previous calendar year, and current and last month's values of both the county-level unemployment rate and the value-weighted average monthly return on the stocks of local publicly listed firms. Controls are coded as monthly changes in the first difference specifications. All variables are defined in more detail in appendix Table A3. The sample period is January 2007 to November 2012. The sample is restricted to active investors (more than one yearly trade on average during their time in the sample), with complete information on all relevant variables, and with valid information on zip code of residence. 
Panel A: Turnover

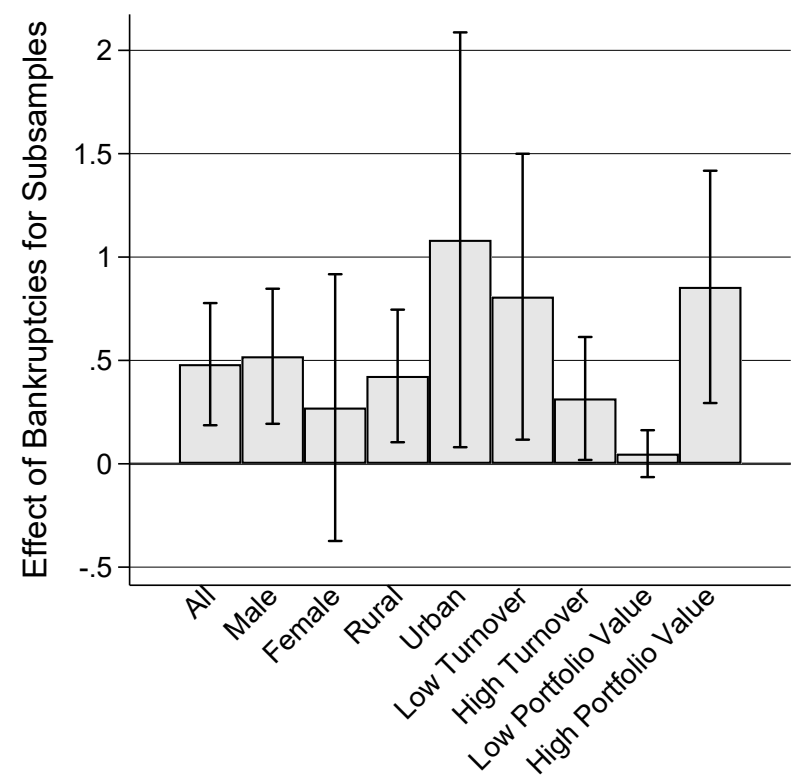

$\mathrm{n}$
Panel B: Buy-Sell Imbalance

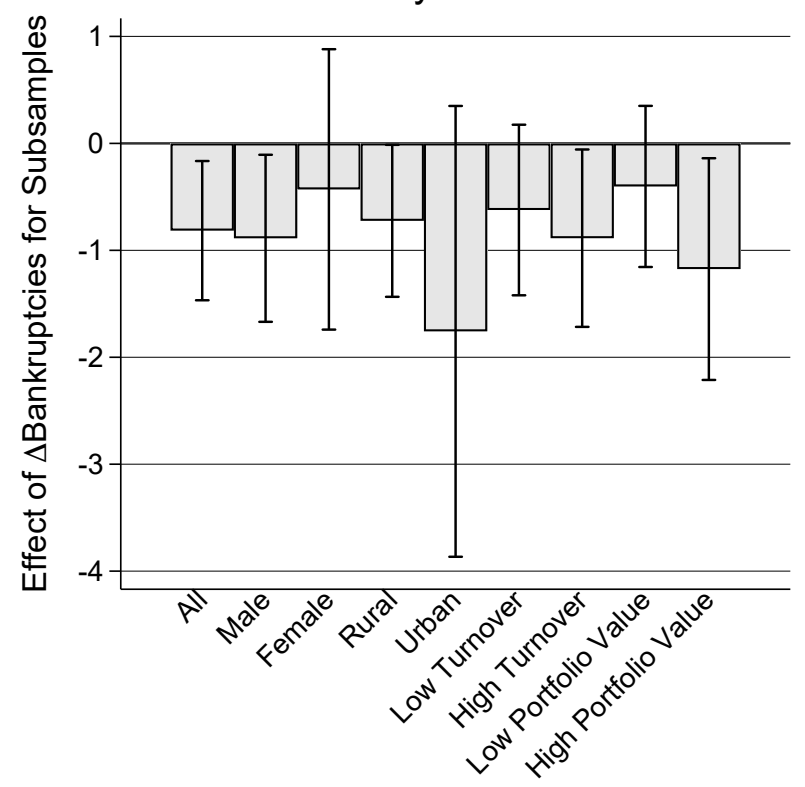

$\mathrm{n}$
Panel C: Active Risky Share
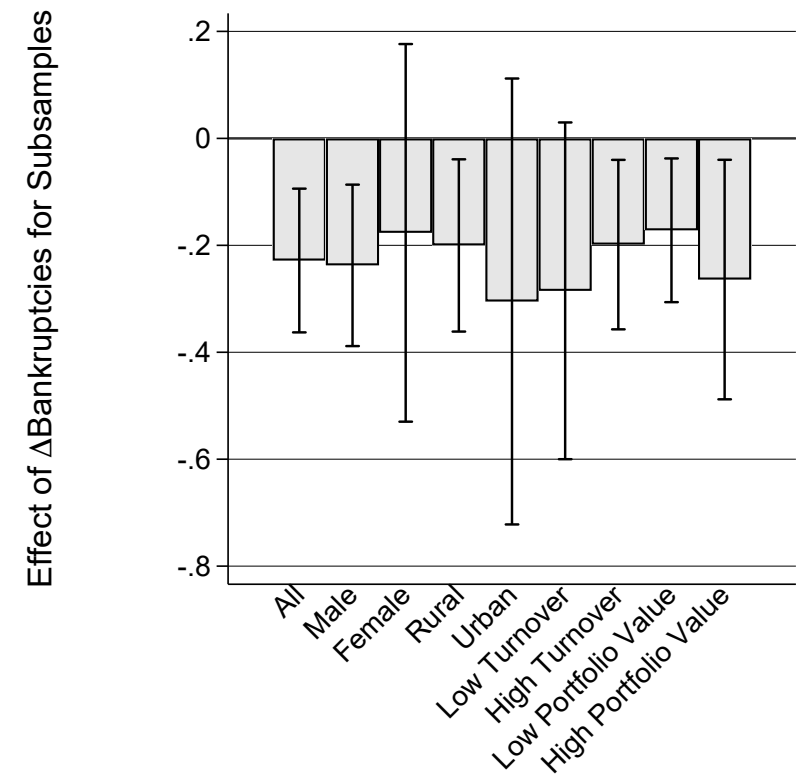

$n$

Notes: This figure examines the effect of local bankruptcies on trading and risk-taking of different subgroups, including men, women, investors living in rural regions, those living in urban regions, those with above- and those with below-median portfolio turnover, and those with above- and those with below-median portfolio value. The bars display OLS coefficient estimates of the effect of (changes in) bankruptcies obtained in individual estimations for each subgroup of the fixed effects model in equation 1 for turnover (Panel A) and of the first difference model in equation 2 for active changes in the risky share and the buy-sell imbalance (Panels B and $\mathrm{C}$ ). The dependent variables capture portfolio turnover and changes in risk-taking as defined in section 2 . The main independent variable, Bankruptcies $25_{t}$, is the number of monthly bankruptcies within a 25 -km radius around an investor's home zip code, scaled by the previous year end's number of firms in the county of residence. The independent variable and the dependent variables are expressed as percentages. All specifications include fixed effects for each month of the sample period and control for the recent monthly return on the investor's portfolio and the log of the total wealth of the investor, both measured at the end of the previous month, for the log of GDP per capita in the county of residence over the previous calendar year, and current and last month's values of both the county-level unemployment rate and the value-weighted average monthly return on the stocks of local publicly listed firms. Controls are coded as monthly changes in the first difference specifications in Panels B and C. All variables are defined in more detail in appendix Table A3. The sample period is January 2007 to November 2012. The sample is restricted to active investors (more than one yearly trade on average during their time in the sample), with complete information on all relevant variables, and with valid information on zip code of residence. Error bands show 90-percent confidence bands constructed from standard errors that are two-way clustered by investor and time period. 
Figure A4: Investor survey: Sources of knowledge about local bankruptcies

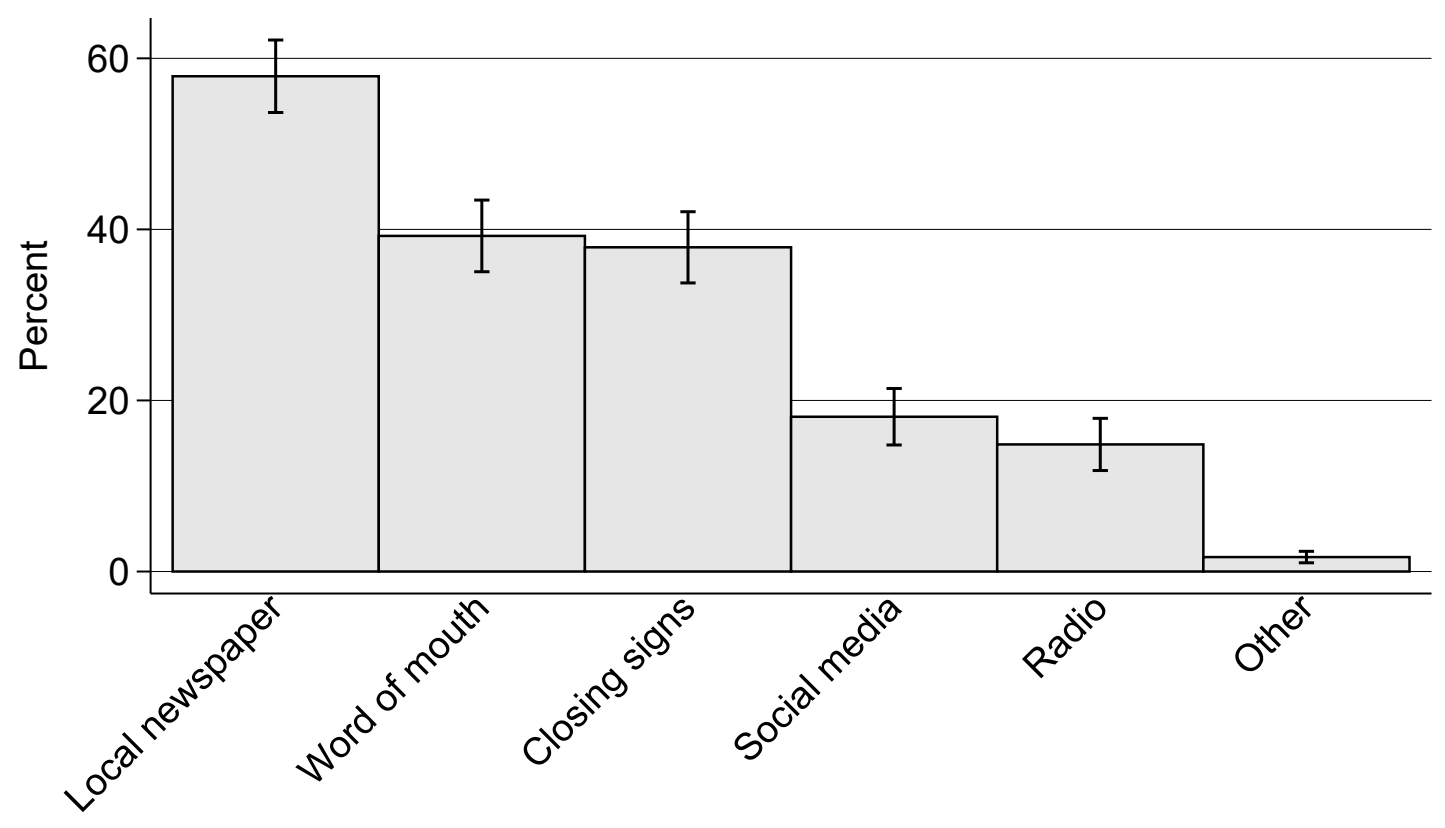

Source of knowledge about bankruptcies

Notes: This figure displays which shares among those respondents to the investor survey conducted in August 2019 who have heard about local bankruptcies over the previous four weeks (37 percent of all respondents) have heard about these bankruptcies from different sources (in percent). In line with the main analysis, the investor sample is restricted to investors with complete information on all relevant variables and response time roughly above the first percentile. 95-percent confidence bands are shown in brackets. 
Figure A5: News coverage of bankruptcies and actual bankruptcies
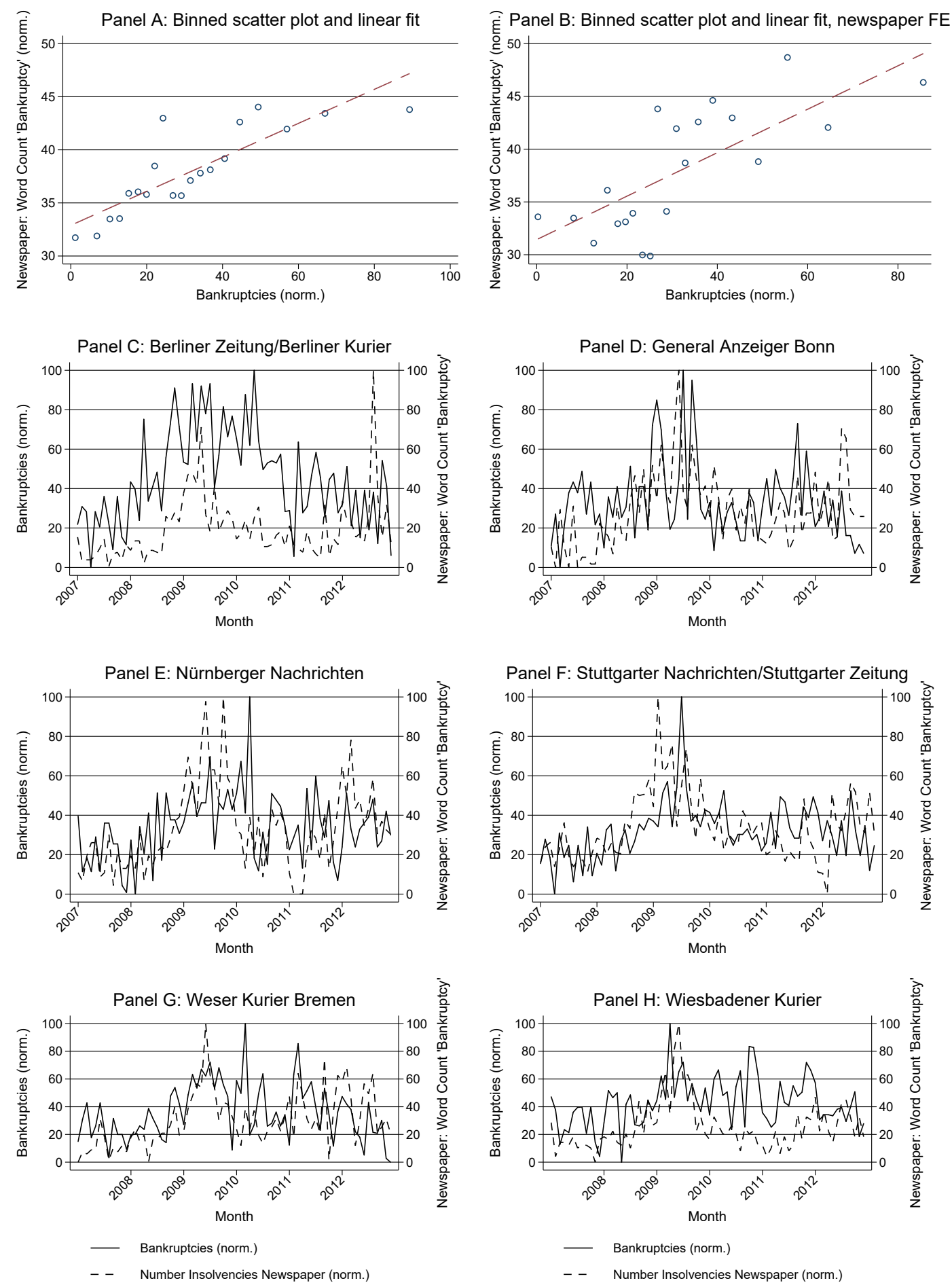

Notes: This figure examines the correlation between how often the word "bankruptcy" ("Insolvenz" in German) is mentioned in a newspaper and the number of bankruptcies (scaled by the previous year's number of firms in the region) at the newspaper region-month level. Panel A shows a binned scatter plot including a linear fit pooling data from all 12 newspapers for which data are available. Panel B shows the same plot after partialling out newspaper region fixed effects. Panels C-H display time series of newspaper mentions of the word "bankruptcy" and newspaper region-level bankruptcies for six major German newspapers, Berliner Zeitung/Berliner Kurier, General Anzeiger (Bonn), Nürnberger Nachrichten, Stuttgarter Nachrichten/Stuttgarter Zeitung, Weser Kurier (Bremen), Wiesbadener Kurier. The number of monthly bankruptcies as well as monthly newspaper mentions are each normalized to lie within the interval $[0,100]$ for each newspaper/newspaper region over the sample period. The sample period is January 2007 to November 2012. 
Figure A6: Google searches and actual bankruptcies
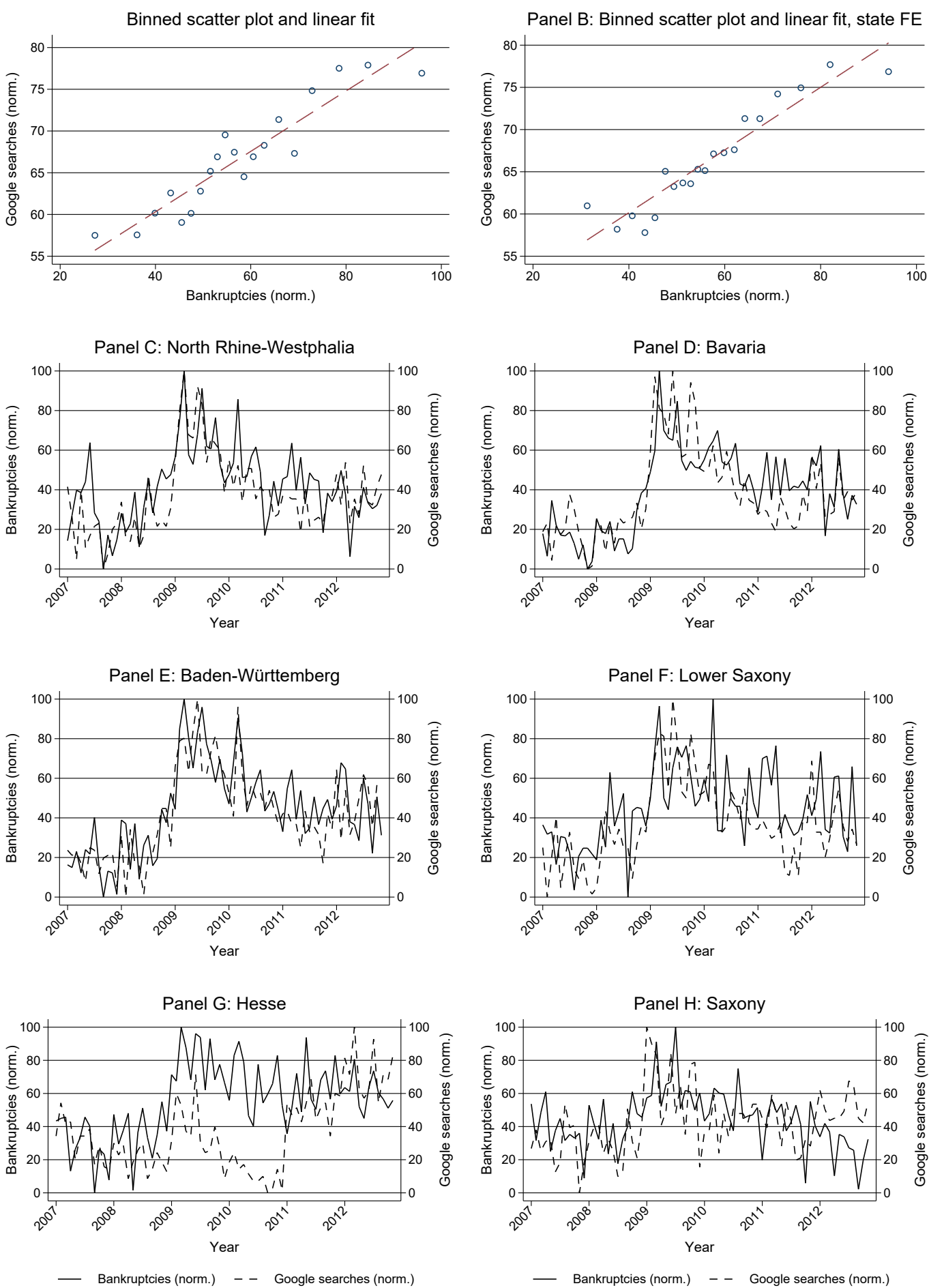

Notes: This figure examines the correlation between Google searches for the word "bankruptcy" ("Insolvenz" in German) and the raw number of bankruptcies at the state-month level. Panel A shows a binned scatter plot including a linear fit pooling data from all 16 states. Panel B shows the same plot after partialling out state fixed effects. Panels C-H display time series of Google searches and bankruptcies for the six largest German states, North Rhine-Westfalia, Bavaria, Baden-Württemberg, Lower Saxony, Hesse, and Saxony. The number of monthly bankruptcies as well as monthly Google searches are each normalized to lie within the interval $[0,100]$ for each state over the sample period. The sample period is January 2007 to November 2012. 


\section{B Additional tables}

Table A1: Variation in Bankruptcies

\begin{tabular}{|c|c|c|c|c|c|c|c|}
\hline & \multicolumn{7}{|c|}{ Bankruptcies $25_{t}$} \\
\hline & (1) & $(2)$ & (3) & (4) & (5) & (6) & (7) \\
\hline Bankruptcies $25_{t-1}$ & & & & $\begin{array}{c}0.919^{* * *} \\
(0.012)\end{array}$ & $\begin{array}{c}0.197^{* * *} \\
(0.020)\end{array}$ & $\begin{array}{c}0.144^{* * *} \\
(0.019)\end{array}$ & $\begin{array}{c}0.122^{* * *} \\
(0.020)\end{array}$ \\
\hline Bankruptcies $25_{t-2}$ & & & & & & $\begin{array}{c}0.134^{* * *} \\
(0.020)\end{array}$ & $\begin{array}{c}0.107^{* * *} \\
(0.022)\end{array}$ \\
\hline Bankruptcies $25_{t-3}$ & & & & & & $\begin{array}{c}0.093^{* * *} \\
(0.020)\end{array}$ & $\begin{array}{c}0.073^{* * *} \\
(0.018)\end{array}$ \\
\hline Bankruptcies $25_{t-4}$ & & & & & & & $\begin{array}{c}0.065^{* * *} \\
(0.018)\end{array}$ \\
\hline Bankruptcies $25_{t-5}$ & & & & & & & $\begin{array}{c}0.035^{* *} \\
(0.017)\end{array}$ \\
\hline Bankruptcies $25_{t-6}$ & & & & & & & $\begin{array}{c}0.055^{\text {*** }} \\
(0.018)\end{array}$ \\
\hline Time FE & Yes & No & Yes & No & Yes & Yes & Yes \\
\hline Zip Code FE & No & Yes & Yes & No & Yes & Yes & Yes \\
\hline R-squared & .015 & .887 & .909 & .843 & .909 & .909 & .908 \\
\hline Observations & 433067 & 433067 & 433067 & 420732 & 420732 & 399593 & 372370 \\
\hline
\end{tabular}

Notes: This table examines the sources of variation and autocorrelation of the bankruptcies measure. It displays OLS regressions of the bankruptcies measure on monthly time fixed effects (column 1), on zip-code fixed effects (column 2), on both (column 3), on its own lag (column 4), on time fixed effects, zip code fixed effects and its first lag (column 5). Columns 6 and 7 add additional lags to the specification in column 5 . Bankruptcies $25_{t}$ is the number of monthly bankruptcies within a 25 -km radius around an investor's home zip code, scaled by the previous year end's number of firms in the county of residence. The regressions in columns 1-7 are weighted by the average monthly number of investors from a zip code during the time in which a zip code appears in our investor sample. Bankruptcies $25_{t-k}$ indicates the k-th lag of the monthly bankruptcies measure. The sample period is January 2007 to November 2012. Standard errors that are two-way clustered by zip code and time period are in parentheses. ${ }^{*}$ denotes significance at 10 pct., ${ }^{* *}$ at 5 pct., and ${ }^{* * *}$ at 1 pct. level. 
Table A2: Investor survey: Summary statistics

\begin{tabular}{|c|c|c|c|c|c|c|}
\hline & \multirow{3}{*}{$\begin{array}{c}\text { PHF } \\
(1) \\
2017\end{array}$} & \multicolumn{5}{|c|}{ Investor survey } \\
\hline & & $(2)$ & $(3)$ & $(4)$ & $(5)$ & $(6)$ \\
\hline & & Mean & SD & Min & $\operatorname{Max}$ & $\mathrm{N}$ \\
\hline Female & 0.49 & 0.41 & 0.49 & 0.00 & 1.00 & 1422 \\
\hline Age & 50.55 & 50.92 & 14.85 & 18.00 & 89.00 & 1422 \\
\hline East & 0.12 & 0.14 & 0.35 & 0.00 & 1.00 & 1422 \\
\hline HH net inc. (median) & 3330.48 & 3250.00 & 2308.81 & 250.00 & 12500.00 & 1422 \\
\hline Highschool & 0.15 & 0.19 & 0.40 & 0.00 & 1.00 & 1422 \\
\hline University & 0.36 & 0.47 & 0.50 & 0.00 & 1.00 & 1422 \\
\hline Employed & 0.63 & 0.68 & 0.47 & 0.00 & 1.00 & 1422 \\
\hline Retired & 0.23 & 0.26 & 0.44 & 0.00 & 1.00 & 1422 \\
\hline HH net wealth (median) & 237891.50 & 125000.00 & 396911.39 & 0.00 & $2.50 \mathrm{e}+06$ & 1422 \\
\hline Holds stocks directly & 0.66 & 0.71 & 0.45 & 0.00 & 1.00 & 1422 \\
\hline Holds mutual funds & 0.60 & 0.73 & 0.45 & 0.00 & 1.00 & 1422 \\
\hline Holds fixed income securities & 0.26 & 0.25 & 0.43 & 0.00 & 1.00 & 1422 \\
\hline Holds riskless assets & 0.88 & 0.83 & 0.38 & 0.00 & 1.00 & 1422 \\
\hline Traded last 4 weeks & & 0.38 & 0.48 & 0.00 & 1.00 & 1422 \\
\hline Net buyer last 4 weeks & & 0.21 & 0.41 & 0.00 & 1.00 & 1422 \\
\hline Net seller last 4 weeks & & 0.09 & 0.28 & 0.00 & 1.00 & 1422 \\
\hline Rebalanced last 4 weeks & & 0.08 & 0.28 & 0.00 & 1.00 & 1422 \\
\hline Plans trade next 4 weeks & & 0.42 & 0.49 & 0.00 & 1.00 & 1422 \\
\hline Plans net purchases next 4 weeks & & 0.24 & 0.43 & 0.00 & 1.00 & 1422 \\
\hline Plans net sales next 4 weeks & & 0.07 & 0.26 & 0.00 & 1.00 & 1422 \\
\hline Plans rebalancing next 4 weeks & & 0.10 & 0.30 & 0.00 & 1.00 & 1422 \\
\hline Exp. inc. growth: Mean & & 3.96 & 7.75 & -30.00 & 30.00 & 1196 \\
\hline Exp. inc. growth: SD & & 4.96 & 5.60 & 0.00 & 24.90 & 1196 \\
\hline Exp. inc. growth: Prob.<-20\% & & 3.33 & 11.48 & 0.00 & 100.00 & 1196 \\
\hline Exp. inc. growth: Worsened & & 0.26 & 0.44 & 0.00 & 1.00 & 1422 \\
\hline Exp. GDP growth: Worsened & & 0.12 & 0.33 & 0.00 & 1.00 & 1422 \\
\hline Exp. stock returns: Mean & & 2.21 & 7.23 & -32.19 & 32.16 & 1180 \\
\hline Exp. stock returns. SD & & 9.80 & 5.21 & 0.00 & 28.83 & 1180 \\
\hline Exp. stock returns: Prob $<-20 \%$ & & 5.16 & 9.87 & 0.00 & 100.00 & 1180 \\
\hline Exp. stock returns: Worsened & & 0.14 & 0.35 & 0.00 & 1.00 & 1422 \\
\hline Exp. foreign stock ret.: Worsened & & 0.21 & 0.41 & 0.00 & 1.00 & 1421 \\
\hline Exp. bond returns: Worsened & & 0.14 & 0.35 & 0.00 & 1.00 & 1421 \\
\hline Risk tolerance & & 47.77 & 31.42 & 0.00 & 100.00 & 1178 \\
\hline Change risk tol. last 4 weeks & & -3.81 & 14.48 & -100.00 & 100.00 & 1161 \\
\hline Any bankruptcies last 4 weeks & & 0.37 & 0.48 & 0.00 & 1.00 & 1422 \\
\hline More bankr. than usual last 4 wks. & & 0.07 & 0.25 & 0.00 & 1.00 & 1422 \\
\hline Affected personally by bankruptcies & & 0.03 & 0.16 & 0.00 & 1.00 & 1422 \\
\hline
\end{tabular}

Notes: This table displays summary statistics on demographics, investment and trading behavior, expectations and risk aversion, and recall of bankruptcies of respondents to our own investor survey conducted in August 2019. In line with the main analysis, the investor sample is restricted to investors with complete information on all relevant variables and response time roughly above the first percentile. Column 1 displays average characteristics of stock investors in the 2017 wave of the Bundesbank's Panel of Household Finances (PHF), which are calculated using population weights. The variables are defined in detail in online appendix D and appendix Table A3. 
Table A3: Variable definitions

\begin{tabular}{ll}
\hline Variable & Definition \\
\hline Trading outcomes in brokerage data: &
\end{tabular}

Trading outcomes in brokerage data:

Sales turnover

Overall turnover

Buy-sell imbalance

Active risky share

beta DAX, CDAX,

MSCI Europe excl.

CDAX, MSCI World

excl. CDAX, GDP

growth
This variable captures sales of risky assets and is defined as $\frac{\text { Shares sold in } t \times \text { Price per share }}{\text { Portfolio value at the beginning of } t}$. We multiply the variable by 100 , so it is expressed as percentage. When there is no sale in a given month, this variable takes value zero.

This variable captures purchases of risky assets and is defined as Phares purchased in $t \times$ Price per share . We multiply the variable by 100 , so it is expressed as percentage. When there is no purchase in a given month, this variable takes value zero.

This variable captures overall trading of risky assets and is defined as $0.5 \times$ Sales turnover $+0.5 \times$ Purchase turnover. We multiply the variable by 100 , so it is expressed as percentage. When there is no trade in a given month, this variable takes value zero. We also calculate overall turnover separately for European, German, European non-German, and non-European equity.

This variable captures an investor's tendency to be a net buyer of risky assets and is defined as $\frac{\text { Value of purchases in } t \text {-Value of sales in } t}{\text { Total value of transactions in } t}$. We multiply the variable by 100 , so it is expressed as percentage. When there is no trade in a given month, this variable takes value zero. We also calculate the buy-sell imbalance separately for European, German, European non-German, and non-European equity.

This variable captures the active adjustment an investor makes to his or her risky portfolio share, abstracting from changes in the risky share due to price changes: $\omega_{i, t}^{a}=\omega_{i, t+1}-\omega_{i, t}^{p}$, where $\omega_{i, t+1}=\frac{P_{i, t+1}}{P_{i, t+1}+C_{i, t+1}}$ and $\omega_{i, t}^{p}=$ $\frac{\omega_{i, t} \times\left(1+r_{t}\right)}{\omega_{i, t} \times\left(1+r_{t}\right)+\left(1-\omega_{i, t}\right)\left(1+r_{f, t}\right)} . P_{i, t}$ is the portfolio value in $\mathrm{t}$ and $C_{i, t}$ are total cash holdings with the bank in t. We multiply the variable by 100 , so it is expressed as percentage. When there is no trade, this variable takes value zero.

These variables capture the portfolio beta relative to different stock market indices (DAX, CDAX, MSCI Europe conditional on the CDAX, MSCI World conditional on the CDAX) and relative to quarterly real German GDP per capita growth (seasonally adjusted). The construction is explained in more detail in appendix C.6.

\section{Main independent variable:}

Bankruptcies 25

The monthly number of bankruptcies within the $25 \mathrm{~km}$-neighborhood of the investor's zip code of residence divided by the previous calendar year's number of firms in the county ("Landkreis") the zip code belongs to. We multiply the variable by 100 , so it is expressed as percentage. Our data cover approximately 3,500 zip codes. We employ the following variations of this variable: Bankruptcies 50, Bankruptcies 100, Bankruptcies 200 accumulate bankruptcies within the 50-, 100-, 200-km-neighborhood of the investor's zip code, respectively. Bankruptcies 25-50, Bankruptcies 50-100, Bankruptcies 100-200 accumulate bankruptcies over 25-50, 50-100, 100-200 km intervals. Bankruptcies ex 25 is the number of bankruptcies occurring outside the $25-\mathrm{km}$ radius. All of the measures varying spatial proximity are divided by the previous year's number of registered firms in the county the zip code belongs to. Bankruptcies 1 month, 2 months, 3 months, 6 months, 9 months, 12 months accumulate local bankruptcies within the 25-km radius to the respective time period, and are divided by the number of firms. We also calculate the bankruptcies measure excluding private bankruptcies, the $\log$ of the bankruptcies measure, dummies for whether the bankruptcies measure is above or below the zip-code level median among observations from this zip code over the sample period, and a variable reaching from one to four indicating the quartile among observations from that zip code over the sample period the observation falls into. We also use the raw number and the log raw number of bankruptcies, which are not scaled by the number of firms.

Notes: This table provides definitions of variables from the brokerage and survey datasets as well as of geographical and macroeconomic variables used in the analysis. 
Table A3 (continued): Variable definitions

\begin{tabular}{|c|c|}
\hline Variable & Definition \\
\hline \multicolumn{2}{|c|}{ Investor controls in brokerage data: } \\
\hline Ln Wealth ${ }_{t-1}$ & $\begin{array}{l}\text { The natural logarithm of the euro value of the investor's total wealth held with } \\
\text { the brokerage, multiplied by } 100 \text {, as measured at the end of the previous month. }\end{array}$ \\
\hline Personal Return $_{t-1}$ & $\begin{array}{l}\text { The return on the investor's portfolio, expressed in percent, over the previous } \\
\text { month. }\end{array}$ \\
\hline \multicolumn{2}{|l|}{ Geographical variables: } \\
\hline Local unemployment & $\begin{array}{l}\text { The end-of-month county-level unemployment rate, expressed in percent. Our } \\
\text { data cover approximately } 400 \text { counties. }\end{array}$ \\
\hline Ln local GDP & $\begin{array}{l}\text { The natural logarithm of the previous calendar year's county-level GDP per } \\
\text { capita, multiplied by } 100 \text {. Our data cover approximately } 400 \text { counties. }\end{array}$ \\
\hline Local Return 25 & $\begin{array}{l}\text { The monthly value-weighted average return on the stocks of all publicly listed } \\
\text { firms within the } 25 \mathrm{~km} \text {-neighborhood of the investor's zip code, expressed in } \\
\text { percent. The stocks of local public bankrupt firms are not contained in this } \\
\text { index. Our data cover approximately } 3,500 \text { zip codes. }\end{array}$ \\
\hline Local Spending Capacity & $\begin{array}{l}\text { An index of purchasing power based on average net disposable income per capita } \\
\text { at the zip code-year level, that is calculated by the market research company } \\
\text { Gesellschaft für Konsumforschung (GfK). It is available for the years 2008-2010. } \\
\text { The index is expressed relative to the national average, which is set to } 100 \text {. }\end{array}$ \\
\hline
\end{tabular}

\section{Macroeconomic variables:}

Aggregate Unemployment The end-of-month national unemployment rate, expressed in percent.

VDAX

ZEW DAX forecast

Summer Holidays

CDAX Return

\section{Survey variables:}

Trade, Net buy, Net sell, Rebalance (realized)

Trade, Net buy, Net sell, Rebalance (planned)
The monthly level of the index tracking the implied volatility of the German stock market index DAX.

The 6 month-ahead outlook for the performance of the German stock market index (DAX) among participants of the Centre for European Economic Research (ZEW) Financial Market Survey of professional forecasters. We calculate the average expectation about the 6-month ahead DAX return by for each participant subtracting the forecast about the level in 6 months from the current level and dividing by the current level and subsequently averaging across respondents.

A dummy indicating the month of the summer school holidays in the state of residence.

The monthly return of the German stock market index CDAX, expressed in percent.

Dummy variables indicating whether over the previous four weeks the investor reports to have traded with equity, have been a net seller of equity, have been a net buyer of equity, or having traded but only rebalanced his or her equity holdings.

Dummy variables indicating whether over the next four weeks the investor reports to plan to trade with equity, to be a net seller of equity, to be a net buyer of equity, or to trade and only rebalance his or her equity holdings.

Notes: This table provides definitions of variables from the brokerage and survey datasets as well as of geographical and macroeconomic variables used in the analysis. 
Table A3 (continued): Variable definitions

\begin{tabular}{ll}
\hline Variable & Definition \\
\hline Survey variables (continued): &
\end{tabular}

Survey variables (continued)

Expected income The mean of the respondent's subjective probability distribution over the growth growth: Mean of total net household labor income over the following 12 months. Midpoints are assigned to the different bins. The variable is coded as percentage.

Expected income The standard deviation of the respondent's subjective probability distribution growth: SD over the growth of total net household labor income over the following 12 months. Midpoints are assigned to the different bins. The variable is coded as percentage.

Expected income growth: Probability<$20 \%$

The percent probability the respondent assigns to a drop in total net household labor income over the following 12 months by more than 20 percent.

Expected income growth: Worsened

A dummy variable indicating whether the respondent reports that his or her prospects for the growth of total net household labor income over the following 12 months have worsened over the previous four weeks.

Expected GDP growth: Worsened

Change risk tolerance

A dummy variable indicating whether the respondent reports that his or her prospects for the growth of German real GDP over the following 12 months have worsened over the previous four weeks.

The difference between the percent share of a hypothetical portfolio of $€ 1,000$ the respondent would allocate to a risky asset with a return distribution that is orthogonal to any actual stock market (instead of allocating it to a safe asset paying a return of 2 percent) now and the share he or she would have allocated to the risky asset four weeks ago.

Expected stock returns: Mean

The mean of the respondent's subjective probability distribution over the return of the German stock market index (DAX) over the following 12 months. Historical conditional mean realizations are assigned to the different bins. The variable is coded as percentage.

Expected stock returns: $\mathrm{SD}$

The standard deviation of the respondent's subjective probability distribution over the return of the German stock market index (DAX) over the following 12 months. Historical conditional mean realizations are assigned to the different bins. The variable is coded as percentage.

Expected stock returns: Probability $<-20 \%$

The percent probability the respondent assigns to a drop in the value of the German stock market index (DAX) over the following 12 months by more than 20 percent.

Expected stock returns: Worsened

A dummy variable indicating whether the respondent reports that his or her prospects for the return of the German stock market (DAX) over the following 12 months have worsened over the previous four weeks.

Expected foreign returns: Worsened

A dummy variable indicating whether the respondent reports that his or her prospects for the return of a diversified portfolio of foreign stocks over the following 12 months have worsened over the previous four weeks.

Expected bond returns: Worsened

A dummy variable indicating whether the respondent reports that his or her prospects for the return of German 10-year government bonds over the following 12 months have worsened over the previous four weeks.

More bankruptcies than

A dummy variable indicating whether a respondent reports that he or she has noticed more bankruptcies than usual in their county of residence over the previous four weeks.

Notes: This table provides definitions of variables from the brokerage and survey datasets as well as of geographical and macroeconomic variables used in the analysis. 
Table A4: Brokerage data: Robustness

\begin{tabular}{|c|c|c|c|}
\hline & $\frac{\text { Turnover }}{(1)}$ & $\begin{array}{c}\text { Buy-Sell } \\
\text { Imbalance } \\
(2)\end{array}$ & $\begin{array}{c}\text { Active } \\
\text { Risky Share } \\
(3)\end{array}$ \\
\hline \multicolumn{4}{|l|}{ Panel A: Sample Restrictions } \\
\hline All Investors & $\begin{array}{l}0.432^{* *} \\
(0.164)\end{array}$ & $\begin{array}{c}-0.762^{*} \\
(0.395)\end{array}$ & $\begin{array}{c}-0.211^{* * *} \\
(0.076)\end{array}$ \\
\hline Controls and Fixed Effects & Yes & Yes & Yes \\
\hline Adj. R-squared & .392 & .007 & .022 \\
\hline Observations & 3154817 & 3111971 & 3111971 \\
\hline More than 0.5 trades per year & $\begin{array}{c}0.461^{* * *} \\
(0.172)\end{array}$ & $\begin{array}{c}-0.825^{* *} \\
(0.387)\end{array}$ & $\begin{array}{c}-0.227^{* * *} \\
(0.079)\end{array}$ \\
\hline Controls and Fixed Effects & Yes & Yes & Yes \\
\hline Adj. R-squared & .39 & .008 & .024 \\
\hline Observations & 2997690 & 2956514 & 2956514 \\
\hline More than 1 trade per year (Baseline) & $\begin{array}{c}0.482^{* * *} \\
(0.180)\end{array}$ & $\begin{array}{c}-0.816^{* *} \\
(0.396)\end{array}$ & $\begin{array}{c}-0.228^{* * *} \\
(0.082)\end{array}$ \\
\hline Controls and Fixed Effects & Yes & Yes & Yes \\
\hline Adj. R-squared & .388 & .008 & .025 \\
\hline Observations & 2822181 & 2783109 & 2783109 \\
\hline More than 2 trades per year & $\begin{array}{c}0.555^{* * *} \\
(0.198)\end{array}$ & $\begin{array}{c}-0.834^{* *} \\
(0.402)\end{array}$ & $\begin{array}{c}-0.245^{* * *} \\
(0.090)\end{array}$ \\
\hline Controls and Fixed Effects & Yes & Yes & Yes \\
\hline Adj. R-squared & .387 & .008 & .028 \\
\hline Observations & 2539073 & 2503676 & 2503676 \\
\hline Only years with at least one trade & $\begin{array}{c}0.496^{* *} \\
(0.190)\end{array}$ & $\begin{array}{c}-0.889^{* *} \\
(0.439)\end{array}$ & $\begin{array}{c}-0.241^{* * *} \\
(0.087)\end{array}$ \\
\hline Controls and Fixed Effects & Yes & Yes & Yes \\
\hline Adj. R-squared & .391 & .009 & .027 \\
\hline Observations & 2765332 & 2727376 & 2727376 \\
\hline
\end{tabular}

Notes: This table provides robustness checks of the estimated effect of local bankruptcies on trading and risk-taking. It displays OLS estimates of the fixed effects model in equation 1 (column 1) and the first difference model in equation 2 (columns 2-3), unless mentioned differently in the footnote. The dependent variables capture portfolio turnover and changes in risk-taking as defined in section 2 . The main independent variable, Bankruptcies $25_{t}$, is the number of monthly bankruptcies within a $25-\mathrm{km}$ radius around an investor's home zip code, scaled by the previous year end's number of firms in the county of residence, unless mentioned differently in the footnote. The independent variable and the dependent variables are expressed as percentages. All specifications include fixed effects for each month of the sample period and control for the recent monthly return on the investor's portfolio and the log of the total wealth of the investor, both measured at the end of the previous month, for the log of GDP per capita in the county of residence over the previous calendar year, and current and last month's values of both the county-level unemployment rate and the value-weighted average monthly return on the stocks of local publicly listed firms. Controls are coded as monthly changes in the first difference specifications in columns 2-3. All variables are defined in more detail in appendix Table A3. The sample period is January 2007 to November 2012. The sample is restricted to active investors (more than one yearly trade on average during their time in the sample), with complete information on all relevant variables, and with valid information on zip code of residence, unless mentioned differently in the footnote. Standard errors that are two-way clustered by investor and time period are in parentheses. ${ }^{*}$ denotes significance at 10 pct., ** at 5 pct., and $* * *$ at 1 pct. level. Panel A applies different thresholds for inclusion in the working sample, showing results for all investors, those with more than 0.5 yearly trades on average, those with more than 1 yearly trade on average (baseline estimates), those with more than 2 yearly trades on average, or for each investor using only years where this investor trades at least once. 
Table A4 (continued): Brokerage data: Robustness

\begin{tabular}{|c|c|c|c|}
\hline & $\frac{\text { Turnover }}{(1)}$ & $\begin{array}{c}\text { Buy-Sell } \\
\text { Imbalance } \\
(2)\end{array}$ & $\begin{array}{c}\begin{array}{c}\text { Active } \\
\text { Risky Share }\end{array} \\
(3)\end{array}$ \\
\hline \multicolumn{4}{|c|}{ Panel B: Bankruptcy Measures (Scaled) } \\
\hline Private Bankruptcies Only & $\begin{array}{c}0.480^{* * *} \\
(0.180)\end{array}$ & $\begin{array}{c}-0.880^{* *} \\
(0.405)\end{array}$ & $\begin{array}{c}-0.255^{* * *} \\
(0.085)\end{array}$ \\
\hline Controls and Fixed Effects & Yes & Yes & Yes \\
\hline Adj. R-squared & .388 & .008 & .025 \\
\hline Observations & 2822177 & 2783109 & 2783109 \\
\hline Log Bankruptcies & $\begin{array}{c}0.558^{* *} \\
(0.247)\end{array}$ & $\begin{array}{c}-1.287^{* *} \\
(0.519)\end{array}$ & $\begin{array}{c}-0.298^{* * *} \\
(0.109)\end{array}$ \\
\hline Controls and Fixed Effects & Yes & Yes & Yes \\
\hline Adj. R-squared & .388 & .008 & .025 \\
\hline Observations & 2822177 & 2783109 & 2783109 \\
\hline Dummy Bankruptcies > Mean & $\begin{array}{l}0.050^{* *} \\
(0.021)\end{array}$ & $\begin{array}{l}-0.067 \\
(0.041)\end{array}$ & $\begin{array}{l}-0.013 \\
(0.010)\end{array}$ \\
\hline Controls and Fixed Effects & Yes & Yes & Yes \\
\hline Adj. R-squared & .388 & .008 & .025 \\
\hline Observations & 2822177 & 2783109 & 2783109 \\
\hline Dummy Bankruptcies > Median & $\begin{array}{c}0.042^{*} \\
(0.022)\end{array}$ & $\begin{array}{l}-0.061 \\
(0.041)\end{array}$ & $\begin{array}{l}-0.013 \\
(0.009)\end{array}$ \\
\hline Controls and Fixed Effects & Yes & Yes & Yes \\
\hline Adj. R-squared & .388 & .008 & .025 \\
\hline Observations & 2822177 & 2783109 & 2783109 \\
\hline Quartile Bankruptcies & $\begin{array}{l}0.022^{* *} \\
(0.010)\end{array}$ & $\begin{array}{c}-0.050^{* *} \\
(0.023)\end{array}$ & $\begin{array}{l}-0.010^{*} \\
(0.005)\end{array}$ \\
\hline Controls and Fixed Effects & Yes & Yes & Yes \\
\hline Adj. R-squared & .388 & .008 & .025 \\
\hline Observations & 2822177 & 2783108 & 2783108 \\
\hline
\end{tabular}

Notes: Panel B displays different transformations of the main bankruptcies measure (bankruptcies scaled by the previous year end's number of firms), specifically: basing the bankruptcies measure only on nonpublicly listed firms, taking the log of the bankruptcies measure, dummies for whether the bankruptcies measure is above the sample mean or median, and a variable reaching from one to four indicating in which quartile among observations from that zip code over the sample period the bankruptcies measure lies. 
Table A4 (continued): Brokerage data: Robustness

\begin{tabular}{|c|c|c|c|}
\hline & $\frac{\text { Turnover }}{(1)}$ & $\begin{array}{c}\text { Buy-Sell } \\
\text { Imbalance } \\
(2)\end{array}$ & $\begin{array}{c}\text { Active } \\
\text { Risky Share } \\
(3)\end{array}$ \\
\hline \multicolumn{4}{|c|}{ Panel C: Bankruptcy Measures (Unscaled) } \\
\hline Raw Number of Bankruptcies & $\begin{array}{c}0.005^{* * *} \\
(0.002)\end{array}$ & $\begin{array}{c}-0.009^{* *} \\
(0.004)\end{array}$ & $\begin{array}{c}-0.001 \\
(0.001)\end{array}$ \\
\hline Controls and Fixed Effects & Yes & Yes & Yes \\
\hline Adj. R-squared & .388 & .008 & .025 \\
\hline Observations & 2822177 & 2783109 & 2783109 \\
\hline Log Raw Number of Bankruptcies & $\begin{array}{c}0.036 \\
(0.036)\end{array}$ & $\begin{array}{c}-0.212^{* * *} \\
(0.077)\end{array}$ & $\begin{array}{c}-0.038^{* *} \\
(0.017)\end{array}$ \\
\hline Controls and Fixed Effects & Yes & Yes & Yes \\
\hline Adj. R-squared & .388 & .008 & .025 \\
\hline Observations & 2822177 & 2783109 & 2783109 \\
\hline
\end{tabular}

Panel D: Fixed Effect Specifications

Bankruptcies $25_{t}$

$\begin{array}{ccc}0.482^{* * *} & -1.050^{*} & -0.196^{* *} \\ (0.180) & (0.605) & (0.094) \\ \text { Yes } & \text { Yes } & \text { Yes } \\ .388 & .286 & .015 \\ 2822177 & 2822177 & 2822177\end{array}$

Controls and Fixed Effects

Adj. R-squared

Observations

2822177 822177

\section{Panel E: Weighted Least Squares Specification (Zip Code)}

Bankruptcies $25_{t}$

$\begin{array}{ccc}0.479^{* *} & -0.884^{* *} & -0.157^{*} \\ (0.185) & (0.400) & (0.086) \\ \text { Yes } & \text { Yes } & \text { Yes } \\ .426 & .043 & .118 \\ 439338 & 425908 & 425908\end{array}$

Controls and Fixed Effects

Adj. R-squared

439338

425908

425908

\section{Panel F: Quarter x State Fixed Effects}

$\begin{array}{lccc}\text { Bankruptcies } 25_{t} & 0.420^{* *} & -0.755 & -0.212^{* *} \\ \text { Controls and Fixed Effects } & (0.188) & (0.494) & (0.094) \\ \text { Adj. R-squared } & \text { Yes } & \text { Yes } & \text { Yes } \\ \text { Observations } & .383 & .008 & .025 \\ \text { Pans } & 2803852 & 2782998 & 2782998\end{array}$

Notes: Panel C displays alternative independent variables based on the raw number of bankruptcies, not scaled by the number of firms in the county, specifically the raw number of bankruptcies (which is trimmed at the 95th percentile to account for the greater impact of outliers in this measure) and the log raw number of bankruptcies. Panel D uses the fixed effects specification 1 not only for the outcomes on turnover, but also for the buy-sell imbalance and the active change in the risky share, thereby controlling for investor-specific linear trends in risk-taking over the sample period. Panel E collapses the dataset at the zip code-month level and estimates weighted least squares regressions, where observations are weighted by the number of investor observations in the zip code in the relevant month. Panel $\mathrm{F}$ adds the interaction of quarter and state of residence fixed effects to the baseline model. 
Table A5: Investor survey: Robustness

\begin{tabular}{|c|c|c|c|c|c|c|c|c|}
\hline & $\begin{array}{c}\text { Trade: } \\
\text { Last } 4 \text { wks. }\end{array}$ & $\begin{array}{c}\text { Net sell: } \\
\text { Last } 4 \text { wks. }\end{array}$ & $\begin{array}{c}\begin{array}{c}\text { Trade: } \\
\text { Next } 4 \mathrm{wks} .\end{array} \\
(3)\end{array}$ & $\begin{array}{c}\text { Net sell: } \\
\text { Next } 4 \text { wks. }\end{array}$ & $\begin{array}{c}\begin{array}{c}\text { Change } \\
\text { risk } \\
\text { tolerance }\end{array} \\
\frac{(5)}{(5)}\end{array}$ & $\begin{array}{c}\begin{array}{c}\text { Exp. stock } \\
\text { returns: } \\
\text { Mean }\end{array} \\
(6)\end{array}$ & 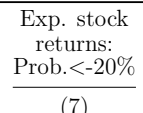 & 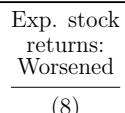 \\
\hline \multicolumn{9}{|l|}{ Panel A: Baseline } \\
\hline $\begin{array}{l}\text { More bankruptcies than } \\
\text { usual last } 4 \text { weeks }\end{array}$ & $\begin{array}{c}0.174^{* * *} \\
(0.052)\end{array}$ & $\begin{array}{c}0.201^{* * *} \\
(0.047)\end{array}$ & $\begin{array}{c}0.264^{* * *} \\
(0.049)\end{array}$ & $\begin{array}{c}0.164^{* * *} \\
(0.045)\end{array}$ & $\begin{array}{l}-5.493^{* *} \\
(2.745)\end{array}$ & $\begin{array}{c}-2.251^{* *} \\
(1.116)\end{array}$ & $\begin{array}{l}4.093^{* *} \\
(1.978)\end{array}$ & $\begin{array}{l}0.091^{* *} \\
(0.046)\end{array}$ \\
\hline Adj. R-squared & .096 & .039 & .108 & .034 & .016 & .012 & .018 & .019 \\
\hline Observations & 1422 & 1422 & 1422 & 1422 & 1161 & 1180 & 1315 & 1422 \\
\hline \multicolumn{9}{|c|}{ Panel B: Not pers. affected } \\
\hline $\begin{array}{l}\text { More bankruptcies than } \\
\text { usual last } 4 \text { weeks }\end{array}$ & $\begin{array}{l}0.182^{* * *} \\
(0.056)\end{array}$ & $\begin{array}{l}0.178^{* * *} \\
(0.050)\end{array}$ & $\begin{array}{c}0.297^{* * *} \\
(0.052)\end{array}$ & $\begin{array}{l}0.175^{* * *} \\
(0.048)\end{array}$ & $\begin{array}{l}-4.965^{* *} \\
(2.499)\end{array}$ & $\begin{array}{l}-2.146^{*} \\
(1.185)\end{array}$ & $\begin{array}{l}3.880^{*} \\
(2.179)\end{array}$ & $\begin{array}{l}0.111^{* *} \\
(0.050)\end{array}$ \\
\hline Adj. R-squared & .095 & .028 & .11 & .035 & .014 & .013 & .019 & .019 \\
\hline Observations & 1383 & 1383 & 1383 & 1383 & 1141 & 1160 & 1283 & 1383 \\
\hline \multicolumn{9}{|c|}{ Panel C: Fine-grained geogr. FE } \\
\hline $\begin{array}{l}\text { More bankruptcies than } \\
\text { usual last } 4 \text { weeks }\end{array}$ & $\begin{array}{c}0.172^{* * *} \\
(0.053)\end{array}$ & $\begin{array}{c}0.193^{* * *} \\
(0.047)\end{array}$ & $\begin{array}{c}0.271^{* * *} \\
(0.051)\end{array}$ & $\begin{array}{c}0.152^{* * *} \\
(0.046)\end{array}$ & $\begin{array}{l}-5.266^{*} \\
(2.789)\end{array}$ & $\begin{array}{l}-2.352^{* *} \\
(1.092)\end{array}$ & $\begin{array}{l}3.939^{* *} \\
(1.874)\end{array}$ & $\begin{array}{l}0.092^{* *} \\
(0.046)\end{array}$ \\
\hline Adj. R-squared & .101 & .041 & .096 & .043 & .033 & .016 & .021 & .025 \\
\hline Observations & 1422 & 1422 & 1422 & 1422 & 1161 & 1180 & 1315 & 1422 \\
\hline \multicolumn{9}{|c|}{ Panel D: Cluster coarser geogr. level } \\
\hline $\begin{array}{l}\text { More bankruptcies than } \\
\text { usual last } 4 \text { weeks }\end{array}$ & $\begin{array}{c}0.174^{* * *} \\
(0.048)\end{array}$ & $\begin{array}{c}0.201^{* * *} \\
(0.049)\end{array}$ & $\begin{array}{c}0.264^{* * *} \\
(0.050)\end{array}$ & $\begin{array}{c}0.164^{* * *} \\
(0.044)\end{array}$ & $\begin{array}{c}-5.493^{* *} \\
(2.612)\end{array}$ & $\begin{array}{l}-2.251^{*} \\
(1.214)\end{array}$ & $\begin{array}{l}4.093^{*} \\
(2.400)\end{array}$ & $\begin{array}{l}0.091^{*} \\
(0.048)\end{array}$ \\
\hline Adj. R-squared & .096 & .039 & .108 & .034 & .016 & .012 & .018 & .019 \\
\hline Observations & 1422 & 1422 & 1422 & 1422 & 1161 & 1180 & 1315 & 1422 \\
\hline Individual controls & Yes & Yes & Yes & Yes & Yes & Yes & Yes & Yes \\
\hline
\end{tabular}

Notes: This table provides robustness checks of the results on the effect of recall of local bankruptcies on trading, expectations and risk aversion of respondents to our own investor survey conducted in August 2019 using OLS. The dependent variables capture trading behavior, (changes in) expectations and risk aversion as explained in sections 3.4 and 4.2 in the main text. The main independent variable, More bankruptcies than usual last 4 weeks, is a dummy variable taking value one if an investor reports to have noticed more bankruptcies than usual in his or her county of residence. The dependent variables in columns 1-4 are dummy variables indicating whether the investor traded with equity, was a net buyer, was a net seller, or only rebalanced the portfolio over the last four weeks. The dependent variables in columns 5-7 are expressed as percentages. The outcome variables in column 8 is a dummy variable taking value one if the respondent indicates that his or her outlook regarding stock returns has worsened over the last four weeks. Panel A displays the baseline estimates. Panel B excludes investors who report that they have been in any way personally affected by bankruptcies over the last four weeks. Panel C includes more fine-grained geographical fixed effects defined by the first two digits of a respondent's zip code. Panel D clusters standard errors at the first two digits of a respondent's zip code instead of clustering at the respondent level. All specifications control for gender, age, education, employment status, household income, household net wealth, participation in different asset classes, and state ("Bundesland") of residence. The variables are defined in detail in online appendix D and appendix Table A3. The sample is restricted to investors with complete information on all relevant variables and response time roughly above the first percentile. Robust standard errors are in parentheses. * denotes significance at 10 pct., ** at 5 pct., and $* * *$ at 1 pct. level. 
Table A6: News coverage of bankruptcies and actual bankruptcies

\begin{tabular}{|c|c|c|c|c|c|c|c|}
\hline & \multicolumn{7}{|c|}{ Number Insolvencies Newspaper $(\mathrm{z})_{t}$} \\
\hline & (1) & $(2)$ & $(3)$ & (4) & $(5)$ & (6) & (7) \\
\hline Bankruptcies $(\mathrm{z})_{t}$ & $\begin{array}{c}0.197^{* * *} \\
(0.037)\end{array}$ & $\begin{array}{c}0.179^{* * *} \\
(0.037)\end{array}$ & $\begin{array}{c}0.174^{* * *} \\
(0.037)\end{array}$ & $\begin{array}{c}0.168^{* * *} \\
(0.038)\end{array}$ & $\begin{array}{c}0.162^{* * *} \\
(0.040)\end{array}$ & $\begin{array}{c}0.170^{* * *} \\
(0.040)\end{array}$ & $\begin{array}{c}0.163^{* * *} \\
(0.042)\end{array}$ \\
\hline $\operatorname{Bankruptcies}(\mathrm{z})_{t-1}$ & & $\begin{array}{l}0.096^{* *} \\
(0.037)\end{array}$ & $\begin{array}{c}0.084^{* *} \\
(0.038)\end{array}$ & $\begin{array}{l}0.082^{* *} \\
(0.039)\end{array}$ & $\begin{array}{c}0.066^{*} \\
(0.040)\end{array}$ & $\begin{array}{c}0.063 \\
(0.041)\end{array}$ & $\begin{array}{c}0.071^{*} \\
(0.041)\end{array}$ \\
\hline Bankruptcies $(\mathrm{z})_{t-2}$ & & & $\begin{array}{c}0.048 \\
(0.039)\end{array}$ & $\begin{array}{c}0.042 \\
(0.040)\end{array}$ & $\begin{array}{c}0.033 \\
(0.040)\end{array}$ & $\begin{array}{c}0.018 \\
(0.041)\end{array}$ & $\begin{array}{c}0.018 \\
(0.043)\end{array}$ \\
\hline $\operatorname{Bankruptcies}(\mathrm{z})_{t-3}$ & & & & $\begin{array}{c}0.030 \\
(0.040)\end{array}$ & $\begin{array}{c}0.015 \\
(0.041)\end{array}$ & $\begin{array}{c}0.014 \\
(0.041)\end{array}$ & $\begin{array}{c}0.009 \\
(0.043)\end{array}$ \\
\hline Bankruptcies $(\mathrm{z})_{t-4}$ & & & & & $\begin{array}{l}0.102^{* *} \\
(0.042)\end{array}$ & $\begin{array}{c}0.091^{* *} \\
(0.043)\end{array}$ & $\begin{array}{l}0.091^{* *} \\
(0.044)\end{array}$ \\
\hline $\operatorname{Bankruptcies}(\mathrm{z})_{t-5}$ & & & & & & $\begin{array}{c}0.044 \\
(0.039)\end{array}$ & $\begin{array}{c}0.047 \\
(0.040)\end{array}$ \\
\hline Bankruptcies $(\mathrm{z})_{t-6}$ & & & & & & & $\begin{array}{c}0.014 \\
(0.038)\end{array}$ \\
\hline Newspaper Region FE & Yes & Yes & Yes & Yes & Yes & Yes & Yes \\
\hline R-squared & .15 & .169 & .172 & .173 & .181 & .182 & .18 \\
\hline Observations & 700 & 686 & 672 & 658 & 644 & 630 & 616 \\
\hline
\end{tabular}

Notes: This table examines the effect of (lagged) bankruptcies on coverage of bankruptcies in the local newspaper. It displays the effect of contemporaneous monthly local bankruptcies (column 1) and adds up to six monthly lags of local bankruptcies (columns 2-7). Number Insolvencies Newspaper $(\mathrm{z})_{t}$ is the monthly number of mentions of the word "bankruptcy" ("Insolvenz" in German) in the newspaper, z-scored using the mean and standard deviation for that newspaper over the sample period. Bankruptcies $(z)_{t}$ is the number of monthly bankruptcies within the region of the newspaper scaled by the previous year end's number of firms in that region, z-scored using the mean and standard deviation for that newspaper over the sample period. Bankruptcies $(z)_{t-k}$ indicates the $\mathrm{k}$-th lag of this monthly bankruptcies measure. The sample period is January 2007 to November 2012. The sample is based on the 12 newspapers for which data on bankruptcies coverage is available. Robust standard errors are in parentheses. * denotes significance at 10 pct., ** at 5 pct., and *** at 1 pct. level. 
Table A7: Google searches and actual bankruptcies

\begin{tabular}{|c|c|c|c|c|c|c|c|}
\hline & \multicolumn{7}{|c|}{ Google Searches $(\mathrm{z})_{t}$} \\
\hline & (1) & (2) & (3) & (4) & (5) & (6) & (7) \\
\hline Bankruptcies $(\mathrm{z})_{t}$ & $\begin{array}{c}0.405^{* * *} \\
(0.076)\end{array}$ & $\begin{array}{c}0.339^{* * *} \\
(0.056)\end{array}$ & $\begin{array}{c}0.286^{* * *} \\
(0.048)\end{array}$ & $\begin{array}{c}0.210^{* * *} \\
(0.047)\end{array}$ & $\begin{array}{c}0.221^{* * *} \\
(0.053)\end{array}$ & $\begin{array}{c}0.219^{* * *} \\
(0.055)\end{array}$ & $\begin{array}{c}0.230^{* * *} \\
(0.061)\end{array}$ \\
\hline Bankruptcies $(\mathrm{z})_{t-1}$ & & $\begin{array}{c}0.195^{* * *} \\
(0.060)\end{array}$ & $\begin{array}{l}0.154^{* *} \\
(0.061)\end{array}$ & $\begin{array}{c}0.118^{*} \\
(0.061)\end{array}$ & $\begin{array}{c}0.056 \\
(0.063)\end{array}$ & $\begin{array}{c}0.085 \\
(0.062)\end{array}$ & $\begin{array}{c}0.035 \\
(0.059)\end{array}$ \\
\hline Bankruptcies $(\mathrm{z})_{t-2}$ & & & $\begin{array}{l}0.143^{* *} \\
(0.052)\end{array}$ & $\begin{array}{c}0.109^{*} \\
(0.054)\end{array}$ & $\begin{array}{c}0.081 \\
(0.062)\end{array}$ & $\begin{array}{c}0.045 \\
(0.062)\end{array}$ & $\begin{array}{c}0.058 \\
(0.053)\end{array}$ \\
\hline Bankruptcies $(z)_{t-3}$ & & & & $\begin{array}{l}0.183^{* *} \\
(0.070)\end{array}$ & $\begin{array}{l}0.161^{* *} \\
(0.071)\end{array}$ & $\begin{array}{l}0.152^{*} \\
(0.082)\end{array}$ & $\begin{array}{c}0.097 \\
(0.084)\end{array}$ \\
\hline Bankruptcies $(\mathrm{z})_{t-4}$ & & & & & $\begin{array}{c}0.143^{* *} \\
(0.063)\end{array}$ & $\begin{array}{l}0.161^{* *} \\
(0.066)\end{array}$ & $\begin{array}{l}0.160^{*} \\
(0.075)\end{array}$ \\
\hline Bankruptcies $(\mathrm{z})_{t-5}$ & & & & & & $\begin{array}{l}-0.049 \\
(0.045)\end{array}$ & $\begin{array}{l}-0.016 \\
(0.044)\end{array}$ \\
\hline Bankruptcies $(\mathrm{z})_{t-6}$ & & & & & & & $\begin{array}{l}-0.011 \\
(0.052)\end{array}$ \\
\hline State FE & Yes & Yes & Yes & Yes & Yes & Yes & Yes \\
\hline R-squared & .162 & .204 & .216 & .227 & .241 & .225 & .207 \\
\hline Observations & 1136 & 1040 & 944 & 848 & 752 & 656 & 560 \\
\hline
\end{tabular}

Notes: This table examines the effect of (lagged) bankruptcies on Google searches for the word "bankruptcy" ("Insolvenz" in German). It displays the effect of contemporaneous monthly statelevel bankruptcies (column 1) and adds up to six monthly lags of bankruptcies (columns 2-7). Google Searches $(\mathrm{z})_{t}$ is a measure of monthly Google searches, z-scored using the mean and standard deviation for that state over the sample period. Bankruptcies $(\mathrm{z})_{t}$ is the number of monthly bankruptcies within the state scaled by the previous year end's number of firms in that state, z-scored using the mean and standard deviation for that state over the sample period. Bankruptcies $(\mathrm{z})_{t-k}$ indicates the $\mathrm{k}$-th lag of this monthly bankruptcies measure. The sample period is January 2007 to November 2012. Robust standard errors are in parentheses. ${ }^{*}$ denotes significance at 10 pct., ${ }^{* *}$ at 5 pct., and ${ }^{* * *}$ at 1 pct. level. 


\section{Data appendix: Brokerage data and main working sample}

This appendix provides additional information on the sources, definition, construction, scaling and transformation of variables used in the main analysis on the brokerage dataset. Table A3 provides an overview of the variables used in the analysis.

\section{C.1 Scaling of bankruptcy measure}

We divide the monthly number of firm bankruptcies within an investor's 25-km neighborhood by the previous year-end number of registered firms in the associated county ("Landkreis"), which is provided by the German Statistical Office. The scaling captures that investors living in zip codes with more registered companies are exposed to both many healthy firms and many bankrupt firms. Germany is structured into 397 distinct counties. On average, each county comprises 16 zip codes. Overall, 3,751,481 firms were registered in Germany in 2006, with 90 percent of them having fewer than nine employees, similar to our bankruptcy sample.

\section{C.2 Investor data}

We calculate the return on the investors' portfolio over the preceding month, which has been shown to be an important determinant of trading activity (Goetzmann et al., 2014; Grinblatt and Keloharju, 2001; Shefrin and Statman, 1985; Statman et al., 2006).

\section{C.3 Local geographical variables}

Data on economic conditions are not available at the zip code level. We therefore obtain yearly GDP from the German Federal Statistical Office as well as monthly unemployment from the Federal Employment Agency at the less fine-grained county level ("Landkreis"). Controlling for local business cycles at the county level should be sufficient i) because the average county is smaller $\left(890 \mathrm{~km}^{2}\right)$ than the area covered by the $25 \mathrm{~km}$-radius around a zip code used to calculate the local bankruptcy measure $\left(1963 \mathrm{~km}^{2}\right)$, and ii) because local business cycles usually extend beyond a $25 \mathrm{~km}$-radius (Addoum et al., 2019). In our main analysis we control for the county-level unemployment rate in the current and the preceding month and the log of county-level GDP per capita over the preceding calendar year. We also calculate the monthly value-weighted average return on stocks of all publicly listed firms within the $25-\mathrm{km}$ radius around an investor's home zip code, which we include contemporaneously and with one lag in our estimations. Note that this measure already excludes those publicly listed firms which have gone bankrupt, which in 
any case only account for 1.5 percent of all bankrupt firms in our sample, with the rest being privately held firms.

\section{C.4 Macroeconomic variables}

In some of our analyses we make use of a set of macroeconomic variables. We obtain monthly returns of the CDAX (the composite stock market index of all stocks that are listed in the General Standard or Prime Standard market segments at the Frankfurt Stock Exchange) and on the VDAX (an index tracking the implied volatility of the German stock market index DAX) from Thomson Reuters Datastream. Moreover, we use a measure of monthly expert forecasts of the 6 month-ahead performance of the German stock market index DAX among participants of the Centre for European Economic Research (ZEW) Financial Market Survey of professional forecasters, based on the average forecast about the percent change of the level of the DAX over the next six months. We also make use of quarterly data on real GDP per capita as well as monthly data on national unemployment, both being seasonally adjusted.

\section{C.5 Classification of industries}

We classify employed investors in our sample according to the type of industry that they work in. Previous literature finds that individuals working, for example, in construction, manufacturing or finance are more strongly affected by economic fluctuations, while individuals working in health, education or the public sector are not as strongly exposed (Guvenen et al., 2017; Takhtamanova and Sierminska, 2016). We follow this classification for the relevant robustness check reported in section 3.5, which results in dropping those 55 percent of investors who should be most strongly exposed to economic fluctuations. Specifically, we classify individuals working in construction, manufacturing, wholesale and retail, tourism, transportation, services and finance as working in cyclical industries; and investors working in agriculture, communication services and information technology, education, health, law, media and entertainment, pharmaceuticals, public services, real estate, research, and utilities as working in non-cyclical industries.

Similarly, we classify individuals into those working in the tradables sector and those working in the non-tradable sector, loosely following the classification by Mian and Sufi (2014). For the relevant robustness check reported in section 3.5 we drop those 63 percent of investors who work in the non-tradable sector and whose labor income should therefore be more strongly exposed to the local economy. Specifically, we classify individuals working in construction, finance, health, law, tourism, real estate, retail and wholesale, services, transportation or utilities as working in the non-tradable sector, which should be particularly strongly exposed to the local economy. 
Besides following previous literature, these classifications leave us with meaningful sample sizes to conduct our robustness checks. Our findings are not sensitive to the exact ways in which investors are classified, with coefficients becoming less precisely estimated when the size of the subsamples becomes smaller.

\section{C.6 Portfolio betas}

To construct monthly betas, we implement an approach similar to that of Elton et al. (2011a) and Elton et al. (2011b). This approach allows us to estimate changing betas over time. In contrast, estimating betas from investor-level time-series regressions using portfolio returns would only allow us to measure an average beta over time for each investor.

Based on an investor's security holdings at the end of each month we generate a threeyear history of backward-looking value-weighted portfolio returns. We use weekly return data for all securities in an investor's portfolio for the preceding three years including the current month. We require that at least 52 weeks of portfolio return data are available. We combine these returns to a value-weighted portfolio return.

Using these portfolio returns, we calculate betas associated with the portfolio an investor holds at the end of each month. We calculate betas using a one-factor model since we are only interested in the systematic risk of the portfolio. We use the two most important German indices as market factors, the DAX and the CDAX. The DAX is a blue-chip stock market index comprising the 30 largest German companies by market capitalization. The CDAX comprises all stocks (more than 600) traded on the Frankfurt Stock Exchange that are listed in the General Standard or Prime Standard market segments. This gives us two measures of systematic exposure to the German market.

We also calculate each investor's exposure to foreign markets (excluding Germany) by first regressing the return of the MSCI Europe and of the MSCI World index on the return of the CDAX. We do this as above on a rolling basis for every month over a threeyear period. We then use the residuals of these regressions and regress our three-year history of backward-looking value-weighted portfolio returns on the residuals. This gives us two measures of exposure to systematic risk of foreign markets (the rest of Europe and the rest of the World). Finally, we calculate portfolio betas relative to quarterly German real GDP per capita growth (seasonally adjusted) in the same way in which we calculate DAX and CDAX betas. 


\section{Data appendix: Investor survey}

This appendix provides details on the investor survey, including procedural details, translations of survey questions, coding of main variables, included control variables and the sample definition. Table A3 provides an overview of the variables used in the analysis.

\section{D.1 Procedural details}

The survey was conducted in collaboration with the panel data provider YouGov in August 2019. Respondents received a small reward for participating in the survey. We only surveyed respondents who invest in stocks or stock mutual funds. Our sample is roughly representative of the population of German retail investors in terms of the targeted dimensions age, gender, income and region (East vs West), as can be seen from the comparison with the Bundesbank's Panel of Household Finances (PHF) in Table A2. However, the survey is also close to the population of investors along non-targeted dimensions such as employment status and participation in different asset classes. The main differences compared to the population of stock market participants are that respondents to our survey are more highly educated, which is a common feature of online surveys, and have lower wealth, probably because wealthier households are harder to reach without providing a high incentive for participation.

Respondents were invited by the survey company by email and were directed to the main online survey after initial screening according to demographics and investment behavior. The survey started with a short explanation on how to use probabilities to express uncertainty about future events that is based on instructions of the New York Fed Survey of Consumer Expectations (Armantier et al., 2017). We then elicited the respondents' subjective probability distribution over the one year-ahead return of the German stock market index (DAX), as well as qualitative expectations regarding the returns on the DAX, bonds and foreign stocks. Respondents continued with a hypothetical investment game to measure their risk aversion and responded to questions on their (planned) stock trading behavior. Next, we elicited the respondents' subjective probability distribution and a qualitative measure of their expected change in their household labor income over the next 12 months, as well as a qualitative measure of expected real GDP growth. Finally, we asked a few questions on the respondent's recall of recent local bankruptcies. The survey ended with questions on total financial assets and net wealth and some remaining demographics. Throughout the survey, whenever the respondents wanted to proceed to the next page without having responded to a survey question, they received a message encouraging them to respond to the question. Only after having received this message could the participants continue without responding. This ensured a very low number of missing values. 


\section{D.2 Survey questions}

This subsection lists the translated main survey questions we use in our estimations. Screenshots of the actual survey (in German) are provided under https: //www . dropbox . com/s/cxzvt0kocl34g3e/Bankruptcies_2019_Survey_Instructions.pdf?dl=0. The wording of the main survey questions is as follows:

- Bankruptcy recall: Over the last four weeks, have you learned about any business or restaurant closures, or bankruptcies of firms in your region of residence? Yes; Yes, more than usual; No.

- Trading last four weeks: Have you actively traded with stocks or stock mutual funds during the last 4 weeks? Please exclude any changes in your stockholdings due to previously existing savings schemes. Yes, I have overall increased my holdings of stocks and stock mutual funds; Yes, I have overall reduced my holdings of stocks and stock mutual funds; Yes, I have rebalanced my portfolio without adjusting the overall level of my holdings of stocks and stock mutual funds; No.

- Trading next four weeks: Do you plan to actively trade with stocks or stock mutual funds during the next 4 weeks? Please exclude any changes in your stockholdings due to already existing savings schemes. Yes, I plan to overall increase my holdings of stocks and stock mutual funds; Yes, I plan to overall reduce my holdings of stocks and stock mutual funds; Yes, I plan to rebalance my portfolio without adjusting the overall level of my holdings of stocks and stock mutual funds; No.

- Expected labor income growth: Distribution: In this question we present you with six possible scenarios for the change in the total net labor income of your household, that is, the money earned through work that the total household (including all family members living with you, but excluding roommates and renters) has available after taxes and transfers, over the next 12 months. Please indicate with what probability you expect each scenario to occur. The probabilities in the six scenarios should sum up to $100 \%$. If you are certain that a scenario will not occur, please enter the number "0". My household labor income will increase by more than 20\%; My household labor income will increase by between $10 \%$ and $20 \%$; My household labor income will increase by between $0 \%$ and 10\%; My household labor income will decrease by between $0 \%$ and 10\%; My household labor income will decrease by between 10\% and 20\%; My household labor income will decrease by more than $20 \%$.

- Expected labor income growth: Qualitative: Have your expectations regarding the prospects for your household's labor income improved or worsened over the 
last 4 weeks? Improved strongly; Improved a little; Unchanged; Worsened a little; Worsened strongly.

- Expected real GDP growth: Qualitative: Gross Domestic Product (GDP) is a measure for economic activity. Real GDP is the real (inflation-adjusted) value of all final goods and services produced in Germany over one year. Have your expectations regarding the growth rate of real GDP over the next 12 months improved or worsened over the last 4 weeks? Improved strongly; Improved a little; Unchanged; Worsened a little; Worsened strongly.

- Expected return German stocks: Distribution: In this question we present you with six possible scenarios for the return of the DAX over the next 12 months. Please indicate with what probability you expect each scenario to occur. The probabilities in the six scenarios should sum up to $100 \%$. If you are certain that a scenario will not occur, please enter the number "0". Return of the DAX higher than 20\%; Return of the DAX between $10 \%$ and 20\%; Return of the DAX between $0 \%$ and $10 \%$; Return of the DAX between $-10 \%$ and $0 \%$; Return of the DAX between $-20 \%$ and $-10 \%$; Return of the DAX lower than $-20 \%$.

- Expected return German stocks: Qualitative: Have your expectations regarding the 12 month-ahead return of the DAX improved or worsened over the last 4 weeks? Improved strongly; Improved a little; Unchanged; Worsened a little; Worsened strongly.

- Expected return foreign stocks: Qualitative: Have your expectations regarding the 12 month-ahead return of foreign stocks improved or worsened over the last 4 weeks? The return refers to the percent change in value of a diversified portfolio of foreign (i.e. non-German) stocks over the next 12 months. Improved strongly; Improved a little; Unchanged; Worsened a little; Worsened strongly.

- Expected return bonds: Qualitative: Imagine a 10-year German government bond, which is making all its payments in ten years at maturity. The return of such an investment in German government bonds is the percent change in the price of such a bond over the next 12 months. Have your expectations regarding the 12 month-ahead return of German government bonds improved or worsened over the last 4 weeks? Improved strongly; Improved a little; Unchanged; Worsened a little; Worsened strongly.

- Risk aversion: Imagine you have to decide how to invest $€ 1,000$ over the next 12 months. You can divide the $€ 1,000$ between a savings account, which pays $2 \%$ interest with certainty, and a risky asset. In $50 \%$ of all cases the risky asset pays a 
return of $15 \%$ and in $50 \%$ of all cases a return of $-7 \%$. How would you divide the $€ 1,000$ ? The division of the money across the two options should sum to 1,000 . Investment in savings account; Investment in risky asset.

- Risk aversion 4 weeks ago: Image we would have asked you the previous question 4 weeks ago. How would you have invested the $€ 1.000$ four weeks ago?

\section{D.3 Coding of main variables}

We code a dummy variable taking value one if the respondent recalls more local bankruptcies than usual, and zero otherwise. We set to missing answers to subjective probability distributions that do not sum to 100 and answers to the hypothetical investment game that do not sum to 1,000. We use the midpoints of the bins to calculate mean and standard deviation of the expected change in household labor income at the respondent level, assigning probabilities of $-30 \%$ and $30 \%$ to the two open bins. We calculate mean and standard deviation of the expected return of the DAX at the respondent level, assigning to each bin the actual conditional mean historical realized return, calculated using data over the last 50 years. This procedure assigns the values $-32.2 \%,-14.8 \%,-5.1 \%, 5.2 \%$, $15.5 \%$ and $32.2 \%$ to the different bins. All our results are robust to using midpoints instead. We code dummies indicating whether the respondent reports that his or her expectations regarding their labor income growth, GDP growth, German stock returns, foreign stock returns or bond returns have worsened over the last four weeks. A measure of the change in risk aversion is constructed as the difference in the share invested in the risky asset between now and 4 weeks ago.

\section{D.4 Control variables}

We include the following control variables: a dummy for females; age; dummies for highest educational attainment being middle school ("Realschule"), high school ("Gymnasium") and university, with below middle school being the omitted category; dummies for being wage-employed, for being self-employed or for being retired, with not working being the omitted category; dummies for net monthly household income between $€ 2,500$ and $€ 3,500$, between $€ 3,500$ and $€ 5,000$, and above $€ 5,000$, where income below $€ 2,500$ is omitted; a polynomial in log net wealth; dummies for holding stocks directly, for holding stock mutual funds, for holding fixed income securities, and for holding "riskless" assets, which include savings accounts and building savings contracts; and fixed effects for the state ("Bundesland") of residence. 


\section{D.5 Sample}

In total, 1,507 investors completed our survey. The survey was designed to take about 11 minutes, which was also announced to participants in the beginning of the survey. The median response time was 10.96 minutes. We drop respondents who completed the survey within less than 4 minutes, roughly corresponding to the first percentile of the survey time distribution, since very short response time likely indicates inattention to the survey. We drop investors for whom any of the control variables we use in our main estimations are missing. This leaves us with a working sample of 1,422 investors. The sample is smaller for some of the estimations due to missing values in the outcome variables. This mostly concerns answers to the subjective probability distributions or the hypothetical investment game that do not sum to 100 or 1,000 , respectively.

\section{E Robustness checks: Brokerage data}

This appendix section provides additional subsample analyses, robustness checks and a placebo analysis on the brokerage data.

First, we split our sample according to various dimensions and repeat our estimations. We find similar active changes in the risky portfolio share for men and women, for investors in urban and in rural areas, for more or less active investors based on relative average portfolio turnover, as well as for investors with smaller and bigger portfolios (Figure A3). While there seems to be more heterogeneity across groups in the effects on overall turnover and on the buy-sell imbalance, these differences are mostly insignificant. Due to the reduced sample size for any specific group all of these effects are more noisily measured than our main results. Particularly in the case of the buy-sell imbalance, this leads to insignificant coefficient estimates for some subgroups. One potential reason for the lower precision as compared to the active change in the risky share is that the buy-sell imbalance is not scaled by the total wealth of the investor. Taken together, these findings suggest that the effects of bankruptcies on trading and risk-taking are not fully driven by any of these particular subgroups

Second, we find very similar results when we apply different criteria for sample selection, such as using all investors, or using only investors with more than $0.5,1$ (the baseline criterion) or 2 yearly trades on average during the time they are in the sample, or using for each investor only years during which this investor trades at least once (Table A4 Panel A). This indicates that our results are robust to the way in which accounts are classified as active or inactive.

Third, our findings are robust to various transformations of the bankruptcies measure. As shown in Table A4 Panel B, we find similar results if we make adjustments to the 
bankruptcies measure that is scaled by the number of firms in the county of residence, such as excluding bankruptcies of publicly listed firms, taking the log of the measure, defining dummies indicating whether bankruptcies were above the mean or median among observations from that zip code over the sample period, or a categorical variable indicating the quartile of the bankruptcies measure among observations from that zip code over the sample period. In case of the mean and median dummies, the effects on the active change in the risky share and the buy-sell imbalance are marginally insignificant, probably because using (changes in) these dummies discards a lot of the variation that is driving the bankruptcies effect. We also find qualitatively similar results when using the raw number or the log of the raw number of bankruptcies not scaled by the number of firms in the county of residence (Table A4 Panel C). These estimates are sometimes more noisy, in line with the differences in the effective scale of the bankruptcies measure across zip codes when the bankruptcies measure is not adjusted for differences in the local number of firms.

Fourth, our results on the buy-sell imbalance and the active change in the risky share are robust to using the fixed effects specification 1, which is otherwise only used for the outcomes on turnover, and which for outcomes on changes in risk-taking effectively controls for investor-specific linear trends in risk-taking over the sample period (Table A4 Panel D).

Fifth, we obtain very similar results as in our main specification when we collapse our data to zip code-month averages and re-estimate our model using weighted least squares, where each zip code is weighted with the number of investor observations in the zip code in the relevant month (Kaustia and Rantapuska, 2016) (Table A4 Panel E).

Sixth, our findings are robust to adding fixed effects for the interaction of quarter and state ("Bundesland") to our baseline specifications (Table A4 Panel F). The bankruptcies effects in these specifications are identified from differential monthly changes in bankruptcies and risk-taking across zip codes within a particular state and quarter. Thus, these specifications control for quarterly shocks hitting every investor in a particular state. ${ }^{5}$

Finally, we address the possibility that the time fixed effects (zip code fixed effects) do not fully account for the effects of macroeconomic shocks (permanent differences across zip codes) using two sets of placebo analyses. First, for each zip code-month we replace its own bankruptcies measure with a bankruptcies measure that is randomly drawn (with replacement) from bankruptcies measures across all zip codes that occurred in the same month. ${ }^{6}$ We re-estimate our main specifications using this alternative bankruptcies mea-

\footnotetext{
${ }^{5}$ Bankruptcies vary at the zip code level. Including more fine-grained interactions of geography and time would absorb too much or all of the variation used for identification given that the number of additional control variables would become very high.

${ }^{6}$ For the first difference specifications we randomly draw changes in bankruptcies. Note that alternative zip codes are newly assigned for each zip code in every month.
} 
sure. The coefficient estimates obtained from repeating this procedure 500 times are much smaller than the ones obtained under the baseline specification and mostly statistically insignificant (Figure A2 Panel A). Second, for each zip code-month we replace the baseline bankruptcies measure with a bankruptcies measure that is randomly drawn (with replacement) from all bankruptcies measures that occurred over the sample period in that zip code. Again, the coefficient estimates obtained from repeating this procedure 500 times are much smaller than the baseline estimates and mostly insignificant (Figure A2 Panel B). These results provide additional evidence that our findings do not reflect macroeconomic shocks or permanent local fixed effects that could be driving both bankruptcies and trading activity.

Taken together, our findings are very stable across different subsamples and robust to various transformations of the main independent variable and alternative specifications. 


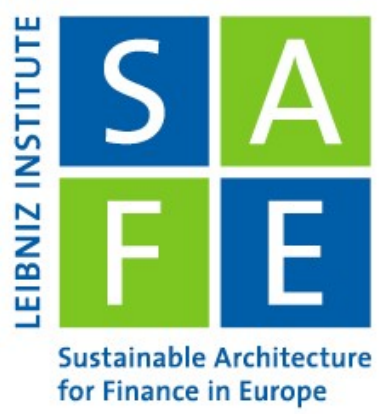

\section{Recent Issues}

No. 271 Pietro Dindo, Andrea Modena, Loriana Pelizzon

No. 270 Mario Bellia, Kim Christensen, Aleksey Kolokolov, Loriana Pelizzon, Roberto Renó

No. 269 Ester Faia, Maximilian Mayer, Vincenzo Pezone

No. 268 Lorenzo Maria Levati, Marie Lalanne

No. 267 Wataru Kureishi, Hannah PaulePaludkiewicz, Hitoshi Tsujiyama, Midori Wakabayashi

No. 266 Benjamin Bluhm, Jannic Cutura

No. 265 Christian Schlag, Julian Thimme, Rüdiger Weber

No. 264 Hengjie Ai, Jun E. Li, Kai Li, Christian Schlag

No. 263 Vanya Horneff, Daniel Liebler, Raimond Maurer, Olivia S. Mitchell

No. 262 Andrea Bedin, Monica Billio, Michele Costola, Loriana Pelizzon

No. 261 Monica Billio, Michele Costola, Loriana Pelizzon, Max Riedel

No. 260 Matthias Thiemann, Tobias H. Tröger

No. 259 Inaki Aldasoro, Florian Balke, Andreas Barth, Egemen Eren
Risk Pooling, Leverage, and the Business Cycle

High-Frequency Trading During Flash

Crashes: Walk of Fame or Hall of Shame?

The Value of Firm Networks: A Natural Experiment on Board Connections

The Impact of Job Referrals on Employment Outcomes in Top Corporate Positions

Time Preferences over the Life Cycle

Econometrics at Scale: Spark Up Big Data in Economics

Implied Volatility Duration: A Measure for the Timing of Uncertainty Resolution

The Collateralizability Premium

Implications of Money-Back Guarantees for Individual Retirement Accounts: Protection Then and Now

Credit Scoring in SME Asset-Backed Securities: An Italian Case Study

Buildings' Energy Efficiency and the Probability of Mortgage Default: The Dutch Case

The Case for a Normatively Charged Approach to Regulating Shadow Banking Multipolar Regulatory Dialogues as a Means to Detect Tail Risks and Preclude Regulatory Arbitrage

Spillovers of Funding Dry-ups 